Florida International University FIU Digital Commons

8-28-1997

\title{
An investigation into the lived experiences of racism among African -American nurses
}

Paula Alexander-Delpech

Florida International University

DOI: $10.25148 /$ etd.FI13101572

Follow this and additional works at: https://digitalcommons.fiu.edu/etd

Part of the Nursing Commons

\section{Recommended Citation}

Alexander-Delpech, Paula, "An investigation into the lived experiences of racism among African -American nurses" (1997). FIU

Electronic Theses and Dissertations. 1260.

https://digitalcommons.fiu.edu/etd/1260

This work is brought to you for free and open access by the University Graduate School at FIU Digital Commons. It has been accepted for inclusion in FIU Electronic Theses and Dissertations by an authorized administrator of FIU Digital Commons. For more information, please contact dcc@fiu.edu. 
FLORIDA INTERNATIONAL UNIVERSITY

Miami, Florida

\section{AN INVESTIGATION INTO THE LIVED EXPERIENCES OF RACISM AMONG AFRICAN-AMERICAN NURSES}

A thesis submitted in partial satisfaction of the requirements for the degree of MASTER OF SCIENCE

IN

NURSING

by

Paula Alexander-Delpech

1997 
To: Linda Simunek, PhD.

School of Nursing

This thesis, written by Paula Alexander-Delpech and entitled, "An Investigation into the Lived Experiences of Racism Among African-American Nurses," having been approved in respect to style and intellectual content, is referred to you for judgment.

We have read this thesis and recommend that it be approved.

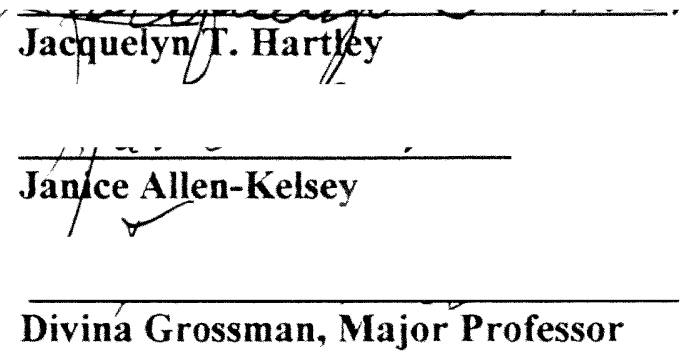

Date of Defense: August 28, 1997

The thesis of Paula Alexander-Delpech is approved.

Deadu Linda Simunek Schoofl of Nursing

Richard Campbell, PhD.

Dean Graduate Studies

Florida International University, 1997 
I dedicate this thesis to my husband Marshall L. Delpech, and my two children Bryan and Brianna Delpech. Without their patience, understanding, support, and most of all their love, the completion of this work would not have been possible. 


\section{ACKNOWLEDGMENTS}

I wish to thank the members of my committee for their helpful comments and patience. I also want to thank Diane Cittadino, for her help with everything, for without her this work would never have gotten finish.

A special thanks must go to my major professor, Dr. Divina Grossman, for her support and encouraging comments, and especially for having the confidence in me to give me the chance to do this project. 


\section{ABSTRACT OF THE THESIS American Nurses \\ by \\ Paula Alexander-Delpech \\ Florida International University, 1997 \\ Miami, Florida \\ Professor Divina Grossman, Major Professor}

An Investigation into the Lived Experiences of Racism Among African-

The purpose of this study was to investigate the lived experience of racism among African-American nurses. Utilizing a qualitative phenomenological approach, data were collected by interviewing 10 African-American nurses currently practicing in Dade county. The interviews were tape recorded and transcribed verbatim. Data were analyzed using the seven step method of Colaizzi (1978).

The findings of this study indicate that racism encompasses attitudes and beliefs which generate behaviors reflecting ethnocentric ideations. The process of racism creates glass ceilings that hinder the career advancement of African-American nurses. Internalizing these experiences of racism engenders feelings of betrayal and erodes unity and cohesion within the group. This study points out the need to openly confront racism in the nursing profession, from the classroom to the workplace. 
CHAPTER

PAGE

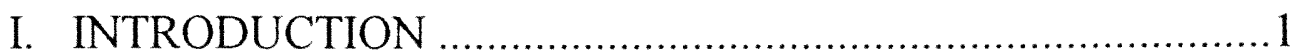

Problem Statement …................................................... 5

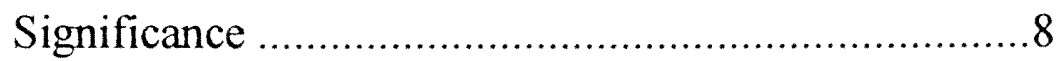

Research Purpose …........................................... 8

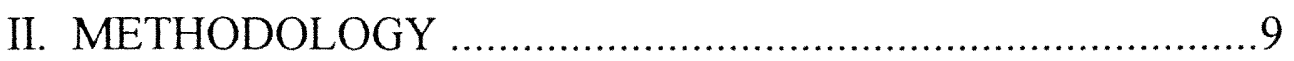

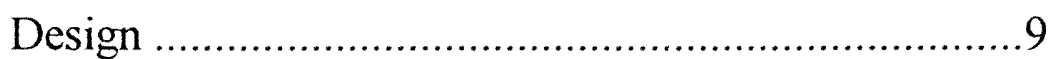

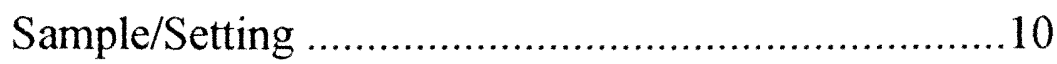

Protection of Participant's Rights ..............................10

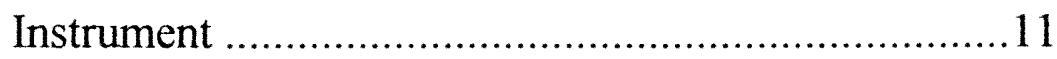

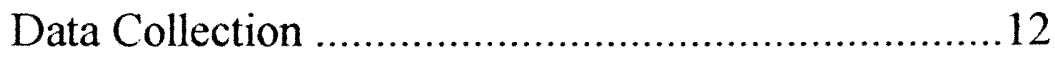

Data Analysis .......................................................13

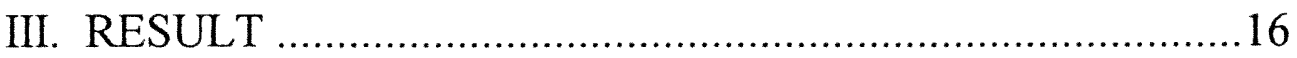

Demographic Profile ................................................16

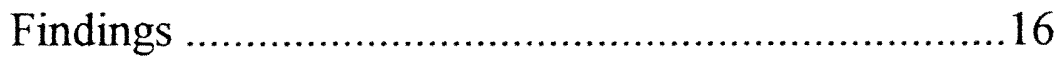

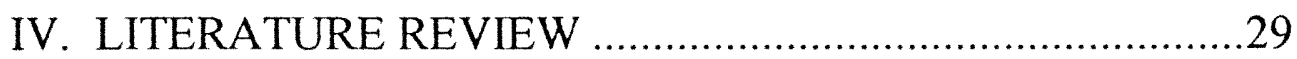

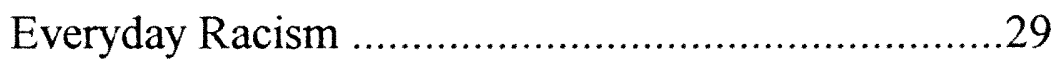

Racism in Health Care .............................................. 34

Historical Perspective of Racism in Nursing .............37

Racism in Nursing Today ........................................38

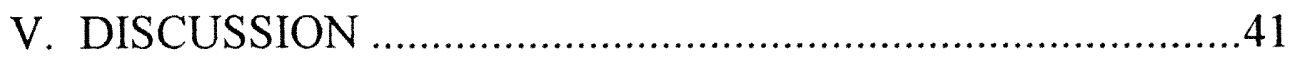

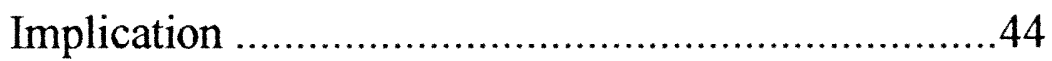

Limitations of the Study ...........................................4

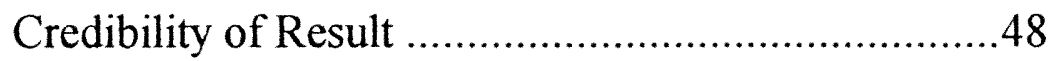

Recommendation for Further Study .........................49

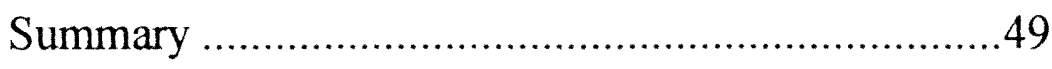




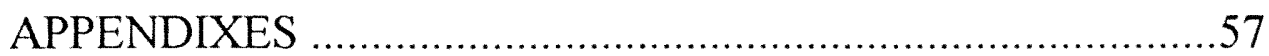

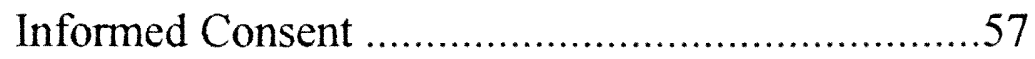

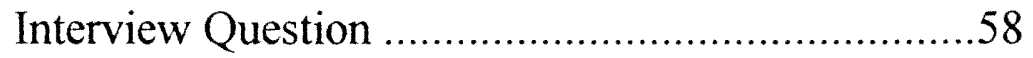

Demographic Profile …….....................................59

Demographic Table …..........................................60

Invitation to Participate ...........................................61

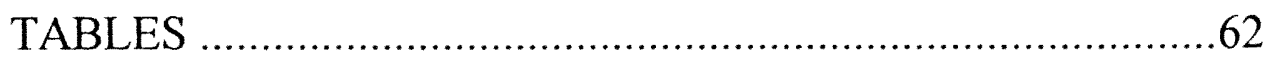

Significant Statements ….....................................62

Formulated Meanings ……….................................72

Cluster of Themes ……..........................................

Exhaustive Description ..........................................79

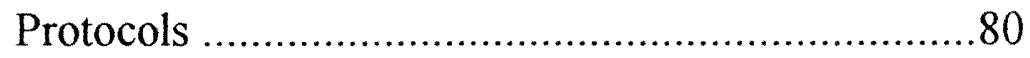




\section{CHAPTER I}

Efforts to raise consciousness and heighten sensitivity toward the issues of race, ethnicity, ethnocentrism and prejudice are being advocated more and more in our society today. This fact can exemplified by the increased use of race and its social dimension, racism as topic of debated in forums as diverse as medicine and sports (Barbee, 1993). Racial inequality has also significantly pervaded into one's personal life, both socially and in professional practice as well. Racial injustice has negatively affected the plight of minorities in our society, and the tension it produces impedes their professional growth. Racial ideology is a social product. It is effected through ordinary patterns of action developed in the systematized ideology of hiring patterns, education, and the formulation of academic theories (Essed, 1991). Racism is a fact of life in America today, just as it was 100 years ago. It is a form of oppression that affects all of us and creates waste of the human potential in our society.

What exactly is racism? Jones (1972) defines three types of racism as follows: (1) Individual racism, which emphasizes discriminatory acts directed towards individuals because of visible biological characteristics. It encompasses attitudes, beliefs, and behaviors that occur in interactions between individuals. Though blatant individual racism still occurs, it has become less socially acceptable during the last forty to fifty years (Griffin, 1991). Individual racism, hence, has become more subtle and sophisticated. As a result, it is less easily challenged and, in many respects, more ominous. (2) Cultural racism which is based on individual and institutional expressions of the superiority of one's cultural heritage over that of others. It is this form of racism that defines the culture of one's group as superior to that of any 
other group. (3) Institutional racism which refers to the intentional or unintentional manipulation or tolerance of institutional policies that unfairly restrict the opportunities of particular groups. Manifestations of institutional racism are often more difficult to identify.

Berreman (1972) deals with the issue of race in terms of social stratification, which is the result of acquired and innate characteristics within a society. From his approach, the term Racial stratification has been developed. This term can be defined as a system of birth-status' associated with physical differences. Racism, therefore, uses biological differences to explain and justify social inequalities. Longstreet (1978), on the other hand, does not deal with racism directly but speaks about stereotypes, "as an integral part of racism. Longstreet defines stereotype as a generalization about the behavior of a group of people that is offensive to that group it describes".

Barbee (1993) defines the type of racism present in nursing today as the denial of racism. Currently and historically, nurses have denied racism with their strong beliefs that, as nurses, they could not be racist by the very fact that the nature of their work is in caring for people. Barbee cites four characteristics of the nursing profession from which avoidance in dealing with racism within the profession is permitted as follows: (1) an emphasis on empathy; (2) an individual orientation; (3) a preference for homogeneity; and, (4) a need to avoid conflict.

Whenever the issue of race is discussed in nursing however, it usually falls under the category of cultural diversity. This implies that the issue of racism is one of cultural bias, resulting from ignorance which can be overcome through the presentation of cultural knowledge. To include race 
under cultural diversity, therefore, reduces it to ethnocentrism, and allows for European-American nurses to avoid the challenge of directly confronting racism or glossing, as it is more commonly known.

Among the many theories of racism, Berrera, (1979) feels that the major perspective of racial prejudice is more than just a dislike of the appearance or attitudes of another. It is a concerted determination of one's class to keep some people and their resources exploitable.

Racism appears to be everywhere, yet evasive. It is one of those subjects which, to borrow a phrase, " is everybody's distant relative and nobody's baby". Does racism of any kind prevail in nursing? Is racism responsible for the under-representation of African-American nurses in decision- making positions, and over-representation in lower status positions? Does the lack of historical representation by African-American nurses in literature also illustrate racism?

Although the issue of racism is being addressed in our society, with efforts being made to raise consciousness and heighten sensitivity, the issues of race, ethnicity, and prejudice, continue to be taboo in health care. In recent years, however, the scarcity of African-American health care workers has become recognized. The following reasons have been attributed to this trend: (1) the lack of motivation; (2) low educational goal attainment. and, (3) the lack of role models. Too often overlooked are the experiences of discrimination and racism African Americans may face at every turn, from early education through higher education, and into adult life.

Without a clear understanding of the impact of racism experienced by African-American nurses, fundamental questions concerning the phenomenon of racism and its ability to erode self-esteem and capture 
feelings of marginalization will continue to remain unanswered within nursing and nursing literature. 


\section{Problem Statement}

General Problem - What is the essence of the lived experiences of racism encountered by African American nurses.

\section{Definition of Terms:}

1. African-American: Someone not born in native Africa, but who is of African descent. (The New Merriam-Webster Dictionary, 1994).

2. Lived Experience: Our immediate, pre-reflective consciousness of life. A reflective or self-given awareness which is, as awareness, unaware of itself (Van Manen, 1990).

3. Racism: The assumption that cultural traits and capacities are determined by biological race, and that races differ decisively from one another, believing in the inherent superiority of a particular race and its right to dominate over others. (The New Merriam-Webster Dictionary, 1994). 


\section{Significance}

The significance of this study is to provide information about the experience of racism from the perspectives of African-American nurses. From this study contributions to nursing research will be given in several way. First, it will generate scientific knowledge concerning the phenomenon of racism experienced within a profession. It will also opened the door for further investigations by nurse researchers, into a variety of topics of interest to nursing contained within the phenomena of racism.

According to West (1993) race matters. Race is a flaw within America's society. It is rooted in historic inequalities and long-standing cultural stereotypes. Because racism matters in America, it is routinely created and reinforced through everyday practices (Essed, 1991), and because of this it is ingrained in the workings of society's formal institutions (Barbee, 1993).

By the year 2000 more than a quarter of the United States population will consist of individuals from culturally diverse groups (Andrews, 1993). It is estimated by this time, one in every three Americans will be a minority (U.S. Bureau of the Census, 1990). This will make it the first time in the history of the United States that minority subgroups would comprise a majority of the population. If current demographic trends continue, by the year 2020 the following racial and ethnic compositions will make up the population of the United States: Whites, 69.5 percent; Hispanics, 11.1 percent; African- Americans, 14.3 percent; and Asians and other groups, 5.0 percent (United States Bureau of Census, "Current Population Reports", 1992). The cultural group consisting of people from African descent is 
projected to grow at almost twice the rate of any other population in the United States. This group's proportions are expected to increase from 12 percent in 1990 , to 13 percent in 2000 , to 14 percent in 2020 , and to 15 percent in 2040 (United States Bureau of the Census, "Current Population Reports", 1992). By the year 2080, minorities will account for 50 percent of the total population (United States Census Bureau, 1983).

According to recent demographic findings, as the face of America changes color so, too, will the face of the nursing profession. In order to keep up with this growing segment of the population, the confrontation and discussion of racism among nurses must accelerate. The nursing profession has to be prepared for inevitable changes, which includes identifying issues of racial insensitivity among nurses, and integrating these issues into current nursing practices, education and research.

The National League of Nursing's (NLN) data for the years 19781990 , reveals an unsettling picture of minority student admissions into basic RN programs. Recent data indicates that of 108,580 students admitted to all basic RN programs in the United States, Whites comprise 81.9 percent of the total population; Blacks, 11.1 percent; Hispanics, 3.2 percent; Asians 3.0 percent; and American Indians, 0.6 percent. Of the 16,503 full-time nursing faculty in the United States, Whites comprised 91.2 percent of the total; Blacks, 5.8 percent; Asians, 1.6 percent; Hispanics, 0.8 percent; and American Indians, 0.6 percent (National League for Nursing, "Nursing Data Source, " 1991).

Despite efforts in the 1970's from the Commission on Nursing Education to establish guidelines for the entry of members from minority groups into nursing programs, it has become very evident that racial bias still 
prevails in nursing today. This fact is demonstrated by the small number of African-Americans entering the nursing profession, as well as the small number of African-American nursing leaders within the nursing profession, today. Statistics indicate that of two million nurses, only approximately 155,000 are people of color, while 92 percent of all nurses are White (Malone, 1993). Statistics on the admission and graduation of AfricanAmericans, and other minority groups, demonstrate the fact that recruitment and retention of minority students continues to be a problem within schools of nursing (NLN, 1993).

These findings can suggest the following possibilities: (1) Has the nursing profession systematically denied access to minorities? (2) Is nursing prepared to meet the needs of the growing majority? (3) Is the nursing profession ignoring discrepancies in representation, yet proclaiming to embrace diversity?

The catalyst of this study was derived from a perceived need. This need was to make visibly aware to others the everyday lived experiences of racism encountered by African- American nurses. The purpose of this study is to explore the experiences of racism among African-American nurses, and to describe their lived experiences with this phenomenon. 


\section{Chapter II}

\section{Methodology}

\section{Design}

In this study a descriptive, qualitative phenomenological approach was utilized. This method was chosen because it preserves the meaning of the phenomenon being studied within the context of each subject's experience. It is an approach designed to study human experience as it is lived (Munhall and Boyd, 1993).

A phenomenological study is based on a philosophy which espouses the idea that there is no reality (Burnes \& Grove, 1887). Since reality is considered to be subjective, each experience is considered unique to that individual. Even the researcher's experiences are viewed in the same way.

The goal of phenomenological research is to describe an experience as it is lived. The researcher examines an individual's experiences in a given situation. From obtaining a description of a particular phenomenon, as experienced by an individual, importance of the phenomenon becomes apparent as it is extracted from the data. Phenomenology is a descriptive research method which aims at gaining a deeper understanding of the meaning of our everyday lived experiences (Beck, 1996). In phenomenology experiences are described "as is", without considering any causal explanations.

According to van Manen (1984) the experiences and reflections of others are "borrowed," so the researcher is able to understand a deeper meaning or significance to an aspect of human experience. The aspect of 
human experience under study in this paper is the lived experiences of racism among African-American nurses.

\section{Sample and Setting}

The number of participants in a phenomenological study is often limited because of the extent and richness of the data (Munhall, 1994). The sample used in this study consisted of African-American nurses practicing in

Dade County, Florida. Participant selection was based upon a snowball design, which consisted of personal references, references through professional contacts, and references from the participants themselves. To be eligible, all participants had to be experienced, registered nurses over the age of twenty-one, who were currently employed and were willing to participate. Each participant spoke English fluently. A maximum of ten participants were interviewed. This number was determined by data saturation and the redundancy in descriptions given by the participants (Lincoln \& Guba, 1985).

The setting for this study was arranged on an individual basis, after the researcher received the confirmation letter from each participant. In the next step, a convenient time and place was then agreed upon by those participating.

\section{Protection of Participants' Rights}

A signed consent form was obtained from each participant, by the researcher, prior to data collection (Appendix A). The participants were told that the interview would be audiotaped and transcribed verbatim. At the interview, each participant was encouraged to speak honestly, and to verbalize their feelings, opinions, and their own experiences of racism. They were also informed of their right to decline to participate in the study, to withdraw from the study at any time for any reason, and to ask any questions 
about the study at any time. Every effort was made to ensure confidentiality of the participants' identities through the provision of a code number for each participant. Their names were not mentioned within their taped recording as well. All forms completed by each participant, as well as their transcribed interviews, were identified with their assigned code number, and a master list with their names and respective code numbers were then kept by the researcher within a locked cabinet. The invitational letters and signed consent forms were also kept in a separate location from the master list as well to anonymity.

Before actually beginning the study, permission then had to be obtained from the researcher's project advisors, and the Florida International University Institutional Review Board.

\section{Instrument}

The researcher used a nondirective interviewing method to collect data for this study. A Nondirective interview produces conversations that focus on a certain point. With this type of interview it is possible to talk about the same experiences twice and make the same point. However, it is highly improbable that the exact words or details used to describe specific events would be used. The interview questionnaire consisted of an open-ended question aimed at simulating natural conversation that would conceptualize the participants' lived experiences of everyday racism (Appendix B). The validity of the question was determined through a pilot test administered to one nurse who met the criteria for this study. At that time, the pilot test did not reveal a need to revise the interview guides used. The following demographic data was collected using a questionnaire (Appendix $\mathrm{Cl}$ ): 
1. Age

2. Gender

3. Place of birth

4. Predominant language

5. Educational attainment

6. Country received nursing education

The following open-ended question was used in the interview:

1. What is it like to be an African-American nurse?

\section{Data Collection}

Each potential participant was sent a cover letter explaining how they were selected for the study (Appendix D). The letter included the name and address of the researcher, purpose of the study, approximate length of time required for the taped interview, a statement concerning the safeguarding of confidentiality of the participant, encouragement to participate, a statement of agreement to participate in the study requiring the participant's signature, and a self-addressed, stamped enveloped to facilitate the return of the cover letter.

Upon receipt of the statement of agreement from the participant, the researcher then contacted each one by telephone and arranged for the interview time and place. At the actual meeting the researcher explained the informed consent and obtained the participant's signature.

In accordance with the phenomenological method, prior to the interview the researcher engaged in the process of reduction (bracketing), to set aside preconceptions of the phenomenon in order to become an effective listener (Knaack, 1984). By bracketing, the researcher was able suspend all assumptions, biases, experiences, intuitions, and perception known about the phenomenon being studied. Bracketing allowed the researcher to be 
noninfluential on the phenomenon under study so that it could be objectively presented (Beck, 1994). Through this process of explicating researcher bias and prior beliefs, they can be more easily surrendered during phenomenological research (Van Manen, 1990).

Prior to data collection, the researcher obtained training on how to conduct a nondirective interview using various interviewing techniques. Data collection for this study was done with in-depth interviews, conducted by the researcher, with data being collected at the time and place specified by the participants. Only the participant and interviewer were present during the interviewing process, which was conducted in a face-to-face manner. Prior to the interview the researcher reviewed the definition of a lived experience, explained the nature of the study, and discussed the procedure of the interview with each participant. The interview was then tape recorded by the researcher. The researcher began the interview by asking the question, "What is it like to be an African-American Nurse?"

\section{Data Analysis}

The interviews were tape recorded by the researcher and then given to a transcriber who then generated unstructured data was from them. All the interviews were then turned into individuals protocols, which were double spaced and printed. After the protocols were returned to the researcher they were verified for accuracy. In the verification process the tapes were listened to while the researcher reviewed the transcription. If no major discrepancies were found, the protocols were then coded.

The data was then analyzed by the researcher according to the sevenstep method developed by Colaizzi ( 1978). The procedural steps used were as follows : 


\section{Reading all of the participants' descriptions}

Once transcribed, each of the protocols were read several times to allow the investigator to obtain a feel for their content.

2. Extracting significant statements

The researcher read the protocols and extracted phrases and sentences directly related to racism. These were maintained verbatim and underlined. Underlining the significant statement was an important step for transposition. Repetitions of the same phrases or sentences by the participants were not repeated. Finally the significant statements were then typed and assigned a code number, which was used throughout the analysis process.

3. Formulated meanings.

In this difficult meanings were formulated by spelling out the intent of each significant statement. This involved starting with what the participants said to what they actually meant. These formulations uncovered and brought out the hidden meanings within the various contexts of the phenomenon presented in the original description. The formulated meanings used the same coded numbering system as the significant statements.

4. Validation of the formulated meanings.

In this step the researcher returned to the original transcripts to validate the formulated meanings.

5. Aggregating formulated meanings into clusters of themes.

Clusters of themes were then organized to form aggregate formulated meanings. This step allowed for the emergence of themes common to all the participants' descriptions.

a. The clusters of themes were used to refer back to the original descriptions in order to validate them. This was done to see if there was 
anything in the original not accounted for in the cluster. The clusters also helped to determine whether any thing was proposed that was not contained in the original. If any of the above was found to be true, a reexamination was necessary.

b. An expert in the field of qualitative research then read the formulated meanings and the clusters of themes determined by the researcher. The expert agreed with the formulated meanings and themes.

6. Writing an exhaustive description.

From the clusters of themes and formulated meanings an exhaustive description of the phenomenon was written. This exhaustive description of the phenomenon resulted from the integration of the above results, and is as unequivocal a statement of the essential structure of the phenomenon as possible.

7. Returning to the participants for validation.

This final step involved returning to each participant and asking if the description formulated validated the original experience. 


\section{Chapter III}

\section{Result}

This chapter contains the interpretative stage of the study.

Demographic profile of sample

Ten African-American nurses, who met the study criteria, agreed to participate. The nurses ranged in ages from 31 to 60 years old, and all were female. Of these 10 nurses, four were born in the United States, while the remaining six were born in the Caribbean. English was the primary language spoken by all of them. In regard to their educational background all the participants obtained their nursing education within the United States. Five of the participants had a master of science in nursing (MSN), four had a Bachelor of science in Nursing (BSN), and one had an associate degree in nursing. Their areas of specialty included emergency care, medical, home health, hospital administration, and teaching, with nursing experiences ranging from 10 years to 40 years. A detailed demographic profile is presented in (Appendix C2).

Findings

All taped interviews were transcribed into 10 protocols, one for each participant (Table 5). As outlined by Colaizzi (1978), the initial step of the content analysis, involved reading the protocols. The second stage consisted of extracting significant statements. One hundred and sixty-three significant statements relating to the phenomenon under study were extracted (Table 1). The third stage called for formulating meanings of the significant statements (Table 2). Once the meanings for these significant statements were formulated, they were organized into ten clusters of themes (Table 3). In the 
following pages, themes are detailed, and include quotes from the interviewees for illustration.

\section{Theme 1. Glass Ceiling}

The first theme emerge related to the creation of informal glass ceilings and how they impeded professional advancement. Participants had this to say about them:

"The hospital would give them time off to go to school during the day. There's been times that I tried to go to school and work and well, they would say, we have to have you here this day. So I would have to quit the job in order to go to class."

"As I have progressed up the ladder, then you start to find obstacles."

"You try to go up a little higher, and the obstacles, there would be the lame excuses they give you why you cannot do that."

Participants also verbalized that they were not given opportunities to use their knowledge or display their qualifications. They became invisible, therefore, advancement was not possible:

"Nobody really asks you, "Well, how do you feel about this"

"As African Americans I felt that she did not give us the opportunity to use our knowledge."

Some of the participants also cited racial differences as a motive for the creation of glass ceilings; as exemplified by the following:

"I've seen my other White colleagues get promoted to assistant head nurse, head nurse. I have an associate degree in nursing. They have associate degrees, and I know that their nursing skills and their judgments haven't been anywhere near where mine are." 
"This girl was the only one left, and she was not given the job. It makes me think that it was related to her being an African-American person." "If the people who are doing the hiring in nursing are mainly White, then of course, they are going to look out for their own group."

"We noticed that she didn't even let the Blacks be in charge."

Participants stated that advancement was difficult inspite of their reliable work experience or their qualifications. They always have to work twice as hard or prove themselves twice as much. These points were reinforces as follows:

"You have to prove yourself twice as much to reach a higher position."

"You always have to prove that you're excellent."

"Despite the educational achievements that you have, you're still trying to prove yourself in your daily profession."

"You have to be more than qualified."

"Sometimes, even with your qualification, you're just not going to get it, because you are Black."

There were two participant who expressed that even if they got a certain position, they would get frustrated because of the lack of trust, or by the covert efforts to undermined everything they did; as shown by the following quotes:

"She would be like a soldier over my shoulder, and watch everything I did, it was very frustrating."

"When the Black person is in the position and tries to do a good job, what happens is that the White nurses get together and undermine the Black person." 
Finally, one of the participants believed that perceived limits to her achievements created glass ceilings:

"Why should he figure that, as a Black person, I couldn't go as high as I wanted to be, or be all that I could be."

\section{Theme 2. Professional and Social Isolation}

The next theme to emerge was that of professional and social isolation which related to a sense of not belonging. Illustrations of this theme are shown by the following direct quotes form the participants:

"Why am I ever trying to fit myself somewhere I don't belong."

"I really don't see where I fit in that setting because everyone above me, basically, is Caucasian."

Being the only African-American nurse implied professional isolation. This as was expressed by several of the participants:

"I was the first Black nurse."

"I was the only Black nurse."

"In fact, in this hospital, there were only two black nurses, me and another woman. After I was there for about three months, the lady left, and I was the only Black nurse in the whole facility."

Participants then went on to say that barriers to socialization were linked to racism:

"They never really socialized with the LPNs, who were the other Blacks on the floor".

"It seemed like it was more a color issue. The Blacks tend to stick to themselves, and the Whites tend to stick to themselves." 
"Honestly, as an individual, she's a very nice person, as a wife, as a mother and as a friend, but she never allowed herself to be that with me. Only because of my color."

There was one nurse who described how being the only person of color made it difficult to socialize:

"I've found myself as the only person of color sitting in these meetings, and it makes a very difficult time."

Another participant expressed experiencing feelings of being unwelcomed when she entered a room where White nurses were talking, or whenever social plans were being made. The nurse stated:

"They'll be just yapping away, and when I come in total silence."

"They plan stuff among just the two of them, and they ask, one asks the other, "Do you want to go get coffee? "Do you want to go to lunch? like I'm not even there."

Another participant talked about deliberately not socializing, because she felt they did not want her around:

"When it came to their little gathering, I wasn't in it, because I know that they were just hypocrites!"

\section{Theme 3. Ethnocentric Ideations}

The third theme emerge revealed the participants' perceptions of White nurses' opinions. The key word here is "perception":

"This is where you should be as a Black person...my maid, even if you are a nurse."

"My power is to write you up and put you in your place."

Participants also perceived that White nurses believed that because they are White, certain privileges were granted to them: 
"If that was an African-American nurse, I am sure she would not be able to sit there and color in and get paid."

"A White nurse could say, I am not doing it, I am White! I am not doing that!"

"The White nurses, they were just getting all the glory of the day, walking up and down, nothing done, nothing said."

The perception that White nurses believed that they are more superior were frequently expressed by participants, as follows:

"I do not know what it is, but I think it's racism. She would not speak to me. I would come in and I would say, "Good morning," and she would literally turn her back."

"It gives advantages to people with white skin."

"The professionalism, also that should be accorded to AfricanAmerican nurses is not accorded to her."

"I do not think they think we could be professionals."

A perceived country club mentality held by White nurses, which implies that these nurses saw nursing as an exclusive club, was expressed by participants:

"So it's beneficial for the Caucasian group to keep out the Black nurses." "You have a White nurse and a Black nurse, and the position is there. They prefer to give the White nurse the position."

It was also brought up by one participant that a presupposed distinction of being superior is designated to Caucasian nurses.

"It is assumed that the Caucasian nurse is excellent, she knows what she's doing. She has certain skills with which she can go right to the top." 
Another participant believed that, because she is Black, credit and recognition were not given in her presence:

"In my presence, they won't accept my suggestions and advice." she ended her statement by saying, "I know what I'm doing."

Believing that White nurses have a specific purpose, that which is to control the African-American nurse, was expressed by one of the participants as follows:

"They keep you in the subservient role, it's a control thing."

An implied right of White nurses, that it is a right to lead Black nurses, was brought out by another participant:

"One of the rights is to lead Black people."

\section{Theme 4. Disregard or Suspicion of Capabilities}

The fourth theme to emerge revealed disregard and suspicion for African-American nurses in a leadership position:

"She downplayed the capabilities of the African-American administrator."

"She would skip over the nurse manager, who was African American, they did not regard her as someone of importance."

"He said that the one thing that he wanted me to know was that he was not going to have me giving orders to his White nursing assistants."

"She's questioning the Black supervisor."

"She, in effect, is running the department. You have a Black supervisor on paper."

They belief that White nurses do not want to be supervised by African Americans was voiced by several participants: 
"The White nurse in the department, who should have gotten the position, quit because she said she would not have a Black supervisor."

"Caucasian nurses do not want to be supervised by a Black nurse."

"White nurses, cannot see a Black person telling them what to do."

\section{Theme 5. Internalized Racism}

This theme was the fifth one to emerge. It revealed that reactions to racism are internalized by African-American nurses. This process, in turn, leads to the development of adaptive coping mechanisms, which are seen as detrimental to the group as expressed by the following:

"They do not want to do the reverse and favor their own, because they don't want to be seen as if they are racist."

"Reverse racism, they become prejudiced against their own kind."

"They will go out of their way now not to help their Black nurses or colleagues, move up the system, or in the organization."

A lack of mentoring from within the group was also verbalized by one participant:

"I think it's alot of the nursing instructor, especially those who are of the same color, they discourage us. They are not supportive."

This same participant also talked about the transference of learned stereotypical attitudes when she expressed these feelings:

"They were taught that Black people couldn't be nothing. So now they have made it, they still have this thing, that even though they have made it, other Black people cannot make it."

Within the theme of internalized racism, a sense of betrayal from within the group emerged, and was expressed by many participants: 
"There are African-American nurses who don't like that. They'll say if you get a promotion or somebody likes you, it's because they think you carry news. There's is this undertone, well why do they like you?"

"I feel that I get alot of pressures from African-American nurses."

"When a White nurse sets their duties for the day, they shut up! They go outside and quarrel, but they still do the work. When a Black does it, "I ain't doing nothing."

" It's almost as if they feel they are in competition with me to gain respect of the White counterpart."

"If I show my White coworkers that I am not pleased with her either, meaning myself as another nurse of color, then they will have respect for me, and like me, too."

"We try to cover for the Blacks, but some of them don't care how you try to work with them. They always turn against us."

\section{Theme 6. Perceived Inadequacies}

This sixth theme materialized through the participants' revelations of a sensitivity toward how others perceived them to be inadequate, and how it made them feel:

"They already have this image of African-American people. They usually are not positive."

"It's sort of like an old cliché that's carried over, if you're Black, there's something less about you than there is about other people."

"I could never do enough."

"You never make the grade."

"Your excellence is always questioned." 
"You're not given the opportunity to maybe carry out certain projects." "You're never given the benefit of the doubt."

"There's someone better than you, but the person who is better than you is always of another color."

"I've always felt like my suggestions did not count."

"Well, I just don't think you're qualified. I mean, I have been an ER nurse for what, eight years."

"They always made me feel bad. They always made me feel bad for being Black."

"Just a dumb, Black girl. That's what he's thinking."

"I feel that, too, for some reason, people, in general, of the opposite race, to me, seem to feel that we don't have that.. we're not as smart, or have the trained capabilities that other people have."

"I know you people are not concerned about your grades anyway."

"It is how White people look at Black people. Sometimes I wonder if it is because of those years ago that we have been like servants."

One of the participants began to question her inadequacies when she stated the following:

"Did she really mean I was qualified for the position, or was I placed in that position as a token."

\section{Theme 7. Perceived Dislike}

This theme emerged as the seventh one, and revealed how feelings of not being liked could promote racial insecurities:

"This lady did not like me for whatever reason, and I think it was racial." 
"This lady, my instructor, did not like anything about me, my looks, my eyes, the color of my hair, there was nothing, nothing that I could do to satisfy her."

\section{Theme 8. Prejudicial Job Assignments}

The eighth theme to emerge revealed how certain duties was assigned to some of the participants solely because of their skin color. This was reveled through the following statements:

"You're always put in some type of lower position or demeaning position because of color."

"The nurses felt that because they were Black, they were the ones that were being sent in the neighborhoods."

"The way we saw it is that they gave us all Black patients, and wouldn't assign the White students to Black patients, but to all the White patients."

"If a Black patient came in, they'd make sure they'd give him to me."

"If the indigent happened to be a Black person who may be homeless, who may have a hostile attitude, they will not deal with it and assume that it is your responsibility, because the person looks like you, therefore, you should deal with that."

"They see that we are Black nurses, like we're supposed to get the pressure from the floor."

One participant expressed that she was assigned a job because of the fear of competition.

"They didn't want a Black woman doing better than them, so they put me up front doing vital signs only."

\section{Theme 9. Devaluing}


The ninth theme to emerge revealed the devaluing of AfricanAmerican nurses in various domains as expressed by several participants:

"Alot of pressure on us until we eventually left."

"African Americans usually come in at a lower end of the pay scale."

"The Caucasian nurses tend to come in at a higher end."

"They are fired at a higher rate than other nurses."

"The color is not valued."

\section{Theme 10. Effects of Racism}

The final theme to emerge to revealed how participants recognized racism and its effects; as voiced by may of the participants

"I notice that racism is very subtle."

"You have a kind of covert racism."

"It tends to punish or try to keep back people with Black skin, or who are African Americans."

"In retrospect, when I look back on all of this, there are acts of racism almost every single day that I went to work! The comments, the sly remarks, the actions."

"I felt it enough to know when it was my color that was bothering someone."

The themes emerged from the analysis of interview data formed the exhaustive description of lived experiences of racism among AfricanAmerican nurses (Table 4). The themes captured personal experiences of racism, as well as its attributes.

Exhaustive Description of the Lived Experiences of Racism Among AfricanAmerican Nurses. 
The experience of racism is a complex, multidimensional phenomenon. Racism encompasses the attitudes, beliefs, and behavior of racial superiority. In nursing, racism contributes to professional and social isolation, which in turn develops and supports autocratic behaviors and ethnocentric ideations. The process of racism generates many things. Among these are glass ceilings, which hinder career advancement for African-Americans nurses, the perpetuation of feelings of inadequacy, feelings of marginalism and self-doubt. The internalization of racism generates a house slave mentality, which engenders feelings of betrayal, and erodes unity and cohesion within the group. These feelings create what Akbar (1991) terms as, "the alien self-disorder."

In Colaizzi's final step the researcher must return to all the participants for validation of results. Each of the participant was shown their transcribed, verbatim interview with its formulated statements, and the exhaustive description of racism. Each participant agreed that the description captured their experiences. At first two participants, felt the final description were too global to match their personal descriptions. However, after an explanation that the description was an exhaustive description of all the participants' experiences and not just those of one person, the participants then agreed with the description. 


\section{Chapter IV \\ Literature Review}

\section{Everyday Racism}

After studying real life, everyday experiences of racism by women of African descent in the United States and the Netherlands, Essed (1991) presented empirical data indicating that the perception of racism is only recognized as problematic in its extreme manifestations.

Using verbal accounts as the sole source of empirical data for the study, fifty-five women of African descent were interviewed. The selection was based on three criteria: (a) references by interviewees, (b) references through the researcher's personal contacts, and (c) references through her professional contacts. The interviews were taped recorded using the nondirective method and then transcribed verbatim. The scheduling of questions was based on clusters of information the researcher had wanted to obtain and study concerning the everyday experiences of racism.

The study concluded that everyday racism does not exist as single a event, but as a complex of cumulative practices that infiltrate everyday life and become part of what is seen as normal by the dominant group. It also concluded that Black women experienced racism in all spheres of social life, but that it is more pervasive and detrimental in the areas of education and work. It is in these areas that artificial ceilings were found to have been created which impeded the Black women's aspirations.

Despite the prevalent White opinion that racism is diminishing in America, Feagin and Sikes (1994) described in their book, Living with Racism, the depth and relentlessness of racism that middle-class African- 
Americans face every day. Feagin and Sikes (1994) showed through indepth interviews of more than 200 Black respondents, that racism is rooted deep in America's society.

The interviewees from $t$ heir study were selected through a snowball design which had dozens of different starting points. The sample was composed of a gender makeup of approximately 50 percent male and 50 percent female. Most subjects held white-collared position or were students, and had reported household incomes of thirty-five thousand to fifty-five thousand dollars annually. The interview, itself, consisted of open-ended questions centering around topics which related to life goals and recent experiences of racial discrimination.

From the study came the conclusion that racism implied, irregardless of the amount of hard work and achievement, and irregardless of the amount of money earned, the resources accumulated, and the success achieved, African-Americans could not be protected from the persistent ravages of White racism in their everyday lives.

This study also inferred that racism has a cumulative impact on individuals, their families, and their communities. Blatant, subtle and covert discrimination continues to be part of the African-American's everyday life experiences, to understand the impact of modern day racism, one must understand the individual's subjective experience.

The impact of racism on the African-American personality, behavior, and health was studied (Thompson, 1996). Its main goal was to learn whether perceived racism produced symptoms of subjective distress when compared with other stressful life events. It also set about to determine if racial identification mediated the psychological impact of perceived 
experiences of racism. The study consisted of 200 participants in the St. Louis Metropolitan area. These participants completed a 30 item racial identification measure. This measure consisted of a questionnaire that requested information from the participants experiences of racism, and the impact of these events. The results showed that one-third of the participants reported that a perceived experience of racism had occurred within six months of the interview. They also reported that they had experienced intrusion symptoms such as, "bad dreams about the experience," or "reminders brought back feelings about it". Avoidance symptoms such as, "I tried not to think of it," and, "I tried not to talk about it," were also reported. From the results of this study, it has been suggested that individuals who experienced racism also experienced psychological distress.

According to Adler, Boyce, \& Chesney (1993) racism and racial discrimination create differences in life chances and living conditions that are reflected across a broad spectrum of socioeconomic indicators, including housing quality, employment, and education which are all considered as stressful life events. Stressful life events have been characterized as those situations that are tension producing and could adversely effect an individual's mental health (Rabkin \& Struening, 1976). Studies of the psychological response to stressful-like events have suggested that intrusion and avoidance symptoms are common (Horowitz, Wilner \& Alvarez 1979), and according to the American Psychiatric Association, (1994) they are two of the three DSM-IV symptoms cluster necessary for a diagnosis of posttraumatic stress disorder. Studies have shown that African-Americans who display reactions consistent with intrusion and avoidance symptoms have reported experiences of racism (Burke 1984), Goldberg \& Hodes (1992). 
Responses to experiences of racism include difficulty in concentrating, frustration, hypervigilence, denial, withdrawal and avoidance behavior.

In a longitudinal study, the relationships between the experience and perception of racism, and the physical and mental health status of AfricanAmericans was studied (Jackson et al, 1991). The study was based upon a thirteen-year, four-wave, national panel. It reported that personal experiences of racism were found to have both adverse and salubrious, as well as, immediate and cumulative effects on the physical and mental well-being of African-Americans.

Given the pervasive presence of racial bias in contemporary American life (Feagin, 1991), failure to report discrimination may reflect an internalized denial of racial bias that could lead to adverse changes in an individual's health. In a study by Krieger (1990) on the association of racial discrimination with hypertension, it was concluded that Black women, who were found to passively respond to racial discrimination, were four times more likely to have high blood pressure than those who coped in a more active manner, which could be exemplified through talking about the experience or admitting it happen. Another important point of this study suggested that African-American women who reported never experiencing racial bias were two or three times more likely to develop hypertension than their counterparts, who reported experiencing racial discrimination.

There have been numerous correlation between increased levels of blood pressure and racism. Three recent studies using ambulatory blood pressure measurements found that the daytime blood pressure levels were similar in Black and Whites. However, African-Americans had a lower nocturnal decline in blood pressure and maintained higher blood pressure 
levels when they are asleep than their White counterparts (Adams, 1988). These higher levels of arousal can be contributed to the African-Americans' attempts at coping with their experiences of racism.

In his book, Faces At The Bottom of The Well, Derrick Bell maintains that "racism is a permanent and indestructible component of this society." Racism is deeply-rooted in American life and Black people will never gain full equality in this country. The racism that made slavery appropriate over 200 years ago is a far cry from being dead in this last decade of the twentieth century! Inspite of unequivocal advances by many to end racism, AfricanAmericans are by no means excluded from incidents of racial discrimination. Walter (1996), pointed out that racism not only still exists, but that despite the material progress of some Blacks, they and poorer Blacks are still subject to the daily ravages of racism's power to oppress them.

In his book, The Rage of A Privileged Class, Cose (1993) tells through interviews with middle-class African-Americans, how destructive racism is in this society. His book shows how African-Americans face racism in their daily lives and how they feet about it He relates that in this age of diversity and multiculturalism, the status of Blacks in American society rates special attention. African-Americans, like no other group in America's history, have withstood a tremendous amount of rejection on the path to acceptance. He believes that most Blacks in America, regardless of their status, political persuasion, or accomplishments, will never experience the arrival of the moment when the phenomena of race can be treated as a total irrelevancy. Instead, too often it is the only relevant factor defining our existence.

According to Griffin (1991) there is a relationship between humiliation and racism, in that they have been silent partners for many years. Griffin 
According to Griffin (1991) there is a relationship between humiliation and racism, in that they have been silent partners for many years. Griffin (1991) stated that we live in a society which uses humiliation to maintain control over African-Americans. He said that the humiliating acts of slavery were the beginning of a vicious and oppressive relationship between White society and African-Americans. Today this oppressive relationship continues in a more subtle form where, although, African-Americans are not being sold into slavery, persistent and pervasive forms of racism still exist. According to Walter (1997) discrimination can be found in all aspects of AfricanAmerican lives, from disparity in pay, to mortgage lending, to criminal justice, to news and even to health coverage.

\section{Racism in Health Care}

In recent years many studies have been conducted to investigate the barriers faced by clients from diverse cultural backgrounds and their ability to obtain effective health care. An in-depth interview of 28 health care providers revealed that the following three types of providers existed: (1) those who were culturally unaware, (2) those who were culturally nontolerant, and (3) those who were culturally sensitive.

The culturally unaware providers failed to recognize different cultural needs and treated all clients the same way. This approach that led to noncompliance on the part of the client. Culturally nontolerant providers recognized diverse needs, but were unwilling to tolerate cultural conflicts; an approach which often resulted in providers terminating treatment. Culturally sensitive providers acquired information on cultural beliefs, worked within clients' limitations and adapted treatment protocols to meet client's needs (Blenner, 1991). Perhaps, the most important implications to surface from 
this study, were the nature of culturally diverse clients, and the need to recognize ethnocentrism as a barrier in the provision of health care by nurses

As the 21 st century approaches, researchers have recognized the need for multicultural education in health care (Leininger, 1990). A study was undertaken to examine multicultural education in institutions of higher education and health care in the United States. Sohier (1988) reported that most American nursing students had little knowledge of any culture outside their own, and that nursing was primarily for the White and middle-classed. As a result, when White nurses encountered cultural differences in their practices, the potential for conflict and miscommunication surfaced.

Sohier (1988), investigated undergraduate nursing students' competencies in working with culturally diverse clients. The study found that students who had some work experience in nursing had significantly more self-perceived multicultural skills and knowledge, but not more multicultural awareness, than students who had no work experience.

From this study, several problems that emerged were described. Nurses learned very little about cultural diversity in both the classroom and in clinical practice (Brink, 1990) . Furthermore, because of its preference for homogeneity, the nursing profession was inherently resistant to cultural diversity (Brink, 1990). Thus, the relationship between work experiences and the acquisition of multicultural competencies among nursing students raises this question: "Is this competency level sufficient enough to deal with the changing demographic composition of our society?

Numerous nursing organizations and associations, influenced by the social changes of the country, made notable contributions to the improvement of health care for culturally diverse clients. This resulted in a growing 
awareness of culturally influenced perceptions of illness, and ethnic differences in how to deal with diseases. Nurses, also, were made to increase their sensitivity toward the clients' beliefs and values about health, their perceptions of illnesses, and their cultural healing practices. But, as this trend continues to improve culturally, diverse health care practices, racial prejudice, and discrimination among nurses is still not being challenged.

African-American nurses believed that by proving their efficiency as nurses, the commonality of being a nurse would supersede other differences. However, the unequal power relationship between African-American nurses and European-American nurses is either denied or not acknowledged. In 1972, six African-American nursing leaders were asked why there were so few African-Americans in nursing. Only one of six respondents mentioned racism as a reason.

In nursing, the practice of caring, which is a fundamental part of nursing identification, can make it difficult for nurses to recognize racial prejudice and discrimination within the profession.

This position was evident to Carnegie and Osborne (as cited in Barbee, 1993):

Maybe it is because nurses, who know facts of human physical uniformity who know that disease knows no colour (sic) and who have pledged themselves to relieve suffering humanity regardless of race creed or colour, cannot in all consciousness condone any form of discrimination.

\section{Historical Perspective of Racism in Nursing}

There has been a continual struggle on the part of Blacks in America for meaningful recognition in all areas of life. The field of nursing and 
racism within nursing are no exceptions in this struggle. Racism within nursing is not a new problem.

Historically, nursing was a role assigned to Black women (Carnegie, 1991). During the time of slavery, for example, Black women were expected to take care of the sick in the families that owned them. Inspite of their roles as nurses, the title was not bestowed upon them.

Because of racism, African-Americans were denied admission to the early schools of nursing (Hine, 1989). As a result, the establishment of Black schools of nursing began, and were founded on the same premises as White nursing schools. Their goal was to bring professionalism to a field that was reduced to domestic servitude. As the White nurses embraced the ideology of professionalization, the Black nurses began to experience increased hostility and restricted access to training and entry into their professional organization.

In 1908 the National Association of Colored Graduate Nurses (NACGN) was founded. Its goal was to open the path to professionalization, and eradicate racial segregation in nursing (Hine, 1989). In 1950, the American Nurses' Association (ANA) adopted a platform that supported "full participation of minority groups in association activities, and the elimination of discrimination in job opportunities, salaries, and other working conditions...." (American Nurses' Association, 1950). In 1951, the members of NACGN felt that their goals were accomplished, and the need for a separate organization was not needed (Hine, 1989). ANA then committed itself to assuming the responsibilities for the functioning of the NACGN.

Twenty years after the integration into ANA African-American nurses continued to encounter barriers. From these encounters they realized that 
only minuscule improvements had been made in the actual status of Black women within the nursing profession (Hine, 1989). As a result, in 1971, the National Black Nurses' Association (NBNA) was formed. The NBNA was formed specifically in response to racism within nursing (Smith, 1985).

Once more a group of Black nurses, a generation after the ones who dissolved the NACGN, perceived little substantive improvement in the status of Black nurses within the nursing organization and joined together to end racism in the nursing profession.

\section{Racism in Nursing Today}

Today in nursing, there is a growing need to raise the consciousness of cultural diversity (Varricchio, 1987). During the 1970's, efforts were made to establish up guidelines for entry into nursing practices, and educational mobility for minority nurses. It was clearly observed, then, that special attention should be given to minorities in the recruitment process. Allowing minority nurses the opportunity to gain entrance into mobility programs that lead to a degree with a major in nursing (Clinton, 1993) was also another area perceived that required special attention.

Today, the emphasis is not only on recruitment, but on cultural perceptions of illness and ethnic differences in diseases among patients as well. The demands for adequate competent care at all times, to all clients, often prevent nurses from addressing the eminent fear of differences within their profession. This, in turn, may be the driving force behind insensitivity. It is because of these fears that racism and cultural insensitivity among nurses, which are natural human responses, are most likely to be Ok as normative acceptable behavior (Malone, 1993). As the nursing profession increases its cultural sensitivity of the clients' beliefs and values about health, 
and illness and healing practices, the issue of racial prejudice among nurses is not being identified. Within the nursing profession there is a lack of understanding about the cultural needs of African American nurses which, in turn, often leads to tensions and conflicts.

Varricchio (1987) found that prejudice and discrimination are alive and well in the nursing profession, and that racism is manifested in the attitudes of nurses toward patients of different ethnic groups, as well as their fellow professionals. It was the treatment of Black nurses by the EuropeanAmerican nursing establishment that led (Hine, 1989) to conclude that this particular establishment simply did not want Black women to be nurses and, in turn could not treat them as equals. Nursing like other professions in the United States, has been predominantly White. Therefore, the highest positions in nursing are commonly occupied by Whites who are often perceived to be of superior intelligence and ability. Because of this, AfricanAmerican nurses are then subjected to the belief that challenging assignments or positions is only permitted for White nurses.

Are nurses of culturally diverse backgrounds subject to cultural barriers or insensitivity in the nursing profession? In a study using historical, personal, and anecdotal data, Barbee (1994) described how the four attributes of nursing--an emphasis on empathy, an individual orientation, a preference for homogeneity, and a need to avoid conflict--provide a climate that allow nurses to avoid dealing openly with racism. Because nursing is based on the concepts of empathy and caring, nurses believe that they see all people as the same, implying that racism does not exist in nursing.

Is there really racism in nursing? According to Vaughan (1997) yes, there is some form of racism within the nursing profession. Vaughan states 
that racist inequalities are not unique to nursing. The theme of the National Conference of Race and Ethnicity in 1994 was: "If racial inequalities are to be combated in the workforce, academia, and in society itself, the first step is for everyone to recognize that it does exist".

In the early 1990s American nursing literature began to uncover issues of racism and diversity. Tullmann (1992), described several case vignettes taken from practices in which racism was manifested, not only in the attitudes of nurses towards patients of different ethnic groups, but toward fellow professionals as well. The NLN published a collection of literature emphasizing the importance of diversity within nursing practice and education. Its goals was not only to accommodate diversity, but to teach faculty members how to bring a different perspective into nursing. 


\section{Chapter V}

\section{Discussion}

The findings of this study provided a view of the participants' subjective experiences with racism. It also revealed how long-held, stereotyped attitudes are still practiced in nursing. By analyzing the participants' experiences, similarities between the larger society and the nursing professional was found.

The first theme found to be consistently expressed within the study concerned participants believing that White nurses held a negative opinion toward them. This was expressed in the following statements, "They already have this image of African-American people. They usually are not positive." Most White Americans, according to Feagin (1994), will candidly express racial prejudices and stereotypes about African Americans. Feagin said that, for most White Americans, antiblack thinking is conscious and deeply embedded; therefore, they think racially. This was supported by a 1990 opinion poll in which 20 to 35 percent of the Whites surveyed had very negative and prejudicial attitudes toward Black Americans. In addition to having very hostile attitudes, the majority of Whites interviewed in a recent survey conducted by the National Opinion Research Center (1990) indicated that most White Americans accepted some racial stereotypes about African Americans.

Another major finding verbalized by the participants, concerned the maintaining of cultural superiority, and a depiction of ethnocentric ideation.
A preconceived characteristic of being superior was also assigned to Caucasian nurses, as verbalized in the following statements, "It is just 
assumed that the Caucasian nurse is excellent, she knows what she's doing. She has certain skills, and therefore, she is now put on certain track ... a fast track to either promotion or management, or what have you within the organization." Regarding the affirmation of White supremacy; "A White nurse would say I am not doing it, I am White! I am not doing that! She can do that." Concerning the country club; mentality: "So it's beneficial for the Caucasian group to keep out the Black nurses." Vaughan (1997) writes about the time she attended the National Conference on Race and Ethnicity in Atlanta in 1994. She said that at many of the meetings she was the only White person in attendance. By the fourth day she began experiencing discomfort, a feeling of anxiety, frustration at having to be referred to as a European American, and being left out of discussions. She consulted a fellow colleague who is African American. Her colleague said to her, "What you are experiencing is what African-American nurses experience every day." Vaughan concluded that once she left the conference she was able to return to her culture, the culture of dominance. African-American nurses do not have the luxury of returning to a dominant culture. The experiences of racism are synergic with being Black.

One participant verbalized awareness of a transference of learned stereotyped behaviors within the group. This produced another theme, "They are taught that Black people could do nothing. So now that they have made it, they still have this thing, that even though they have made it, other Black people cannot make it." She expressed that members of the group internalized the feelings that they could not be any good, since nobody in the group could be any good. This phenomenon was explained by Griffin (1991) as a lack of group-esteem, which is displayed frequently by members of a 
group who cannot accept the fact that other members of their group could possible be competent, skilled, or knowledgeable.

In extracting the theme the used of adaptation strategies by the oppressed group became apparent (Essed, 1991). There is evidence to support that these groups constantly try to define their own reality in the face of racial experience. This study confirmed Pettigrew's (1964) finding that the oppressed tried to obtain acceptance and approval from the larger society by moving toward the oppressor. This was described by one participant, "She gives you praises and tells you how wonderful of a nurse you are, and that you're not like the others, or you're different, or you're this. When in reality, if you take those words and go, wow, it's unbelievable. I'm not like her! That is why I can treat this Black nurse, who looks like me, or this Black nurse who speaks like me or this Black nurse who lives in my neighborhood this way, because it makes me more acceptable to my White counterpart. It's almost as if they feel they are in competition with me to gain respect of the White counterpart."

Another major finding of this study is that glass ceilings are created to prevent qualified individuals from advancing. In the 1991 Civil Rights Bill, Lynn Martin, Secretary of Labor in the Bush administration, established a commission on the "Glass Ceiling" (Walter, 1997). In a report published in 1995, the "Glass Ceiling" was described as, "those artificial barriers based on attitudinal or organizational bias' that prevent qualified individuals from advancing upward in their organization into management level position." It went on to say that minorities did not advance in many organizations due to a lack of encouragement to participate in the informal culture of their organization, weak mentoring, and poor recruitment efforts. 
As described in the literature review, there are many studies that described the experiences of racism among African Americans. Feagin (1994) discussed the experiences of racism for middle-class AfricanAmericans as an everyday life event. Racism is a peculiar sensation that doubles as a consciousness. It forces African Americans to always look at themselves through the eyes of others.

The findings of this study are also supported by the works of Essed (1991). Essed described features of everyday racism that involved practices which infiltrated everyday life and became part of what was seen as normal by the dominant group. The main mechanisms of these features are a feeling of marginalization, the creation of an artificial ceiling, and the perception that White women are intellectually more qualified than Black women.

\section{Implications for Nursing}

The lived experiences of racism were described by African-American nurses using the phenomenological approach. The findings of this study have significant implications for nurses and nursing professionals, Which include the dimensions of clinical research, nursing education, nursing administration, and nursing research.

The findings of this phenomenological study suggest that racism is an integral part of nursing. The question is, "Can this experience be mediated?" Some attention has been given to factors that could mediate the impact of the experience of racism. Studies have suggested that strong ethnic identification result in active and positive strategies for coping with discrimination (Chavira \& Pinney, 1991). Racial identification, according to Allen \& Stukes (1982), refers to the positive attitudes African Americans hold toward 
themselves. As noted in many of the interviews, the participants expressed a similar perception that their experiences of racism did not affect their selfesteem, or the belief in themselves. They expressed that these experiences allowed them to continue pursuing their goals, helped strengthen their spiritual beliefs, reinforced beliefs in their family values, and allowed for the reaffirmation of self. Though positive racial identification is not documented in the literature as a mediating factor on the impact of racism, it can, however, be used for clinical research studies in the development of coping strategies.

The findings of this study have produced implications that should generate discussions of racism, and also lead to the integration of the awareness of racism into nursing education. This study suggests that racism is real and exists in nursing. Recognizing that racism exists is the beginning step in recognizing ethnocentric behaviors and its impact on AfricanAmerican nurses. For a long time nursing educators have been participating in the development, teaching and implementation of culturally diverse health care for patients, as well as recognizing of ethnocentrism among health care providers. According to the American Academy of Nursing in its panel report on Culturally Competent Health Care (1992), they stated that cross cultural care is being provided to the growing minority populations, and ongoing efforts are being made to improve the delivery of culturally sensitive health care. Leininger (1991) states that becoming aware of one's own dominant cultural values and ethnocentric tendencies is essential for an effective and successful professional working relationship. Attention must now be given to the development, teaching, and implementing of strategies that can be used to identify and combat ethnocentric ideation and racism 
among nursing professionals.

As suggested by this study, there is a critical need for the development of educational programs, which would include a culturally sensitive curriculum to address racism in nursing, and help elevate the awareness of such behavior among health care professionals. To do this strategies to openly discuss racism and understand this phenomenon must be designed. The initial step in this direction would be to train nursing educators to listen to what the African-American nurses are saying about racial attitudes. Opportunities for nonconfrontational discussion must also be started in order for racism to be brought out into the open. Methods to help facilitate mediating factors, such as positive racial identification for AfricanAmericans nurses, must be implemented into nursing education. This would involve the inclusion of more African-American nursing pioneers into nursing literature. The recognition of the need to provide role models in administrative and faculty positions is also an essential step to consider. And finally, providing training on how to get in touch with recognizing one's own learned stereotypical attitudes and ethnocentric behaviors needs to be developed and implemented.

The classroom is the ideal arena in which to begin the discussion of racial discrimination and racism within structured and informal lectures. Opportunities to openly discuss racial experiences and stereotyped perceptions in a nonconfrontation environment can also lead to coping responses that would have significantly positive effects on African-American nurses.

As suggested by this study, the creation of glass ceilings are a product of racism. African-American nurses have indicated that they are perceived to 
be inadequate, unqualified, and therefore, advancement is limited or nonexistent. The experiences of racism for all participants took place in a variety of domains, but the majority occurred in the workplace. Because of this fact, nursing administrators must wake up to the reality of racism and its viability within the workplace. Nursing managers and administrators must also begin to clearly identify disparities in the numbers of African-American nurses in decision-making position Versus those in nondecision making positions. As stated in this study, African Americans are a growing minority. Therefore, more African Americans will be entering into the nursing profession over the next decade. Nursing administrators are in the position to close this gap by looking beyond racial differences and focusing more on the educational and professional qualifications of the African-American nurse. On-the-job workshops to raise issues involving race relations, and the discussion of these issues must be developed and implemented in the workplace. These workshops would allow for the sharing of perceived opinions and attitudes, and the correction of these negatively stereotyped attitudes. Knowing that racism could be discussed or focused on an open forum would create an environment for assisting in the development of trust and conflict resolution.

The findings of this study show that data can be gathered directly from individuals. The analysis of these findings can also be communicated so that the meaning of the experience is not distorted, reduced, or fragmented (Munhall \& Boyd, 1993). These meanings are then viewed as part of the individual's whole experience. Thus, by using a descriptive qualitative method, the participant's feelings and perceptions of being in a racial situation have bee effectively captured. 
In essence, phenomenology goes beyond the boundaries of traditional science. It is concerned with the understanding of human behavior from the participant's frame of reference. By using this method to study the question, "what does it feel like in certain situation?," nursing research gains an increased understanding of the phenomenon of racism.

Limitations of the Study

First of all, this study was limited by the method used to determine the sample. By using the snowball sampling design, the sampling framework followed a social network. This method did not allow for a wide representation of the population under study. Further research using the same phenomenological approach is needed, but with a different sample.

Secondly, a different ethnic group could be studied, and its results compared with the African-American nurses result for similarities and differences.

Credibility of Results

According to Lincoln \& Guba (1985) in qualitative research, credibility is the equivalence of internal validity in quantitative research. This criterion addresses whether the researcher carried out the inquiry in such a way that the findings would be found credible. According to Beck (1994) credibility can be assured if the researcher unitizes the seven step method developed by Colaizzi. In the final step of Colaizzi's method, the researcher returned to the participants for validation. The participants were then asked if the findings agreed with their description. They all agreed and stated that there were no contradictions.

Recommendation for Further Study

There are many themes that surfaced in this study that are worthy of further investigation. Questions remain concerning the impact of racism on 
African-American nurses and the nursing profession. An area of possible research should be the development of positive mediating factors and their impact on the experience of racism. Further study into the differences between experiences of racism in nurses born within the United States and nurses born outside the United States is also another possible area for future study. And finally, there still remains alot to known about the psychological distress induced by the experiences of racism as well.

After each interview the researcher observed that the participant would give a sigh of relief when the tape was turned off. The researcher felt that all participants went through a cleansing while talking about their experiences. The question, "What did it feel like to talk about your experiences." was not asked of the participants by the researcher, and would be another area worthy of study by future researchers.

Summary

For nursing to deal effectively with racism, nurses must recognize that racism is not just a problem concerning Black people, but that it is a flaw within the American society itself. White nurses must realize that they share a historical and cultural heritage of racism which has been focused predominantly on African Americans. They must recognize that because they have been raised in a racist society, they harbor its hidden influences. They must recognize that they, and the system their ancestors created, are deeply racist. In other words, White nurses must begin to listen and hear what is being said by those who are affected by the ravages of racism.

This study has reported that the African-American nurse's experiences of racism is real. It is not too late for the nursing profession to implement changes that would bring about equality and put a stop to racism within 
nursing. Continual denial of the existence of racism, and the unwillingness to recognize its presence in nursing would not only inhibit further nursing research, but would have significant effects upon the nursing profession in the long run. 


\section{Reference}

Akbar, N. (1991). Mental disorder among African American. In Black psychology (3rd. ed.). Berkeley, CA: Cobb and Henry Publishers.

Adler, N. E., Boyce, T., Chesney, M. A., Folkman s. \& Syme, L.

(1993). Socioeconomic inequalities in health: No easy solution. Journal of the American Medical Association, 269 (24), 3140-3145.

Allen, W. \& Stukes, S. (1982). Black family lifestyles and the mental health of black Americans. In F. Munoz, \& R. Endo (Eds.), Perspectives on minority group mental health. (pp. 43-52). Washington D.C: University Press of American, Inc.

American Academy of Nursing. (1992). Expert panel report:

Culturally competent health care. Nursing Outlook, 40, (6), 277-283.

American Nurses Association. (1987). Facts about nursing. Kansas City, MO: American Nurses Association.

American Psychiatric Association (1994). Diagnostic \& statistical manual of mental disorders (4th Ed). Washington, D.C.: American Psychiatric Association.

Andrews, M. M. (1992). Cultural perspectives on nursing in the 21st century. Journal of Professional Nursing, 8, (1), 7-15.

Barbee, E. L. (1993). Racism in U.S. nursing. Medical Anthropology Quarterly. 7. (4), 346-362.

Barrera, M. (1979). Race and class in the Southwest: A theory of racial inequality (pp. 174-219). Notre Dame, IN: University of Notre Dame Press. 
Beck, Tatano, C. (1994). Reliability and validity issues in phenomenological research. Western Journal of Nursing research, 16, (3), 254-267.

Beck, Tatano, C. (1996). Nursing students' experiences caring for cognitively impaired elderly people. Journal of Advanced Nursing, 23, $992-$ 998.

Beckerman, A., Grossman, D., \& Marquez, L. (1995). Cardiac catheterization: The patients' perspective. Heart \& Lung, 24 . (3), 213-219.

Bell, D. (1992). Faces at the Bottom of the Well: The Permanence of Racism. New York: Basic Books.

Berreman, G. D. (1982). Race, caste, and other invidious distinctions in social stratification. In N. Yetman \& C. H. Steele (Eds.), Majority and minority (pp. 15-33). Boston: Allyn \& Bacon.

Blenner, J. L. (1991). Health care providers' treatment approaches to culturally diverse infertile clients. Journal of Transcultural Nursing, 2. (2), 24-31.

Brink, P. J. (1990). Cultural diversity in nursing: How much can we Tolerate? In Current Issues in Nursing (3rd ed.), (pp. 935-939). Boston: Blackwell Scientific Publications.

Burke, A. W. (1984). Racism and psychological disturbances among West Indians in Britain. International Journal of Social Psychiatry, 30, 5068.

Burns, N., \& Grove, S. (1987). The practice of nursing research: Conduct, critique, and utilization. Philadelphia: W. B. Saunders.

Carnegie, E. (1991). The path we tread: Blacks in nursing 18541990. New York: National League for Nursing Press. 
Chavira, V. \& Phinney, J. (1991). Adolescents' ethnic identity, selfesteem \& strategies for dealing with ethnicity status. Hispanic Journal of Behavioral sciences, 13, 226-227.

Clinton, M. M. (1993). Black psychiatric nurses: Historical perspectives, 1964 to 1984. Journal of Black Studies, 24, (2), 213-232.

Colaizzi, P. (1978). Psychological research as the phenomenologist views it. In R. Vall \& M. King (Eds.), Existential-phenomenological alternatives for psychology (pp 48-71). New York: Oxford University Press.

Essed, P. (1991). Understanding everyday racism: An interdisciplinary theory. Newbury Park: Sage Publications, Inc.

Feagin, J. R. (1991) The continuing significance of race: Antiblack discrimination in public places. American Sociological Review, 56, 101116.

Feagin, J. R., \& Sikes, M. P. (1994). Living with racism: The black middle-class experience. Boston, Beacon Press.

Funkhouser, S. W., \& Moser, D. K. (1990). Is health care racist? Advance Nursing Science, 12, (2), 47-55.

Goldberg, W. H. \& Hodes, M. (1992). The poison of racism and the self-poisoning of adolescents. Journal of Family Therapy, 14, 51-67.

Griffin, J. T. (1991). Racism and humiliation in the african-american community. The Journal of Primary Prevention, 12, (2), 149-159.

Hine, D. (1989). Black women in white: Racial conflict and cooperation in the nursing profession 1890-1950. Bloomington: Indiana University Press. 
Horowitz, M. J., Wilner, N.., \& Alvarez, W. (1976). Impact of event scale: A measure of subjective stress. Psychosomatic Medicine, (41), 209218.

Jackson, J. S. (1991). Life in Black American. Newbury park, CA: Sage Publications.

Jackson et al. (1996). Racism and the physical and mental health status of African Americans: A thirteen year national panel study. Ethnicity \& Disease, $6,132-147$.

Jones, J. M. (1972). Prejudice and racism. Reading MA: AddisonWesley.

Knaack, P. (1994). Phenomenological research. Western Journal of Nursing Research, 6, (1), 106-114.

Leininger, M. (1990). Culture: The conspicuous missing link to understanding ethical and moral dimensions of human care. In M. Leininger (Ed. ), Ethical and moral dimensions of human care. (pp. 46-66). Detroit, MI: Wane State Press.

Lincoln, Y., \& Guba, E. (1985). Naturalistic inquiry. Beverly Hills; Sage Publications.

Longstreet, W. S. (1979). Aspects of ethnicity: Understanding differences in pluralistic class-rooms (pp. 3-57). New York: Teacher College Press.

Malone, B. L. (1993). Caring for cultural diverse racial groups: An Administrative matter. Nursing Administration Quarterly, 17, (2), 21-29.

Merrian-Webster's collegiate dictionary (10th ed.). (1994). Springfield, MA: Merrian-Webster. 
Munhall, P. L. (1994). Revisioning phenomenology: Nursing and health science research. National League of Nursing: New York.

Munhall, P. L., \& Boyd C. (1993). Nursing research: A qualitative perspective National League of Nursing: New York.

National League for Nursing. (1991). Nursing data source 1990. New York: National League of Nursing Press.

National League for Nursing. (1991). Nursing data source 1991. New York: National League of Nursing Press.

Merrian-Webster's collegiate dictionary(10th ed.). (1994). Springfield, MA: Merrian-Webster.

Pettigrew, T. F. (1996). A profile of the Negro American. Princeton, New Jersey: Van Nostrant.

Rabin, J. G. \& Struening, E. L. (1976). Life events, stress and illness. Science, 194, 1013-1020.

Sohier, R. (1988). Raising cultural consciousness in nursing Anthropology, 10, (7).

Thompson Sanders, V. L. (1996). Perceived experiences of racism as stressful life events. Community Mental Health Journal, 31 (3).

Trice L. B. (1990). Meaningful life experience to the elderly. Image: Journal of Nursing Scholarship, 22, (4), 248-251.

Tullmann, D. F. (1992). Cultural diversity in nursing education: Does it affect racism in the nursing profession? Journal of Nursing Education, 31. (7), 321-324.

Van Manen, M. (1990). Researching lived experience. New York: State University of New York Press. 
Van Manen, M. (1984). Practicing phenomenological writing phenomenology and pedagogy. New York: State University of New York Press.

Vaughan, J. (1997) Is there really racism in nursing? Journal of Nursing Education, 36, (3), 135-139.

U.S. Bureau of the Census. (1983). General population characteristics. Washington, DC: US Government Printing Office.

U.S. Bureau of the Census. (1992). Current population report. Washington, DC: US Government Printing Office.

West, C. (1993). Race Matters. Boston, MA: Beacon Press. 


\section{Appendix A \\ Informed Consent}

I freely and voluntarily consent to be a participant in the research project titled An Investigation into the Lived Experience of Racism Among African-American Nurses to be conducted at the Florida International University during the Spring/Summer Semester, 1997, with Paula Alexander-Delpech, as the principal Investigator.

I understand that the purpose of this research is to investigate the lived experience of racism among African-American Nurses.

I understand that the research procedures will be as follows:

I will be invited to participate through a letter and conversation.

If I am interested, I will confirm by indicating "yes" on the confirmation slip.

I will then mail the confirmation slip to the principal investigator in the self addressed envelope.

The researcher will then call me to schedule a time and place for the interview.

The research will ask me questions about my lived experience with racism.

My name and identity will be kept confidential. Any forms I complete will be kept in a secure place.

I understand that there are no known risks or benefits involved in my participation in this research. There are no known risks greater than those of daily living. I have been told that my responses will be kept strictly confidential. A Code number will be assigned to my name, and my individual responses will not be revealed to anyone without my express permission.

I understand that I may withdraw my consent and discontinue participation in this research project at any time with no negative consequences. I have been given the right to ask questions concerning the procedure, and all questions have been answered to my satisfaction.

I understand that if I desire information about this research I should contact Paula Alexander-Delpech at 305-758-5615. I have been offered a copy of this informed consent form.

I have read and I understand the above.

Participant's Signature

Date

I have explained and defined the research procedure in which the participant has agreed to participate. I have offered him/her a copy of this informed consent form. 


\section{Appendix B}

\section{Interview question}

What is it like to be an African-American nurse? 


\section{Appendix C1}

\section{DEMOGRAPHIC QUESTIONNAIRE}

1. AGE (in years)

2. GENDER
a) female
b) male

3. PLACE OF BIRTH
a) United States
b) Caribbean (Haiti, Jamaica, etc.)
c) Other Specify

4. EDUCATIONAL ATTAINMENT
a) diploma certificate (nursing)
b) associate degree (nursing)
c) bachelor of science (nursing)
d) master of science (nursing)
e) PhD

5. PREDOMINANT LANGUAGE
a) English
b) French
c) Spanish
d) Other Specify

6. COUNTRY RECEIVED NURSING EDUCATION Specify 


\section{Appendix C 2}

\section{DEMOGRAPHIC PROFILE}

\begin{tabular}{|c|c|c|c|c|c|c|c|c|c|c|}
\hline Participants & P1 & P2 & P3 & P4 & P5 & P6 & P7 & P8 & P9 & P10 \\
\hline Age(in years) & 38 & 47 & 54 & 39 & 36 & 40 & 46 & 40 & 43 & 65 \\
\hline Gender & $\mathrm{F}$ & $\mathrm{F}$ & $\mathrm{F}$ & $\mathrm{F}$ & $\mathrm{F}$ & $\mathrm{F}$ & $\mathrm{F}$ & $\mathrm{F}$ & $\mathrm{F}$ & $\mathrm{F}$ \\
\hline Place of Birth & C & $\mathrm{C}$ & $\mathrm{C}$ & US & US & $\mathrm{C}$ & $\mathrm{C}$ & US & $\mathrm{C}$ & US \\
\hline Educational Attainment & BSN & BSN & MSN & MSN & AS & MSN & BSN & MSN & BSN & MSN \\
\hline Predoninant Language & Eng. & Eng. & Eng. & Eng. & Eng. & Eng. & Eng. & Eng. & Eng. & Eng. \\
\hline $\begin{array}{l}\text { Rec'd Education } \\
\text { (Country) }\end{array}$ & US & US & $\mathrm{J} / \mathrm{US}$ & US & US & US & US & US & US & US \\
\hline Areas of Specialty & $\mathrm{HH}$ & $\mathrm{PH}$ & $\mathrm{TCH}$ & $\mathrm{ADM}$ & MED & $\mathrm{ADM}$ & $\mathrm{HH}$ & $\mathrm{MH}$ & MED & TC \\
\hline
\end{tabular}

Keys: Gender: F-Female Place of Birth: C-Caribbean; US-United States

Rec'd Education: US-United States; J-Jamaica

Areas of Specialty: HH-Home Health; PH-Public Health; TCH-Teaching; ADM-Administration

MH-Mental Health; MED-Medical 


\section{Appendix D \\ Invitation to participate}

\section{An Investigation into the Lived Experiences of Racism Among African-American Nurses}

Dear Ms./Mr.

My name is Paula Alexander-Delpech, a graduate student at Florida International University School of Nursing. I am conducting a study to investigate the lived experience of racism among African-American nurses. The study involves taped interviews that will be arranged at your time and place of convenience. Your experiences are very important to the study.

You were invited to participate as a result of our professional relationship or your name was given to me by a colleague. The interview is completely confidential and your identity will not be revealed.

If you would like to participate in this study, please complete the information found at the bottom of the page, and mail the confirmation back to me in the enclose self-addressed envelope. When I receive your confirmation, I will contact you by telephone to arrange the interview time and place. Thank you very much for your cooperation and assistance in this project.

Sincerely,

Paula A. Delpech, R.N., B.S.N

(circle the yes if you would like to participate)

Yes I would like to participate in this research study.

Name: Phone\#

Print Name

Address: 


\section{Table 1}

\section{Significant statements}

1. You're always put in some type of lower position or demeaning position because of color.

2. You have to prove yourself twice as much to reach a higher position.

3. This lady did not like me for whatever reason, and I think it was racial.

4. Did she really mean I was qualified for the position, or was I place in that position as a token.

5. Alot of pressure on us until we eventual left.

8. We're pressuring our own nurses, and they're just as afraid or fearful of going into some of these neighborhoods as Caucasian nurses. It's like we felt that we were being used against our own people, so it was very difficult to deal with that. The nurses felt that because they were Black, they were the ones that were being sent in the neighborhoods.

9. As African-Americans, I felt that she did not give us the opportunity to use our knowledge.

10. She down played the capabilities of the African-American Administrator.

11. She would it like a soldier over my shoulder, and watch everything I did. It as very frustrating.

12. When I would give advice good, sound advice on how things would function better, all of it was ignored.

13. She would skip over the nurse manager, who was also African-American, they did not regards her as some one of importance.

14. If that was an African-American person. I'm sure should not be able to sit there and color in and get paid. 
15. They try to send myself and other African-American nurses into the projects. they definitely save those patients for the African-American nurses.

16. You find that you have to put your foot down. You definitely have to put your foot down or you get railroaded. They will railroad you.

17. It seems like, I said you have to work twice as hard, or open up your mouth twice as much to get some sort of respect.

18. When you open up your mouth, they want to say that you're aggressive. It's not being aggressive, its being assertive and standing up for what you want or what you believe in.

19. Why an I ever trying to fit myself some where I don't belong.

20. I really don't see where I fit. I cannot fit in that setting because every one above me, basically is Caucasian.

21. They already have this image of African-American people. They usual are not positive.

23. I was the first Black registered nurse.

24. They never rally socialized with the LPN's who were the other blacks on the floor.

25. He did not expect that the person to be in charge was going to be a Black Person.

26. Why would he figure that, as a Black person, I couldn't go as high as I wanted to be, or be all I could be.

27. White nurses really never invited the other Black nurses.

28. She felt threatened. Here I am an Associate, she is my supervisor and I was more qualified than her.

29. Reverse racism, they become prejudice against their own kind.

30. I think prejudice, whether it's reverse or what, starts from nursing school.

31. I was being insubordinate.

32. I notice that the racism was very subtle.

33. I didn't release alot of times that I was experiencing racism until after the fact. 
34. They were accord certain courtesies or benefits.

35. African-Americans usually come in at a lower end of the pay scale.

36. The Caucasian nurses tent to come in at the higher end.

37. She always has to prove herself over and beyond.

38. I can never do enough.

39. You don't have enough skills.

40. You never make the grade.

41. Your excellence is always questioned.

42. You're not given the opportunity to maybe carry out certain projects.

43. It is just assumed that the Caucasian nurse is excellent, she knows what she's doing.

45. African-American not up to snuff...don't excel.

46. You always have to prove that you're excellent.

47. You're never given the benefit of the doubt.

48. The color is not valued.

49. There's somebody better that your, but the person who is better than you is always of another color.

50. Nobody really asks your, well how do you feel about this?

51. Black people have internalized them this inferiority.

52. They don't want to do the reverse and favor their own.

53. They will go out of their way now not to help their Black nurse or colleague.

54. If the people who are doing the hiring in nursing are mainly White, then of course, they're going to look out for their own group.

55. The white nurse in the department, who should have gotten that position quit because she said she would not have a Black supervisor. 
56. Caucasian nurses do not want to be supervised by a Back nurse.

57. One of the rights is to lead Black people.

58. White nurses, cannot see a Black person telling them what to do.

59. When the Black person is in the position and tries to do a good job, what happens is that the White nurses get together and undermine the Black person.

60. She, in effect, is running the department. You have a Black supervisor on paper.

61. She is questioning the Black supervisor.

62. It gives advantages to people with white skin.

63. It tends to punish or try to keep back people with Black skin, or who are AfricanAmericans.

64. So it's beneficial for the Caucasian group to keep out the Back nurses.

65. This is where you should be as a Black person. My maid even if you're a nurse.

66. I see you, historically, as a maid, and therefore, that's where I'm going to place you.

67. My power is to write you up and to put you in your place.

68. They are fired at a higher rate that other nurses.

69. You're not coming with a very strong sense of self into nursing.

70. Nursing can destroy the African-American women.

71. The professionalism, also that should be accord to African-American nurses is not accord to her.

72. As I have progressed up the ladder, then you start to find obstacles.

73. They took somebody without any experience and put them in the nurses slot.

74. You have a kind of covert racism.

75. You see African-Americans in certain positions, and then you go no higher. 
76. You try to go up a little higher, and the obstacles, there would be the lame excuses they give you why you can't do that.

77. I experienced racism once I became an Associate Head Nurse.

78. The nursing instructors, especially those who are of the same color, they discourage us. They are not supportive.

79. They were taught that Black people couldn't be nothing. So now that they have made it, they still have this thing, that even though they have made it, other Black people cannot not make it.

80. I don't know what it is, but I think it's racism. She would not speak to me. I would come in and I would say "Good morning," and she literally turned her back.

81. This whole issue of insubordination. I think people use that as a way of keeping you back, and keeping black, African-American, in other words your are an AfricanAmerican you should know you place.

82. Everybody is running behind this one's back to write up this one. What l've found is that it was just used as a tool to keep nurses, especially African-American nurses, in their place.

83. It seemed like it was more a color issue. the Blacks tent to stick to themselves, and the Whites ten to stick to themselves.

84. It is how White people look at Black people. Sometime I wonder if it is because of these years ago that we have been like servants.

85. I don't think they think we could be professionals.

86. Despite the educational achievements that you have, you're still trying to prove yourself in your daily profession.

87. You feel that people are looking at you, at your skin color first, before looking at your ability as a nurse.

88, The first Black nurse at this place.

89. My supervisor was threatened by me, because I found out that she only had an associate Degree, and I had a Master's Degree.

90. I was introduce to other people as "This is --.--, sand she has a Master's Degree," like Black nurses don't have Master' Degree. 
91. I find that some doctors, Caucasian, White, whatever you want to call them have problems when I come and tell then something. Even though I'm right, they'll argue against it.

92. In my presence, they won't accept my suggestions and advice.

93. They'll be just yapping away, talking away, and when I come in total silence.

94. They plan stuff among just the two of them, and they ask, one asks the other, "Do you want to go get coffee?" "Do you want to go to lunch?" like I'm not even there.

95. I feel that some of the White nurses were standoffish. They weren't helpful.

96. It's been more of a struggle.

97. I've always felt like my suggestions did not count.

98. She almost makes it totally known that she don't not like Black people.

99. She's come out and made comments about Blacks, and says, "Well she's Black, you know".

100. Well, I just don't think you're qualified". I mean, I have been an ER nurse for what eight years.

101. We noticed that she didn't ever let the Blacks be in charge.

102. A White blonde, came in off the street, she put her right in charge over me.

103. I've seen my other White colleagues get promoted to Assistant Head nurse, Head Nurse. I have an Associate Degree in Nursing. They've have Associate Degrees, and I know that their nursing skills and their judgments haven't been anywhere near where mine are.

104. The hospital would give them time off to go to school during the day. There's been times that I tried to go to school and work and, "well, we have to have you here this day". So I would have to quit the job in order to go to class.

105. I was the first Black nurse to work there.

106. They would never let me take care of a cardiac arrest patient. " you don't have the experience, so get away". How else am I going to get the experience unless they give it to me. 
107. I was also the lowest paid nurse in the ER, even though I didn't have the least experience.

108. I mean, they just assumed, because I'm Black, that I know every other Black person in the world.

109. They had me orienting with a nurse that hated me, of course a White nurse a s I was the only Black. The nurse absolutely hated me.

110. To this other White girl, "Yes go for your dream, girl. Go for it". And to me, "I don't think you're smart enough. I don't think you can do it.

111. Just a dumb, Black girl. That's what he's thinking.

112. They always made me feel bad. They always made me feel bad for being Black.

113. If a Black patient would come in, they'd make sure they'd give him to me.

114. They didn't want a Black woman ding better than them, so they put me up front doing vital sign only, for $\$ 28.00$ an hour.

115. Every day I'd go to work in the hospital, and they just assumed that I worked in the kitchen.

116. Being a black nurse, it's part of the definition "Racism" we have to deal with it day in and out, whether we want to or not.

117. In retrospect when I look back on all this, there are acts of racism almost every single day that I went to work! The comments, the sly remarks, the actions.

118. Basically, North Shore Just waited for us to weed ourselves out.

119. The issues that come up from just being African-American extend into your nursing career as well.

120. Issues of prejudice, sometimes not outwardly, but to you it's sensed or it's felt that people are not being fair, not just because of your type of work, but because of who you are.

121. This girl was the only one left, and she was not given the job. It makes me think that it was related to her being and African-American person. 
122. She didn't mind when the other R.N's who were White, were in charge. Whenever I was in charge, she had an issue with me, she had an issue with the assignment.

123. She would never continue working there with a Black person in charge of her.

124. I went in and I was the only one there, the only African-American nurse.

125. Everything she did, they just felt it wasn't done right, wasn't done well enough. She had to constantly be on her toes.

126. I feel that I get alot of pressures from African-American nurses.

127. There are African-American nurses who don't like that. they'll say if you get a promotion or somebody likes you, it's because they think you carry news.

128. There's this undertone, "well, why do they like you?" that I find even more painful, because it's coming from my own people.

129. I was going to apply for the position that was available. She said, "They're not going to give it to you". I said, "Why?" She said, "Because you're Black!" "They're not going to give it to you because they don't want Black people in that unit anyway".

130. There's hardly ever been any Black nurses in there. They don't treat them well, and the few that go in there end up leaving.

131. I know you people are not concerned about your grades anyway. I don't know what she meant by "you people, but I figured what she meant was Black people.

132. I feel like I'm being put down, and I'm going to leave.

133. They see that we are black nurses, like we're supposed to get the pressure from the floor.

134. The white nurses, they were just getting all the gory of the day, walking up and down, nothing done, nothing said.

135. Every time there was something wrong, they would always blame us.

136. they've been dogging us. I mean, they've been really making thing rough for us, it just seems like since we're black, we're to be treated like that.

137. We tried to cover for the Blacks, but some of them don't care how you try to work with them. They always turn against. 
138. When a White nurse sets their duties for the day, they shut up! They go outside and quarrel, but they s till do the work. When a Black does, "I aint't doin' nothing.

139. When it came to their little gathering, I wasn't in it, because I know that they were just hypocrites!

140. A White nurse would say, "I'm not doing it, I'm White! I'm not doing that! She can do that.

141. You have a White nurse and a black nurse, and the position is there. They prefer to give the White nurse the position.

142. You have to be more that qualified.

143. Sometimes even with your qualifications you're just not going to get it, because you're black.

144. It is very difficult, it is very trying. It is very biased. It is a very hostile environment most of the times.

145. It is a very demanding type of role that you have to play, sometimes submissive, sometimes passive.

146. If the indigent happens to be a Black person who may be homeless, who may have a hostile attitude, they will not deal with it and assume that it is your responsibility, because the person looks like you, therefore, you should deal with that.

147. I've found myself as the only person of color sitting in these meeting, and it makes for a very difficult time.

148. This lady my instructor, did not like anything about me, my looks, my eyes, the color of my hair, there was nothing, nothing that I could do to satisfy her.

149. She said to me, privately of course because this was for my ears only, "Well, why don't you just go ahead and be and LPN

150. I can feel tension in the room, and the only reason that there's tension in the room is because I'm a person of color.

151. I felt it enough to know when it was my color that was bothering someone.

152. She gives you praises and tells you how wonderful of a nurse you are, and that you're not like the others, or you're different, or you're this. When in reality, if you take those words and go, "wow, it's unbelievable, I'm not like her! That why I can treat this 
Black nurse, who looks like me, or this Black nurse who speaks like me or this black nurse who lives in my neighborhood this way, because it makes me more acceptable to my White counterpart.

153. It's almost as if they feel they are in competition with me to gain respect of the White counterpart.

154. If I show my White coworker that I am not pleased with her either, meaning myself as another nurse of color, then they'll have respect for me, and like me, too.

155. Honestly, as an individual, she's a very nice person as a wife, as a mother, and as a friend, but she never allowed herself to be that with me. You understand what I'm say? Only because of my color.

156. They keep you in the subservient role, it's a control thing.

157. She knew she couldn't find mistakes in the paper, but it was me.

158. He said that the one thing he wanted me to know was that he was not going to have me giving orders to his White Nursing Assistants.

159. In fact, in this hospital, there were only two Black nurses, me and another woman. After I was there for about six months, the lady left, and I was the only Black nurse in the whole facility.

160. She was a Black nurse who was already there, and they made her a Head Nurse. I guess to me, they made it look like maybe it wasn't discriminatory, because at the time, they didn't have any Black Head Nurses. They made her a Head Nurse, but not me. I mean, they could have afford to use both of us.

161. The way we saw it is that they gave us all-black patients, and wouldn't assign the white students to Black patients but to all the White students.

162. I feel that, too, for some reason, people, in general, of the opposite race, to me, seem to feel that w e don't have that we're not as smart, or have the trained capabilities that other people have.

163. It sort of like an old cliché that's carried over, if you're black, there's something less about you that there is about other people. 


\section{Table 2}

\section{FORMULATED MEANINGS OF SIGNIFICANT STATEMENTS}

1. Underrated job assignment because of skin color

2. Advancement is not easily attainable

3. Perceived dislike because of skin color

4. Internalize self-doubt

5. Systematic badgering to force out

8. Prejudiced job assignments

9. Hindrance of development

10. Underestimation of leadership qualities

11. Absence of trustworthiness

12. Limitation of imput

13. Disregard for authority

14. Privileges granted based on racial preferences

15. Prejudiced job assignments

16. Racism produces aggressiveness

17. Racism produces aggressiveness

18. Assertiveness perceived as aggressiveness

19. Sensed unacceptance

20. Feelings of isolation

21. Negative preconceived portrayals

23. Professional isolation

24. Sense of unwillingness to socialize

25. Prejudiced expectations regarding position

26. Established preconceived beliefs which set limitations on achievement

27. Social isolation

28. Educational advancement among African-American Nurses creates insecurity within the Caucasian work force

29. Racism turned internal

30. Grounded preconceptions concerning racism

32. Recognized insidious racism

33. Delayed recognition of racial experiences

34. Privileges granted based on racial preferences

35. Economic repression

36. Inequality in salary

37. Advancement is not easily attainable

38. A sense of inadequacy prevails

40. Perceived inability to achieve

41. Inadequacy or criticism 
42. Suffocation of growth

43. A preconceived distinction of "being better" is given to Caucasian nurses

45. Stringent expectations hinder growth

46. Hard work is not enough

47. Lack of confidence

48. Being Black is not respected

49. Attack on self-esteem, disrespect of person

50. Insensitivity towards growth

51. Assault on one's own self-esteem

52. Intentional lack of support due to fear of reprisal

53. Intentional hindrance by one's own group

54. Racially motivated hiring practices

55. Disregard for Black authority

56. Disapproval of Black authority

57. Influence from bigoted ideation regarding leadership

58. Denial of Black authority

59. Systematic sabotage of Black advancement

60. Tokenism

61. Interrogation of decision making abilities

62. Racism implies superiority

63. Racism means oppression

64. "Country club" mentality

65. Validated supremacist attitude

66. Validated supremacist attitude

67. Autocratic complex

68. Lack of job stability

69. Racism extends into one's profession

71. Withholding of professional courtesies

72. Racism is covert at the top

74. Racism is camouflaged

75. Informal barriers to advancement

76. Informal barriers to advancement

77. Racism is covert at the top

78. Lack of mentoring from one's own group

79. Transferring of learned stereotyped behaviors among one's own group

80. Racial differences breed negative behavior

82. Misuse of institutional methods for the purpose of oppression

83. Self-imposed social isolation

84. prejudiced vision

85. Inferred judgment concerning ones status

86. Educational attainment is not an entitlement for acceptance

87. Emphasis on skin color precedes performance

88. Self-imposed social isolation

89. Education advancement among African-American nurses creates insecurity within 
the Caucasian work force

90. Anticipated threat from African-American nurse's educational achievements

92. Withholding of credit and recognition

93. Indirect message of unwelcomeness

94. Social isolation

96. Being an African-American Nurse is stressful

97. Internalized feelings of marginalism

98. Outward demonstration of dislike

99. Stereotyping and labeling

100. Uncertainty about one's qualifications

101. Recognized leadership restraints

102. Racial bias hinders upward mobility

103. Racial characteristics supersede qualifications

104. Imposed informal barriers

107. Economic repression

108. Assumptions based on skin color

109. Racial dislikes interfere with work relations

110. Lack of encouragement and support when African-American nurses reveal their goals.

111. Prejudiced opinions

112. Internalized negative opinions about one's ethnicity

113. Delivery of health care based on one's race

114. Fear of competition leads to remedial assignments

115. Preconceived stereotyping about ones position

116. Everyday racism is synergic with ethnicity

117. Racism is an everyday experience

118. Systematic badgering to force out

119. Racism extends into one's profession

120. Preconceived judgments

121. Racial appearance outweighs qualifications

122. Disregard for Black authority

123. Disregard for Black authority

124. Profession isolation

125. Projected feelings of marginalism

126. Presume tension from one's own group

127. "House slave" mentality

128. An association of betrayal from within one's own group

129. Transferring of learned stereotyped behaviors among one's group

130. Systematic badgering to force out

131. Assumptions based on skin color

132. Systematic badgering to force out

133. Relegation of task based on one's skin color

134. Favorable recognition based solely on racial preferences

135. Accusations based on race 
136. Systematic badgering to force out

137. Internalize self hatred

138. Rejection and rebellion within one's own group

139. Racism causes cynicism

140. Affirmation of White supremacy

141. References toward homogeneity

142. African-America nurses must go beyond standards

143. Racial appearance supersedes qualifications

144. Racism creates a tense environment

145. Need to adopt a subservient role to survive

146. Designation of health care based on racial stereotype

147. Isolation

148. Racial obstacles to acceptance

149. Lack of encouragement to succeed, and blatant disrespect of goals.

150. Racism creates a tense environment

151. Self-development of internal sensitivity towards racism

152. "House slave" mentality

153. Internal rivalry for White respect

154. Betrayal for White approval

155. Racism hinders socialization

156. Colonial complex

157. Assumptions based on skin color

158. Disregard for Black authority

159. Professional isolation

160. Prejudiced job assignments

161. Prejudiced job assignments

162. Negative preconceived portrayal

163. Negative preconceived portrayal 
Table 3

\section{CLUSTERS OF COMMON THEMES}

\section{GLASS CEILING}

2. Advancement is not easily attainable

9. Hindrance on development

11. Absence of trustworthiness

26. Established preconceived beliefs which set limitations on achievement

45. Stringtend expectations hinder growth

46. Hard work is not enough

50. Insensitivity towards growth

54. Racially motivated hiring practices

59. Systematic sabotaging of Black advancement

76. Informal barriers to advancement

86. Educational attainment is no guarantee for advancement

101. Recognized leadership restraints

103. Racial characteristics supersede qualifications

104. Imposed informal barriers

121. Racial appearance outweighs qualifications

142. African-American nurses must required to go beyond the norm

143. Racial appearance supersedes qualifications

\section{PROFESSIONAL AND SOCIAL ISOLATION}

19. Sensed unacceptance

20. Feelings of isolation

23. Professional isolation

24. Sense of unwillingness to socialize

27. Social isolation

83. Self imposed social isolation

93. Indirect message of unwelcomeness

139. Racism causes cynicism

147. Isolation

155. Racism hinders socialization

\section{ETHNOCENTRIC IDEATIONS}

14. Privileges granted based on racial preferences

43. A preconceived distinction of being superiority is designated to Caucasian nurses

57. Influenced bigoted ideation concerning leadership

62. Racism implies superiority

64. "Country club" mentality 
65. Validated supremacy stereotype

67. Autocratic complex

71. Withholding of professional courtesies

80. Racial differences support superiority complexes

82. Misuse of institutional methods for the purpose of oppression

85. Inferred judgment concerning one's status

92. Withholding of credit and recognition

134. Favorable professional recognition based solely on racial preferences

135. Accusation based on race

140. Affirmation of White supremacy

141. Preference toward homogeneity

156. Colonial complex

\section{DISREGARD OR SUSPICION OF CAPABILITIES}

10. Underestimation of leadership qualities

13. Disregard for authority

25. Prejudiced expectation regarding one's position

55. Disregard of Black authority

56. Disapproval of Black authority

58. Denial of Black authority

60. Tokenism

61. Interrogation of decision making abilities

\section{INTERNALIZED RACISM}

29. Racism turned internal

52. Intentional lack of support due to fear of reprisal

53. Intentional hindrance by one's own group

78. Lack of mentoring from ones own group

79. Transferring of learned, stereotyped behaviors among one's own group

126. Presumed tension from one's own group

127. "House slave" mentality

128. Association of betrayal from within ones own group

137. Internalized self-hatred

138. Rejection and rebellion from within one's own group

153. Internal rival for White respect

154. Betrayal in return for White approval

\section{PERCEIVED INADEQUACIES}

4. Internalized self doubt

21. Negative preconceived portrayal

38. A sense of inadequacy prevails

40. Preconceived inability to achieve

41. Inadequacy or criticism

42. Suffocation of growth 
47. Lack of confidence

49. Attack on self-esteem, disrespect for person

51. Assault on ones own self-esteem

84. Prejudiced vision

87. Emphasis on skin color proceeds performance

97. Internalized feeling of marginalism

100. Uncertainty about one's qualifications

108. Assumptions based on skin color

111. Prejudiced opinions

112. Internalized negative opinions about one's ethnicity

120. Preconceived judgment

125. Projected feelings of marginalism

\section{PERCEIVED DISLIKE}

3. Perceived dislike because of skin color

98. Outward demonstration of dislike

109. Racial dislikes interfere with work relations

148. Racial obstacles to acceptance

\section{PREJUDICIAL JOB ASSIGNMENT}

1. Underrated job assignment because of skin color

8. Prejudicial job assignment

113. Delivery of health care based on ones race

114. Fear of competition leading to remedial assignments

133. Relegation of tasks based on ones skin color

146. Designation of health care based on racial stereotype

\section{DEVALUING}

5. Systematic badgering to force out

36. Inequality in salary

35. Economic repression

48. Being Black is not respected

68. Lack of job stability

\section{EFFECTS OF RACISM}

16. Racism produces aggressiveness

32. Racism is recognized and insidious

63. Racism is oppressive

72. Racism is covert at the top

74. Racism is camouflaged

117. Racism is an everyday experience

144. Racism creates a tense environment 


\section{Table 4}

\section{EXHAUSTIVE DESCRIPTION OF THE LIVED EXPERIENCES OF RACISM AMONG AFRICAN-AMERICAN NURSES}

The experience of racism is a complex, multidimensional phenomenon. Racism encompasses the attitudes, beliefs, and behaviors of racial superiority. In nursing, racism contributes to professional and social isolation which in turn develops and supports autocratic behaviors and ethnocentric ideations. The process of racism generates many things. Among these are glass ceiling, that hinder the career advancement of African-America nurses, the perpetuation feelings of inadequacy, marginalism and self-doubt. The internalization of racism generates a house slave mentality, which engenders feelings of betrayal and erodes unity and cohesion within the group. These feelings creates what Akbar (1991) terms as "the alien self-disorder." 
Table 5

\section{Interview Protocols}

Participant \#1 Pages 81-98

Participant \#2 Pages 99 - 110

Participant \#3 Pages 111 - 131

Participant \#4 Pages 132 - 141

Participant \#5 Pages 142 - 152

Participant \#6 Pages 153 - 186

Participant \#7 Pages 185 - 202

Participant \#8 Pages 203 - 212

Participant \#9 Pages 213 - 231

Participant \#10 Pages 232 - 258 


\section{Participant \#1}

Interviewer: What is it like to be an African-American nurse?

Participant: Well, basically. . to be a nurse, first of all, you don't get as much rewards or praise for doing what you're doing. To be African American, most of the organizations that you work for: 1) are not owned by African Americans, and you're always put in some type of lower position or demeaning position because of color ... or so $\underline{I}$ feel . . . that you have to prove yourself twice as much to reach a higher position. Experience... ?

Interviewer: $\quad$...Yes, uh huh. . .

Participant: Number one. I was. . . this was in New York. I was being interviewed for a position as a regular med.-surg. nurse. I was a recent graduate, and I was interviewed by the human resource person, who then sent me to the Head Nurse of that floor to be interviewed. While being interviewed, she just kept giving me these looks that, as soon as I entered the room she knew... I knew that she didn't like me just from the way she looked at me. She kept looking at my head. I always wear my hair covered. . . it's a type of African ... gailay, as they call it. . I wrap my hair. Even though she would ask me regular interview questions, the answers didn't even make sense to her. She was just ignoring everything I was saying. . just 
going through the procedure because it was an interview, and quickly told me after the interview was over to go back down to Personnel. When I went back down to Personnel, the lady gave me a paper. She told me that that Head Nurse had called and said for her to give the paper to me. When I read it, the paper said that there is no way. . no employees can work with any kind of garment covering their hair. The lady looked at me. . . I looked at her and said, "So what about people that are Muslims or some type of religion that they wear their hair covered?" She said to me, "To be honest with you, I have never seen this piece of paper, and I have worked here for five years." She actually took a long time before she could dig that paper up. She said, "We never use it." So, it just. . yeah, it was just an indication to me that this was directly targeted to me. This lady did_not like me for whatever reason, and I think it was racial. Definitely!

Other experiences. . . I recently moved to the state of Florida and was working as a Q. A. nurse in home health. I wanted to move up the ladder, and I took a job. . . I went for an interview for a clinical supervisor position at another agency. Well. . I was told that I was more than qualified for the position. . . they were so happy that I came by, and they were ready to rush me through orientation... everything! Anyway, I told them I needed some time to give in my resignation letter and take a week off, or whatever. 
When I finally got there, I realized that the director was African American. They had a nurse manager, who was African American, and then myself. . . that would be the third African American in management. So management started with the clinical supervisor, which is what I would be. . l lower management. Then they had the nurse manager, which is middle management, and then a director. I thought it was really nice to be working with your own people, in that respect. But what I got to realize was. . . I was told by one of those ladies. . . she said. . . we were at lunch. . . and she said, "Do you know why. . . do you understand why we're here?" I said, "No," because I recently moved, and I was not aware of what was going on in the community with this particular hospital and agency. I understand. . . I got to understand that there was some racial problems with the agency.

The organization must have had a robbery with one of the nurses. . . I'm not sure if it was an African-American nurse, or a Caucasian nurse, or whatever. . . but there was a robbery while the nurse was out seeing a patient in a particular northwest neighborhood. The Director of Nursing at the time was this Jewish lady, and she sent out a memo to the Supervisor. . . the Clinical Supervisor... that they should not assign any more nurses in the northwest neighborhood. The memo had to circulate, also, to the coordinators in the hospital who were receiving the referrals ... so they would not be able to accept referrals in certain neighborhoods 
... Liberty City, Overtown. . . those kind of rough neighborhoods. In any case, the memo got into the hands of the N.A.A.C.P. From there it was made public, and they wanted a full investigation of what was going on.

I heard. . . up to this point I have not. . . because I said I was going to go to the library and pull up that article... I have not gotten a chance to do that, to really read and see what it was about, but I heard it was front page. . . yes, front page. It was really disgusting ... about this particular hospital, and the agencies associated with the hospital. The news. . the N.A.A.C.P. was pressuring the hospital. They wanted to know what kind of discrimination is this? ... you're giving health care! Health care is not only for one race, it is for everyone. Whatever you have to do to secure your nurses in certain neighborhoods . . . you need to do that, but you cannot say that you're not sending a nurse to a particular neighborhood.

So I was told this story, and I came on directly after that had. . . it hadn't even cooled down. . . it was just quiet. It was in the workplace. . . no one really talked about it. . . but I understand right after that, they had gotten rid of that Jewish director. . . because of the pressure they were getting. They got rid of her.

The next person that was hired was an African-American director. The next person that was hired was an African-American manager. The next person that was hired was myself, which was an African-American supervisor. I wasn't too proud of the 
position after I heard that story. Because here I'm wondering. . . "Did she really mean that I was qualified for the position, or was I just placed in that position as a token?" We were the only three in management, of color or African American. Everyone else that was African American were in clerical positions or home health aides, or just regular field nurses.

It was only for a time, of course. I felt that the pressure that was put on us, as managers. . they eventually wanted to show that we weren't qualified, or whatever. They started putting alot of pressure, alot of pressure, alot of pressure on us, until we eventually left. Changes came about. The part that bothered me most of all was the reason why I was placed in that belief (?)... so I heard. . the reason why we were placed in that position. . . to kind of cool down everything.

The pressure is, basically, here we are now in a position where we have to send the nurses out in these neighborhoods that they didn't want to send anyone else out in. Of course, being the manager, you have to weigh. . y you have to definitely provide the services for the patient. But who are you going to send out there? If you were being faced with nurses complaining of being the ones . . we were actually sending African-American nurses in those neighborhoods, because a Caucasian person would stand out like a sore thumb. So here we are. . caught in this situation where we're pressuring our own nurses, and they're just as afraid or fearful of 
going into some of these neighborhoods as Caucasian nurses. So we had nurses that were upset with management's decision to send them in these neighborhoods, and that. . . I think that that's what they wanted to see. Even in politics or in regular society, you always ... or back in slavery days. . they always get another slave to beat another slave, or to convince another slave to do something, or get their own people on their side, or whatever. . the house slaves, the ones that get all the extra stuff. It's like we felt that we were being used against our own people, so it was very difficult to deal with that. Here we couldn't say, "No, you can't go," . . because all this attention is on us. So here we definitely dealt with the problem by providing escort service, whether it was through Metro-Dade police, or whoever we could. . whatever organization we could get to assist us in that. But it was very difficult, because the nurses felt that because they were Black, they were the ones that were being sent in the neighborhoods.

Other pressures came about because administration had also changed while we were there. They were pressuring the nurses into seeing certain amounts of patients. The new administrator felt that nurses were getting away with murder. We were paying full benefits for these nurses, and who were being paid full-time salary. They were supposed to be maxing out at least 35 to 40 patients a week. . . and if they were given 7 patients a day, and out of that 7 they only saw 3 or 4 , they weren't... sometimes they weren't even seeing 
30 patients. . 20 something patients a week, and they were getting full-time salaries. We had to start pressuring the nurses into seeing 35 to 40 patients a week. If they did not reach that goal by the end of the week, it was mandatory that they put in a weekend day. Nurses started leaving. They all started resigning. . . changing from fulltime to per diem positions. . it became a chaos. It was chaotic!

The administrator at the time, we felt, did not ever. . . as a whole. . . not as just African Americans, but as a whole. . .did not respect nurses at all. Then she started having clerical people do nursing functions. . . accept referrals over the phone. They had no knowledge of medical diagnosis, and all of that. As African Americans, I felt that she did not give us the opportunity to use our knowledge. . . she came out of her office and would start doing the work herself. . . so what were we there for? She just took over. We felt that if there were someone else there, she would have never done that. She would have given them whatever directions, and they would go ahead and do it. No, she downplayed... downplayed the capabilities of the African-American administrator and her staff and took over.

When she. . . when the Director left, a Caucasian lady was hired, and there were four clinical supervisors. . myself, a Hispanic, and two Caucasians. She would come there and she would sit like a soldier over my shoulder, and watch everything I did. It was very frustrating. I felt that she was just trying to pressure me into 
leaving. I really felt that. . it was a gut feeling. When I would give her advice. . good, sound advice on how things would function better, all of it was ignored. . . or, she would take the advice, pass it on directly. . . she would skip over the nurse manager, who was also African American. . . they didn't even regard her as someone of importance. As a matter of fact, they wanted to get rid of her, so they got rid of the position. She would go. . . this new Director would go directly to the Administrator and bring these suggestions to her as if they were her own!

I always felt that the person at the bottom does the work and gets no reward for it. . . and then she reaps the rewards and she does nothing but sit there and color in the schedule. . . it was so annoying! We would work, work, work, work, work, and she sat there like a soldier. . . not moving all day, and take the highlighter pen and marking in the days. I'm like, "Is this what a Director gets her money for?" If that was an African-American person, I'm sure ... sure she would not be able to sit there and color in and get paid. It just doesn't make sense to me!

Right now I'm doing field visits. There I also experience some bit of racism. There's one supervisor. . . there's a supervisor that I report to, but that's on Team 1. There are two teams. One of the supervisors is African American, and the other one is Caucasian. The one that I report to is Caucasian, but sometimes I see patients on the 
other team. I sometime, purposely, would speak to the other supervisor to avoid speaking to this one supervisor.

I don't know if it's a personal thing. . I don't know what it is ... but I think it's racism. She would not speak to me. I would come in and I would say, "Good morning," and she literally turned her back. I observed her behavior with other people, and she does not do that to other people. Caucasian people she does not do that to. What she does, also, is they try to send myself and other AfricanAmerican nurses into the Project. They definitely save those patients for the African-American nurses. Of course, I started refusing. They don't know who to send. Well, find someone else to send, because I'm not going up in there. If I go around there and it looks quiet. . . they have some projects that are quiet. . . I will go there, but don't save those addresses for me.

You have some nurses that will only work Miami Shores ... they will only work anywhere along Biscayne-northeast. . . northwest they don't. They don't work at the northwest section. Now some of these nurses are full-time nurses, and they're not supposed to be rejecting cases. Maybe they don't reject the cases, but this particular supervisor who looks out for her own, will make sure she doesn't send her nurses over there. I even. . . I said, "What happened to this particular nurse?. . Why can't she go? . . She's staff,". . . "Well, it's dangerous for her." I said, "It's dangerous for me, too!" Well, the statement we hear is that, of course. . she sticks 
out like a sore thumb. . . more than I would. I said, "Well, the safety problem is still there. If I have to go up in there, you're going to have to find security ... you're going to have to arrange something with Metro-Dade." Then she tells me that I need to get on the phone and call Metro-Dade. I said, "Oh no! I'm out here seeing patients. . you're sitting at a desk. . . that's an administration's problem to find security for the nurses." I'm not going to call. That patient won't be seen by me.

You find that you have to put your foot down. You definitely have to put your foot down or you will get railroaded. . . they will railroad you. It seems like, like I said, you have to work twice as hard, or open up your mouth twice as much to get some sort of respect. Now, sometimes when you open up your mouth, they want to say that you're aggressive. . . and it's not being aggressive, it's being assertive, and standing up for what you want or what you believe in.

Interviewer: Being an African-American nurse, have instances of racism affected your self-esteem?

Participant: Actually, what it does for me. . initially it does. . . initially it really does, but after you sit and you think about it, for me, it gives me the drive to keep pushing. . it really does. At first you say, "But why am I even trying to fit myself somewhere where I don't belong!". . Even right now, in trying to obtain my master's, I'm. . people would say, "Oh, when you finish you're going to get 
that director position, huh?" I say, "No, I'm getting this master's for my personal accomplishment," because I really don't see where I fit. I cannot fit in that setting because everyone above me, basically, is Caucasian.

Now that the hospitals have been bought out by these big corporations, everyone in the corporation is Caucasian. . . all the regional this, and the regional directors, and the regional managers ... and coming straight down, maybe the local people, or the lower management end are African American, but everyone above you is Caucasian, and it's nothing but pressure, pressure, pressure, pressure, pressure. Not only pressure from the work, which is expected, but they already have this image of African-American people. They usually are not positive. I don't want to stereotype everyone and say that, but for the most part, you have to prove yourself twice as hard. I don't see why I should have to prove myself to anyone.

So initially, it affects you negatively, but then. . . what it's doing for me is pushing me into trying to do something for myself. It makes me not want to be a part of all that "politicking." Within it there is alot of racism. . within these big corporations. I just want to do something for my people. Something that I have to get into with my profession that is going to be dealing with my people in an African-American community. That's what my goal is. 
Racism. . . I basically have experienced. . I I really got the sense of racism when I went to college. Basically, I grew up in a predominantly African-American neighborhood, but at the same time I went to a church that we were the only African-American people in that church. So it wasn't like I wasn't exposed to Caucasian people. I had exposure... I have actually grown up with these people and didn't even know the difference. You know when people would say, "You don't see color," I didn't see color. These people. . . we loved each other. We would go to their house and eat. They picked us up for church. They... we were treated good, and we liked them and they liked us. We had no problems. . . at least. . I I think at that time I was blinded, because as I got older and I understood certain things, I started to see what was really happening.

Before I get to that. . . where my eyes became open was when I left high school and received a scholarship to go to a state university. There I lived in a dormitory. I didn't have any friends that went to this university with me, so I was pretty alone. In that particular university, it was approximately one percent African American. I was in this dormitory, and I was the only Black person in the dormitory of about 200 people. I would go in. . . there was this evening that I went in to my room, and as I opened the door I almost slipped and fell. Why? Because someone squirted powder under my door. . squirted powder under my door and the floors were tiled, so with the powder and the tile, it creates a slippery surface. That was 
the intention. . for me to slip and fall. The whole week went by and it was happening every single day. I went to the dormitory. . . I forget what they call them. . like the head of the dormitory, but he was a student as well. . . and mentioned it. Nothing. . . he did absolutely nothing! The next day. . . the next day I hear. . . the next day I go into the bathroom and someone wrote on the mirror, in lipstick, "Nigger get out of here!" I knew. . .I didn't even realize at the time why the powder was being put under my door, because. . like I said. . . I was naive to these things. Then I started understanding what was going on. Of course, I found out who did it, and I jacked her up in the bathroom. Anyway, it didn't happen after that.

I started. . . I really became paranoid, and I didn't trust these people at all. I got to realize that these people weren't like the people I used to go to church with. In any case, I wanted to continue to go to church while I was at school. We had branches of the different churches all over. The first Sunday of the month all the churches would get together in. . . like a big, large college auditorium. There would be thousands and thousands of people. I used to sing solo as a little kid. . . yeah, six years old in front of all these people. .. and I was like the only Black. . . I didn't see color at the time. We... the pastor from my local church got in touch with the people at this. . . near this other. . . near this university and arranged for me to be picked up on Sundays to go to church. They came out 
and picked me up on several occasions. Youth programs. . they picked me up.

They would go out to eat and everything. Here's where the problem came up. One evening they stopped at a Howard Johnson's, and they were eating. Of course, I'm noticing that I really don't fit. This is the suburbs, you know. . you don't see any other Black people. So even though there was a group of White people. . . even within the restaurant you're not seeing any other Black people. I'm starting to feel uncomfortable. They would go out to Howard Johnson's and eat after a youth meeting at 9 - 10 o' clock at night, and I would tell them, "No."I would stay in the car. I would sit in the car for an hour and a half while they had a good time eating. I would sit there until they were ready to drop me at my home.

One particular evening one of the boys asked me, "How do you feel to be a part of a church that all . . . basically all the people are White?. . the head, which is called the Chief Apostle, and District Apostle, and all the Apostles. .. Other than the countries that they've invaded and converted. . . the African countries and certain other Caribbean countries. . .other than those people, the real heads, or the administrators for the church. . . they are all White. How do you feel?"

I was. . I didn't know what to say because I never saw color. I didn't. . . I had to answer and say, "It doesn't matter to me because we're all equal." But it really, really made me think. 
That's when everything started. With this. . yes, yes. . . that's when I really started to think, "What is going. . ?" I noticed that I was not being treated right. They would make little racial remarks. I know, where we lived, the church would encourage the youth not to go to the movies, not to go to roller skating rinks, because all those things were ungodly. So we wouldn't do anything. We would watch T. V., have little meetings, Friday's we would get together and play scrabble. . . usually as a youth group in a local church. These were a few Black people, now. Now we're recruiting more Black youth into the church as time went by. I wasn't the only one at. . at ... when I was about teenager, more Black people started coming. So we had our own little Black group there.

What I got to realize when I went out into this university ... into the suburbs of this state, that they were doing all the things that they told us not to do. . . the priest was taking his family to the movies, when we were forbidden to go to the movies. I started to become curious, so I called the priest back in our local area, and he was White. Of course, they ordained my brother as Deacon and wouldn't move him. For years and years he would never move up the ladder. The Deacon would go ahead and fix the alter, dust it, get the water ready. . the consecration water and the drinking water, find a berth for the Bible, make sure the church was clean, and open up when it was time. He would never move up. When was he ever going to become a Priest? Never to see that! They wanted to keep 
him on that lower position. So I started questioning why was there a difference between what we could do and what they could do. I couldn't get an answer.

Also, I got to. . . you hear things, and you find out that this particular one. . some evangelist, an evangelist was above the priest, an evangelist's daughter was pregnant, and she had an abortion, and the evangelist paid for it. We would never dream of those things ever happening. That's something you just don't do! Then you get to find out ... well, what is this? Oh, it's just a bunch of hypocrisy here! This is an evangelist who professed all of this, and this, and this, and this, and here his children are doing all of this. But then they're telling us we can't do that. . racism!

I mean, this is a way of getting our money, or winning over us . . lowering our status. As a matter of fact when I think about it, my sister, at that time, had graduated from high school, and was much older than me. I remember she had graduated from my high school, and she was working as a manager at McDonald's. The priest said to her, "That's quite an accomplishment. . .ha, ha, ha, ha, ha, ha! That rang in me. . it's something I just cannot forget! I remember my brother. . he had this gift to do drafting, like architectural work, but he wasn't certified or he didn't have a degree to do it. . . he just had that gift. He used to work for a company, and I remember he went one evening after church and said, "Oh, I got a promotion in my job!" And then he [the priest] goes, "So, are you making any 
more money?" And he says, "No, but they promoted me." And then he [the priest] goes, "Ha, ha, ha, ha. . . . that doesn't mean anything!" When I look back at it. . . all these priests. . . all these priests, they basically own their own company or they had very high positions. . . CEO positions, or V.P. positions. . . and not one time would they hire anyone from our community to help us. These are people that are supposed to be helping. No, no, no, no, no!

I remember my mother was laid up in bed, in the hospital bed, because she had hurt her leg. . . this was when I had gotten a scholarship to go to the university. They didn't want me to go. They wanted me to stay in the congregation so I could play the organ for the rest of my life. They went and visited my mother in the hospital, and instead of praying with her about her health, they went there and kind of whispered in her ear, "You shouldn't let her go. Don't let her go. Don't you want to see her become head organist in the church?" When my mother told me I said, "No way, no way. . I'm going." Later on I began to realize that his [the priest's] daughter never went to college. His daughter never went to college because he knew people in high positions. . she left high school, she went to a secretarial school, and she elevated to some executive secretary in some big corporation. Here I am, trying to better myself and get an education, and here are these people trying to stop me... and trying to work it through my mother. It's just unbelievable. . unbelievable, the experiences that you have with some of these people. 
My worst and rudest awakening was in college, in the universities, where people would actually call you "Nigger." That was a rude, rude awakening. Now it's not as overt, but there are things there. . . the way people treat you. . . the responsibilities that they give you. It's as if you can't accomplish those things. It's all there. . underlying. 


\section{Participant \#2}

Interviewer: What is it like to be an African-American nurse?

Participant: As a nursing student at Miami-Dade, I never really felt racism. . . I guess I just really felt I was basically older than most of my students. . . most of the other students. My first job as a registered nurse ... I started working at Jackson. . .as a. . . I started working as a ( ), whatever you call it. . I didn't have my license yet so I started working as a student nurse-like, but I had already graduated from nursing school. I worked on an orthopedic floor. Basically, at that time there, I was the first Black registered nurse. There were about three other Black nurses, but they were all licensed practical nurses.

Coming from the islands. .. I mean. . . you know, you hear about racism, and I never really delved into it, but once I started to work on the floor. . . at first I thought it was, basically, I guess a different profession, but it started off with the nurses, like the registered nurses, which were basically White Americans. They worked together, but they never really socialized with the L.P.N.'s, who were the other Blacks on the floor. Like I said, I was the first. . . I was the only Black registered nurse on the floor. Like lunchtime they would not. . they didn't have lunch together. I thought it was 
real strange, but then again, I have noticed here in America that people of the same class or the same socioeconomic background tend to gather together.

Then as time go along, I realized, to me it seemed like it was more a color issue. . the Blacks tend to stick to themselves, and the Whites tend to stick to themselves. It never bothered me because I was not part of it. To me, I basically. . . I guess I got all caught up being an R.N. . . .I ate with the R.N.'s according to when my break was, or I ate with the L.P.N.'s.

I experienced racism once I became an associate head nurse, which happened after I worked. . . after I passed boards. . .after I worked on the floor. . .after I worked on the floor over a year. But even before I became the position, they... they ( ) for the position and they were going were going to hire within. I was already working on the floor, the shift 11 to 7 , and was ( ).

They applied for the position, it was about three or four of us who applied for the position. Again, I was the only Black one. . I think there was about three or four other candidates. I didn't get the position. I never was, no. . . I was sore that I didn't have enough experience. Another Whiteness got the position that didn't work on the floor, never worked nights, was a day nurse from another floor. At that time I realized she didn't have the experience of being a night nurse ... she had the experience as a nurse. . but she didn't have the 
experience as a night nurse. She already had a past where because of her kids she was missing work, but anyhow, the position was given to her. They explained to me that I was a good candidate but I needed more experience. I didn't query about it. I was new, so I figured, I enjoy with them. . . do them good. . . but anyhow. . . this person did not last. I don't think she held the position for about three months. She had to. .. she quit, and the position became open again.

I decided that I was not going to apply because I think I was. . . the reason they gave, I think. . .even if they didn't want to give me the position, give somebody else that had nighttime experience. So the position was open and I decided I was not going to apply for it again. . f for them to turn me down, because other people who had had working on the floor for a long time had said, on that floor that a Black person had never really held the position. But still, again, I never look at it. . . it didn't bother me.

So the position stayed open for about another three or four months, and eventually the. .. one of the associate head nurses in the daytime said, "Why don't you apply?" I said, "No, I'm not going to apply for the position." I thought I deserved to get the position. . I was already active in the position, so I said I wasn't going to apply. It lingered on. . lingered on, until they eventually decided that if I wanted the position... I did not apply... and I said yes. So I took the position. 
Things were going fine until we had a patient. . he had a complaint on one of the L.P.N.'s, which all the L.P.N.'s on the floor were Black. He wanted to see the person who was in charge. On the intercom I told him I would be there in about ten minutes. He had never met me and I hadn't met him, so he really didn't know who he was talking to. When I entered the room you could see the expression on this patient's face. . .he did not expect that the person to be in charge was going to be a Black person.

I introduced myself, and I asked him what I could do for him. He really started really being verbally abusive, and said he really didn't. . if the issue was his pain medicine he'd think he was waiting on. . too long for his pain medicine. Then he went on to say that he wanted to see my boss. . . he didn't even go into all the detail what was wrong. Then I realized. . . well, I guess he didn't want to talk to me because I was Black, or whatever.

It didn't even bother me that much until about six months after that incident. We had one of the doctors, who was a doctor at Jackson. I think he worked either in the emergency room or the unit. He had. . . I cannot exactly remember what was the problem. . now at that time now we had other Black ... at that time now we had, besides me being the Associate, we had two other Black nurses, and they were both from Jamaica. 
I don't know what the issue, but the issue was involving one of them. The patient had back surgery, and I didn't think he was transferred from the stretcher to the bed too rough. . . but anyhow, he wanted to see who was in charge. When I came into the room, he said it wasn't a big deal, he didn't want to make any trouble. So I left it at that. The next morning he called the head nurse, and from an incident that he didn't want to make any big deal about, he made a big deal in the morning.

When the head nurse asked why didn't he complain, he said, well he didn't know me, he didn't feel comfortable. . . which I think, him being a doctor, we were both professionals. . yes, at that time he was a patient, but still. . . since it was no big deal why he made the big issue about it the next day? When he used the thing about he didn't know me, I thought you were all there for the good of the patient. So I realized that it was basically racial.

For the time I have worked at Jackson, I have had several incidents where the patient is White, and they want to see the person in charge. And when you walk in their whole confidence changes, their whole facial expression. . . like they didn't really want to deal with you, or they didn't feel comfortable to complain to you if it was pertaining to another Black nurse.

I also had where you, as a Black nurse, you entered a patient's room... when the patient is White you did what you're supposed to 
do as a nurse, they would always ask, "Nurse can you empty my garbage?" Not even a good fifteen or twenty minutes before you, a White nurse might have left the room, and they really never asked those same requests of the White nurse.

I came to realize, I guess, maybe it is how White people look at Black people. Sometime I wonder if it is because of these years ago that we have been like servants that I . . sometimes I don't think they think we could be professionals.

Even going back to when I wanted to become. . . decided I was going to become an R.N., I was working in a cafeteria. When I spoke to the supervisor and told him what was my plans, his first impression was, "Why don't you become an L.P.N.?" To me, when I look back over the years, that was racially motivated, because I never told him I wanted to be an L.P.N. Why would he figure that, as a Black person, I couldn't go as high as I wanted to be, or be all I could be.

Those are really just some of the incidents I have, that I can say is racially motivated. Can I really prove it? I cannot. But when I look at everything else, it seems like that was the problem. . because I was a Black person, that certain patients didn't feel comfortable talking to me. . or didn't feel comfortable bringing their problems to me. 
Now I do home health, and I really cannot say that I have experienced racism, personally. I basically... most of my patients are Latin, and to most of them their biggest problem is if you speak English. It's much different out in the field. I have not been in the hospital now for about six. . . five to six years, so I really don't know what's going on. But that's just my. . my experience as a Black American.

Interviewer: You talk about racism that you probably experience among. . . with your patients. Talk to me about your coworkers. Talk to me of your interactions with other nurses in your profession. Participant: I don't want to say that my coworkers were racists. I tend to more want to think that. . .I don't know, maybe in America Blacks tend to stay together and the Whites tend to. . .because when you look at. . besides working together, when they'd have extracurricular activities, the Whiteness is really never invited. . the other Black nurses.

As an Associate, I interacted with other Associates because of the job related to in the hospital compound, but to say, go out of the hospital compound. . . I. . .when I got my bachelor's, I knew there started getting a rift between me and my head nurse. I cannot say I think she felt more threatened by me. . I cannot say it was a racist thing, because you really. . . I guess they talk among themselves, but to really say that among my peers that I was, besides the promotion, we have a...it's a committee, and the committee is made... the 
committee was made up of about five people, and there was only one Black person. . . the other four were all White, but besides that, I really cannot pinpoint that I can say that. . . I am sure there are incidents, but I really cannot come up and say that I was slighted for something, or because I was. . I was Black.

I went to this conference with. . . there were four of us in the hotel room, and I was the only Black, and... we get along... they were more curious at some things that were "culture-wise," . . like, White people wash their hair every day, whereas as Black people... we don't do that. But, I really cannot recall any specific incident.

My head nurse didn't have a bachelor's. There were other Philippino nurses who had the bachelor's from their country, but they were more. . . they were more passive. I am more aggressive, and I didn't become aggressive because of my bachelor's, because I was an associate before I had my bachelor's.

I know one time we had a meeting and. . . I cannot remember the exact term the head nurse used, but it was like I was being insubordinate, or I didn't agree. . . well, I didn't change. . . to me I didn't change. I was. . . if I had something to say at the meeting I said it. After I got my. . .I had to make one day. . I had said that I really didn't want her job. . it seems like once I got my bachelor's, at meetings we did not agree. I guess she feels I should agree with her, which I never... even though I was the associate... if I didn't 
agree with something, I didn't agree with it. It didn't change after I be. . . after I got my bachelor's, so. . . I cannot think which was. . I just had it down that she felt. . she felt threatened. Here I am an associate, she is my supervisor and I was more qualified than her. That's the only thing I could have...

The first patient, he became very verbally abusive. Before he told me he wanted to see my supervisor, he became very verbally abusive. He was cursing and carrying on, and I tried to explain to him that I know he was in pain, but as nurses we prioritize. To him ... I understood that his pain was very important, but to us there are other pressing things, and as soon as the nurse could, she would bring his pain medicine. I even tried to illustrate to him ( ) even though he was in pain, and his mother was down the hallway having problems breathing, and it was an emergency. That is when he started using the f-word. . that he didn't care about whose work, all he knew he was in pain. I told him. . . at that time I told him. . . Jackson doesn't pay me enough money to stand up and have him abuse me. When he quieted down I would talk to him, and that's when he wanted to speak to the . . . the. . my supervisor. I don't even think he ever got to speak to the supervisor, because eventually he got his pain medicine. I really don't think he got to speak to the supervisor.

The other patient, who was the doctor, I never heard exactly what happened until days after. I had forgotten about it, 
because the doctor had told me it was not a big issue. It was long after. . I don't know how the head nurse happened to mention that this patient had this problem, and so... but the head was like, no big deal, because, I guess, it was her friend, but it was not. . . because I guess I didn't do anything wrong, so nobody had to be reprimanded or anything ... it was just like in passing she said that. He was... he had already gone home, as a matter of fact, and she happened to remember the patient and what happened at night. She tried to make. . to cover up, not to feel bad about it. . .

Interviewer: Has your own view of yourself, your self-image, been affected by instances of racism?

Participant: $\quad$ No. . no. . . no, no, because I have this philosophy that that person has the problem. . I don't have the. . .I don't have the problem. I'm going to ( ) patients with dignity, with respect, no matter where they come from, no matter the color of their skin ...so. . .

Interviewer: What about. . right, you're for. . .

Participant: ... I want to go back to when I was a nursing student. I ... this was basically, mostly, the Black instructors at the ( ). I found that they were harder on the Black students than they were on the White students. It seems like they spoke up to the White students, and it seems like they spoke down to the. . down to the Black students. 
One day I. . . because I guess coming from the islands where you never had no prejudice. . you never hear anybody doing any studies saying that Blacks are inferior... I felt pretty ( ) here come. .. not that I wanted this Black instructor to take sides, because she was Black, and the few Black students, but I wanted ours to treat us equally, because from ever since, I believed that whether you were White, Black, I think you had the same brain matter. I never had a thing that I was inferior to anybody else. When I asked her, and she said that the few Black students she had in the class, she wanted to make sure that they passed. . . that she had to push us more. I guess at that time I didn't have that much experience, but now that I look back I think I was going to ask her how she may push us more? Were we inferior? Why did she have to work? . . . but I guess that's just a kind of reverse. . .

Sometime I think that. . I have this theory that Black people in America, given positions, I think you don't really know how to act. I think they do a kind of reverse racism. . . they become prejudice against their own kind. I think you're supposed to give special treatment to people of your own kind, because even when I was an Associate head nurse I knew they would do this. Assistants expected that because I was Black I was going to give them special privileges ... and from jump, I let them know that I had a job to do and I had a supervisor to answer to, so everybody would be treated equally. 
So I guess, when I look back, prejudice can be. . . to me it's more than just a White and Black thing. . . it can go. . . some people are prejudiced because of their status, or because of different things. I really think prejudice is more than a White and Black issue. I think why there is not alot of Black nurses, too... I think it's more than just that. . . that they have a poor self-esteem, I think it's alot of the nursing instructors, especially those who are of all the same color, they don't. . they discourage us.

They are not supportive. I guess, maybe, they have been indoctrinated for years, because I guess you are looking at nursing instructors who, maybe, were teenagers in the ' 60 's, and the years. . . the times when Blacks had to ride in the back of the bus. . that they were taught that Black people couldn't be nothing. So now they have made it $\quad .$. I still. . . they still have this thing, that even though they have made it, other Black people cannot make it, and I think, because as a nursing student, I went through nursing school without any support. I didn't have

... I didn't have any advisors to advise me, because my first experience with advisors was like. . . I thought an advisor, if I said this is what I would like to be. . you're supposed to help me, not try to deviate me to go into something else that. . . maybe it's good, I am not the kind of person to put down jobs, but if I said I wanted to be a registered nurse, they'll try to beat around the bush and get me to 


\section{Participant \#3}

Interviewer: What is it like to be an African-American nurse?

Participant: I came into the nursing profession at a pretty late stage $\ldots$ at about age 43 , so I had alot of experiences outside of the nursing profession. When I came into nursing, I did not experience overt racism. What I noticed was that the racism was very subtle. As a matter of fact, I didn't realize alot of times that I was experiencing racism until after the fact. . . after I analyzed certain situations that I either experienced or that I saw happening around me.

A very good experience. . . one instance is that I applied for a position in nursing after I graduated from nursing school. I was told that I could not start working until I had received the nursing license ... I had to wait a few months until I received my results. I started working, and during the orientation period there were a couple of Caucasian nurses, who were still student nurses, who had begun working at the same place where I was told that I could not work until I had a license. How I knew that? During the orientation period they took a couple of days off to go and do the exam. It was when they told me that, I put two and two together. I realized that they were accorded certain courtesies or benefits, as student nurses coming out of nursing school, that I was not accorded. There was 
no other reason, that I could see, except attributing that to racism. I cannot say that I experienced overt racism. I notice that it is always very, very subtle.

Also, in my job I've noticed that the pay scale, which is my major bone of contention, is usually different. One is not told that there is a range of pay for each position, and that one can come into the company or the organization at a different. . . at a certain level within the range. So, say a position carries a salary of, say, $\$ 30,000.00$ to $\$ 40,000.00$, with everything being equal. . . experience, education, age, skills, what have you. . .what you tend to find, I've experienced it personally, and I've spoken to other African-American nurses. . . what happens is that the African Americans usually come in at a lower. . . at the lower end of the pay scale. The Caucasian nurses tend to come in at the higher end. I've seen it. As a matter of fact, you have Caucasian nurses coming into the profession who will start out making more money coming out of nursing school than experienced African-American nurses. With everything else being equal, I cannot attribute it to anything else but racism.

Those are two areas where it was not overt, because I didn't have anything to compare it to at the time. It was just very subtle. I mean, just by putting alot of. . . just different areas together and looking into different situations, I was able to come up with that conclusion. 
Another thing I noticed, and I'm still noticing, is when an African-American nurse comes into the profession, or is in the profession. She always has to prove herself over and beyond. It's like. . . the African-American nurse. . . I can never do enough. . you don't have enough skills ... you're never. . . you never make the grade, or your excellence is always questioned. Therefore, you're not given the opportunity to maybe carry out certain projects or do certain projects. While it is just assumed that the Caucasian nurse's excellence. . . she knows what she's doing. She has certain skills, and therefore she is now put on a certain track. . .a fast track to either promotion or management, or what have you within that organization. It is assumed that this person has certain skills and is an excellent person. I think I'm not happy with this perception.

There's always a perception. .. it's in the White of society, and of course, nursing is a part of the White of society. The perception in the White of society is that African Americans are. . just don't. . are not up to snuff. . . don't excel. Therefore, that perception is carried over into the area of nursing. The African-American nurse, or even myself. . . it's like you always have to prove that you're excellent. . . you're never given the benefit of the doubt. That is my major bone of contention.

The color Black does not carry any. . . or should I put it the other way...the color White, you are given certain excuses. 
Although it's not called an excuse. But when you're Black you have to always prove yourself. . .oh yes, I'm good... yes, I do belong here. . . yes, I can do this. It's like you have to do so much to prove that this is where you should be, or you should be doing more. It's subtle. It's insidious, it's subtle, and that's why it's so demoralizing...because what happens is, it's not open and upfront.You can't just confront it and put a stop to it.

So the subtly. . . I'll give you an example, in terms of the pay scale. When I did find out that there were these disparities, and other people have found out, then you feel... If you find out a year or two later, you've already been in the position two years, you're not going to go back to management or to personnel and say, "Why did I start out at $\$ 30,000.00$, and this other person with the same experience as I have started out at $\$ 35,000.00$ ?" It's two years later, so you just figure, "Well, I won't bother to make any waves. . I'll just go along with it." But it demoralizes you in a way because what it is saying is that, "I did not think of you, or I did not find out enough about you to see if you were worth starting at $\$ 35,000.00$." Alot of it is just this perception. .. this insidious perception that the color Black carries with it. That's really what it is because nobody...

Another big point is that the color. .. it's not a matter that the color. . you're inferior. . . it's not that. It's that you're not valued. The color is not valued. So certain values are attributed to your color. One of the values is that, "Oh well, you're not good enough, 
or there's somebody better than you." But the person who is better than you is always of another color. You're never really spoken to. Nobody really asks you, "Well how do you feel about this?. . Have you ever done this?" They just approach you, talk to you, and find out what is going on with you. . "Can you do this?" They find out something about you to be able to say. . ."Well, this person would be good in this area." It's all very superficial. I think it's because of the, as I said, the sociological aspects, where the society. . . They hold the values, or lack of values that are put on Black people and African-Americans, in general, in the society.

And then there's the other concept. . . that people tend to favor people of their own group. If the people who are doing the hiring in nursing are mainly White, then of course, they're going to look out for their own group. I think that is natural, too. So sometime it is maybe racism on one end, but on the other it's a group dynamic of, "I'm going to favor my group." The reverse of this is what you find alot of times, and because of the whole concept that. . . because Black people have internalized them. . . this inferiority. . what happens is that when you have Blacks in positions of authority, they don't want to do the reverse and favor their own. . . because they don't want to seem as if they are racist. They will go out of their way now not to help their Black nurse or colleague or whatever, move up in the system, or in that organization. That person says, "Well I made it this far, but I don't want the majority group to think that I'm 
favoring my African-American nurse, even though I'm African American.

It operates doubly. So the African-American nurse, not only in nursing but in alot of different professions, just gets caught because the majority of the culture doesn't see her strengths then. Her own. . . if she has, say. . .one of her own has made it into management. That person now feels that, "Well, I'm under the gun here ... I may be watched by upper management if I move too many of my group ahead." It works doubly against the African-American nurse.

In terms of promotions in the organization. What I've seen happen is that. . . and it happens in nursing, and it happens in other organizations. . . Because the different groups, African Americans and Whites, don't socialize outside of the work arena, alot of business discussions, or work discussions take place in a social setting. What happens is, when certain decisions are being made in a social area, if that African-American nurse is not there, she doesn't tap into that grapevine to find out what is going on. So she, now, is at a disadvantage in the work setting. . . in terms of finding out where the promotions are, because nobody is going to tell you. . . it's just not done.

A lot of times you hear in a social area, and I'll give an example in the organization I'm in. There were a number of openings in management, and the head of the organization was looking to 
promote a number of White nurses. The Black nurses didn't realize this until it was more or less a done deal. What had happened was, this particular nursing director was friendly with these nurses outside of work. Therefore, outside of work she could probably get on the phone and say, "Well, an opening is coming up here. Call . . . let's have dinner and discuss such and such. . . let's have lunch and discuss such and such." While maybe within the organization during the workday, those are confidential. . . maybe. . or it's just not discussed.

So, it wasn't until the Black nurses saw that all these openings were there, and they went to the interview. They didn't get it. But then all these White nurses were then getting promoted. . some had come into the organization after these nurses. Then they said, "No, this has to stop." They came together, had meetings, and went to management and said that something had to be done. . "We service a large Black population. . . we need to have some visible nurses, Black nurses. . . African-American nurses."

At that time, two positions were not given to the Whites and were given to two Black nurses. What happened, in one instance I know for a fact, one of the Black nurses, when she received that supervisor position, one of the White nurses in the department, who should have gotten that position, quit because she said she would not have a Black supervisor. I heard that. . I overheard that! 
So, that's another topic again. What you find is that alot of Caucasian nurses do not want to be supervised by a Black nurse. It comes back to that whole thing of. . . my color accords me certain rights. One of the rights is to lead Black people.

It is difficult for some people. . . it's a psychological thing, I think. Psychologically alot of White people, including White nurses, cannot see a Black person telling them what to do. When the Black person is in that position and tries to do a good job, what happens is that the White nurses get together and undermine that Black person.

I'll give you a good example. Right now I see it in a certain department. There's a White supervisor. . . no, correction. . . a Black supervisor. . . everybody else in the department is Black, and there is one White nurse. She, in effect, is running the department. You have a Black supervisor on paper, but what happens is that she gets all the information from management. .. the White nurse. . . alot of times even before the Black supervisor, and will take it to the Black supervisor. When the Black supervisor makes decisions, she'1l [the White nurse] say to her, "Why did you do so and so," in front of the other nurses. . . "Why didn't you do such and such." She is questioning the Black supervisor, and that's not her position. Now, if it were the other way around, the Black nurse would have probably said, "Well, she's the supervisor, I'm going to give her that respect" ... based on. . " I'd like her decision." But based on her position, I'm going to give her that respect. 
It just manifests itself in so many ways. It just comes back to that whole thing that it's not. . . and I don't even think that people deliberately think it's racism. It's just a matter of socialization, where in America people are socialized to be racists. The institutions. . . including nursing. . . what it does, it gives advantages to people with White skin, and it tends to punish or try to keep back people with Black skin, or who are African Americans.

When you're benefiting from something, you want to perpetuate it. If I have White skin, I get a certain salary. . .I have a certain status based on the color of that skin. . .I can live in a certain neighborhood. . .my children can go to a certain school. People can give me respect based on the color of that skin. Obviously, in maybe not an overt way but in a covert way, I'm going to try and maintain that system. It's not that somebody is going to deliberately say, “Oh, I don't like. . they don't like me, or I want to keep you back. .." It's not overt, it's not an open thing. A certain group is benefited in nursing from these benefits. So it's beneficial for the Caucasian group to keep out the Black nurses.

One thing, it is beneficial because it decreases competition. If I can pay a Black nurse less, then maybe there will be more of a bonus, or a higher salary for myself. It just operates on... It's just how the system is set up. . .to reward one group at the expense of another group. 
In nursing, I didn't go into the hospital setting. I went into public health because of the whole status. Nursing, because it's a female-dominated profession, I find it can be. . . can tend to be a low status profession. When I say low status, you're not respected for what you know. . you're not respected for your education. . . you're just not respected as a human being.

I saw it overtly in the hospital. The doctor spoke to you in a way which I just could not tolerate. . . I will not tolerate it. I know I wouldn't last a week. Everybody told me that. . I would not last in the hospital. As a matter of fact, there was a doctor. . . I don't even know if it was racism or what it was, maybe he just didn't like me. He spoke to me in a way that I did not. . . because how I look at it, I give respect and I expect respect. He spoke to me in a way, in front of people, that I did not like. I called him on it right in front of everybody. I knew, politically, that I was not going to last too long. So I needed to do something else.

But what I've found, too, is that the whole concept of the Black person, the African-American person. . . this whole thing of being a maid. That's a concept that I just couldn't deal with in the hospital. I'm a grown woman, I entered nursing at 43! I mean, people are calling me. . patients are saying, "my girl" and "this girl." It just rubbed me the wrong way. It's not just ...it's more than nursing. It's as if to say, "Well, this is where you should be as a Black person. .. my maid, even if you're a nurse, I'm not going to give you that 
respect, because I see you, historically, as a maid and therefore that's where I'm going to place you." Since I don't internalize that. . . I have never seen myself in that position. I just couldn't deal with it. I found that within the hospital setting. . . with it's bureaucracy, and this thing. . . that as a nurse you must know your place, especially as an African-American nurse. The hospital setting was totally, totally out for me. I know that I would not have been able to survive because I'm a very outspoken person.

What I find, too, is that sometimes this whole issue of insubordination... I think people use that as a way of keeping you back, and keeping Black, African Americans. . . in other words, you are an African American. . you should know your place. Therefore, if you speak out, obviously you did not know your place. I'm going to put you back in your place. How I put you back in your place is to hold over your head that I can fire you, okay? Or I can demote you, or whatever it is.

What I've found is that instead of. . . because I knew eventually ... everybody told me that, and I saw it when I was training in the hospital. . . how the bureaucracy is set up. Everybody is looking to write you up. You're getting written up, and all of this crap. Written up for what? We're all adults! We should be able to discuss something and work it out. Everybody is running behind this one's back to write up this one. What I've found is that it was just used as a tool to keep nurses, especially African-American nurses, in their 
place. If you think you're too big for your boots, I can show you that I have the power here. My power is to write you up and to put you in your place.

I'll give you a good example. I have a friend who is also African American, who was working with an agency in this hospital just a couple of weeks ago. She was sent to a new floor. . . a renal floor to work, and she wasn't very. . . she really didn't know much about that floor. She went, was looking around, and was asking for help to learn what she needed to do.

When she went up on the floor, she was sent to transport a patient, which she did. When she came back the charge nurse, or one of the nurses, said to her, "Go and transport this other patient." So she said, "Well, don't you have somebody like a nurses aide, or somebody to transport? I'm not a transporter." She said that that was resolved, and she finished out the day. The next thing she knew, when she called the agency to go to work the next day, they said the hospital had put her on a "Do Not Use," because she was insubordinate, she wouldn't follow orders, she questioned orders, she said she didn't want to transport patients, and all of this.

So in other words, what I find is that a lot of times when you speak out. . . and alot of times, too, when you're an AfricanAmerican nurse, and you speak out. . people don't expect you to speak out, because nurses on the whole tend to be passive. 
So you stand out even more when you speak out. Therefore, the pressure comes down on you even harder. . to put you back in the box and in your place. So, that. . it can be a problem, especially for people who are not used to being in the box. I mean, we're in the box in terms of American society, because we're more or less regulated in America. But there are some people who just will not tolerate the labels, and the pressure and all of that. You find that the pressure comes down real hard, and usually you're fired. I've seen it happen with alot of African-American nurses. They are fired at a higher rate than other nurses.

Even sometimes the people talk about the Philipino nurses. You'll hear that the Philipino nurses, ". . .Oh they're such good nurses,". . . and they are. Which is fine! I don't know if it's that they're such good nurses. It's that they tend to be passive. . in that they don't question. I just think. . . and that's a problem I have with nursing, too. . a as an African-American nurse.

My big problem with nursing is that. . . here it is. You are told that you have to go to college. . you have to get a bachelor's. When I went into nursing school, I already had a bachelor's. . that was no big thing to me. You are told you have to get this degree. So you get a degree. Then after you get the degree they say, "Well, you need a master's, a bachelor's isn't enough." Which is fine. What gets me is, we are supposed to be intelligent people, intellectuals. You know, thinkers. . .you know, question, attitudes and beliefs, and all of this 
in whatever system we're operating in. In this case, it's the nursing profession. But, on the other hand, you're told not to say anything. To stay where you are. Not to question anything. . . not to question the doctor. It's a conflict. . . it just doesn't add up. I think what it does, it demoralizes nurses and. . . especially African-American nurses. Here it is, African-American nurses have to be dealing with the racism on one hand, and also you have to be dealing with this anti-intellectualism in nursing, that says you don't question anything. Now if you are an intelligent person, a thinking person, and you see a problem, of course you're going to analyze the problem and ask now why is this so... and let's get together and try and find a solution. That's how thinking people are.

Nursing is like. . to me, it's like a form of slavery. That's how I see nursing. Don't question anything. . . do as I say. As a matter of fact, it has a type of a military structure. It's like being in the Army... just follow along, just follow the leader, just march in lines, don't even look behind. . . whatever we say to do, that's what it's all about. What it does is it demoralizes African-American nurses. The AfricanAmerican nurse has to deal with so many levels of the bureaucracy. If you're in a hospital, you're going to deal with the nursing bureaucracy, the medical bureaucracy, the hospital bureaucracy. I mean, can you imagine, you're at the bottom of all those bureaucracies. . . what that does to you. . . psychologically? 
I don't think people really look into it! You go into a hospital to work, and you're more or less... I mean, I think maybe on the level of housekeeping. . . is that it? Is that below nursing? What is going on? You are answering to so many entities within the nursing profession, because you're still. . . I mean, you have to answer to the medical. . . to the doctors. That can be difficult. You don't get the support from the nursing structure. You don't get support from nursing. So, it's really a lot you have to deal with.

One good thing, I see, is that what it has. . . what has happened is that, because of this pressure, it has forced African-American nurses to organize on a certain level. What you'll find. . you'll have the American Nurses Association. . you'll have the Florida Nursing Association. . you'll have these large nursing organizations that are supposed to advocate for nurses, generally. But then to feel a sense of belonging and camaraderie, you find you'll have the Black Nurses Association. You'll have different ethnic groups, like the Jamaican Nurses Association. . . and all of that. Then, at least there's somewhere to go where people understand that. . . listen, you are somebody of worth, you... People know who you are. . what you can contribute. They know something about you.

What you'll find happens in the hospital, because of the nature of a hospital. . . the type of business it is. . . where it's a serviceoriented business, but it's dealing with illness and disease, and all of that. . what it does is that the African-American nurses... when the 
African-American nurse experiences this demoralization...I think what the nurse may do, or what I've seen people do, and even what I have begun doing. . . and I've only been in nursing now three years ... is to sort of withdraw. Just take a step back. . just go in and do the minimum. . . do the 9 to 5 , or the 7 to 3 , or the 3 to 11 . . just try and get through that shift or that day. Then devote your time and your experiences and your skills to other areas.

What you find is that alot of African-American nurses probably have other careers. A number of African-American nurses, I know, have other businesses. Some are into real estate. Right now I'm in the travel business. Because what it does is. . then you're going into areas where you can have a little more control over your career and your work experience, and just the outcome of what you do. You'll find that alot of African-American nurses will complain, but then they won't make. . Say they need to go back to school. They will not go back to school. So, what it does is, in a way. . . the AfricanAmerican nurse just sort of short circuits her career in nursing, and now focuses on other areas and says, "Well, I'll just work on something else. . . this is just, maybe a paycheck. . .just to get the bills paid." But the energy, the focus, the professionalism is put into other areas. That's what I see. That's what I think I'm doing, and I've seen alot people doing it.

Interviewer: Have instances of racism, that you have seen or lived, affected your self-esteem? 
Participant: I would not say that incidences of racism in nursing have affected my self-esteem. I'm going to tell you why. Because I'm from such a strong family background. I'm from a background where I know who I am. . because I know who I am. I'm from a background where my parents are highly respected people. My parents have a name. . . in certain places where their name is called it means something. So, although I may be in this situation here where I'm more or less anonymous, because of the background I have, I know. . coming from that background. . . that I'm not anonymous. Therefore, I'm able to use those past experiences of upbringing and childhood that I had. . . that strong family background that I have . . to bolster me against all of the racist attitudes, beliefs, and conditions.

But not everybody has that kind of background. So what happens is that, if you're not coming with a very strong sense of self into nursing, I think nursing can destroy the African-American woman. What I find is that the professionalism, also, that should be accorded to African-American nurses is not accorded to her, or to them.

I'll give an example. I was in the hospital, as a student nurse this time, and I went to a meeting. I was told one morning I was on the floor that there was a meeting. I should not have been at the meeting. I did not know this. All the nurses said that there was a meeting, so I assumed I should have been at the meeting. I should 
not have been at the meeting. It was myself and another student nurse. When we got into the meeting, the supervisor did not tell us we were not to be in the meeting. Do you know how we knew we should not have been there? When she passed the memo around, she passed it to everybody except us. To me, there's no. . . there's a lack of respect pervasive in nursing.

I think that's why. . . even why the wider population does not give nurses respect that they should give. We, as nurses. . . we don't respect ourselves, so we don't respect each other. I've seen it happen so many times in a hospital. I mean. . nurses shout at each other. I think alot of it is coming from the stress of the work, of course. . the burn-out factor. Still, it's just. . I d don't see doctors speaking to each other like that. They accord each other certain amounts of respect because you're a doctor. I've seen lawyers according each other certain levels of respect because they went to law school. So we know what it is like. . .only nurses, I find, know the pressures of nursing know what it took to be a nurse. But still we just try to destroy each other. It operates on so many levels.

If there's a problem on a floor, instead of the nurse trying to teach the other nurse and showing this nurse where she went wrong, that nurse would run to the administration and report the nurse so a nurse can get written up. So that a nurse can get fired, not using that experience as a learning... Everything is a confrontation. Nursing is 
very confrontational. What it does, just like any battle, half of the time it wears you down. What you do, you just try to run and hide and protect yourself from the battle. Some people get very angry. They may take it out on the patients. . they don't make eye contact and treat the patient as a human being. They may not treat the other nurses as human beings. . in a very humanistic way. What happens is that the person withdraws, psychologically, and tries to protect herself. When she withdraws, she just does not react, or she just doesn't deal with the other person on a. . . as a human being. The other person is just like a thing.

I think it is just coming from this whole confront. . . everything in nursing is a big confrontation! I just don't see the point. How can you be confrontational in your job, and then be expected to take care of a human being. ... and to nurse somebody? I thought nursing meant caring. But if you're busy fighting over here with your colleagues, and trying to protect yourself. . . trying to see if you got the right raise, or if you were...

Talking about raises, I'll give a very good example. When I came out of nursing, and I started my first job, I received the manual ... the policy manual. The manual explicitly said that there was a differential for the second shift, 3 to 11 . I started working the second shift. I never received that differential. There were people there for years. I was there about two months, and then one day I picked up the manual. I said, "But, we're supposed to be getting a 
differential." It was never given to us. Now what does that do to the nurse when you're being robbed? To me, that's a crime... that's criminal! If you say in your policy that I should get a differential, I should get a differential! It's criminal! Then when you treat me this way. . you expect me to smile, and be nice and caring, and cater to the needs of my client. . . it's very difficult! That is a big part of the problem in nursing, you know...

Interviewer: $\quad \ldots$ and that's with all nurses. But what does it do to the African-American nurse?

Participant: It is even more detrimental to the African-American nurse, because she is coming from a lower socioeconomic status, especially the economic. The social part, whether they. . .it's bad. But what happens is that, if she's making less money. . . in a lot of instances she may be the head of her household. What happens is that, financially, she's not able to bring to her household the amount of money that she needs to live the kind of lifestyle that really should be accorded to her as a nurse.

Here we are saying that she is a professional, but her salary is like a factory worker. So she has a professional title. She may have the education at that level, but her salary is a factory worker salary, or maybe less. So what it does. . it comes back to the same point of demoralizing her, because she doesn't have the money now to do what she needs to do, economically, to better her family. She suffers, her family suffers, the neighborhood she probably lives in, if she lives 
in an African-American neighborhood, has less money in that area. So, there's just a downward spiral. Everything just falls apart. Some people maybe get involved in excessive partying, or maybe excessive drinking. It can affect the person in so many ways, when a person experiences this burnout. . . because the person just cannot meet the financial needs. I see where it impacts AfricanAmerican women, especially. This area where you are not paid what you should be paid. I think it has a very detrimental effect on African-American families. . on African-American women. 


\section{Participant \#4}

Interviewer: What is it like to be an African-American nurse?

Participant: As a Jamaican first, and then an African-American nurse second, I have now come to be aware. . . Coming here as an adult, there were many things that I wasn't aware of. In the Caribbean, not that there isn't racism as such. Ours is not so much, I don't think racism, like the color issue. . . such as, "you're a little bit lighter and you're a little bit darker," and stuff like that. There are certain things that you are aware of at home, but that didn't stop you, really. . . especially in my experience. But in coming here, and with that experience in the background...

I came here and there were certain things I wanted to do, and I just went about doing them, such as obtaining a certain level of education. I just went about doing it, not considering if there was someone who was going to stop me because I'm Black, or whatever. Which is kind of different from what. . . When I speak to people here in the States, native-born African Americans who say, "You can't do this, because of the prejudice," ... and then that was their point. Nobody can stop you! But then, as I have progressed up the ladder, then you start to find obstacles. 
I came here, started from scratch. . nursing assistant, went on to L.P.N. school, went on to diploma school, went on to bachelor's, then went on to master's. Now I'm trying for the Ph.D. I walk into the same hospitals, back and forth, change from this floor to I.C.U. . .. to this and that. They would ask me to do lectures in education or whatever.

Then, it was almost at the end of my master's studies, I said, "Well, I need to go a little bit further, I need some challenges." There was a position in the education department. So, I said, "Okay, let me apply for this. I think I have the qualifications." I thought that they would ask me to do a lecture, here and there, and I'd go ahead and do it. So I applied, and one day I was at work in the unit. The head of the education department called me. She said, "_-_, do you have any management experience?" I said, "No, not apart from what I do here in charge." "Have you taught adults?" I said, "Not apart from what I do here in the nursing department, but I do have education experience because I was a teacher in my country." I went to a teacher's college, so certain principles are there. She said, "Oh well, we really want someone who has management experience, because then they would be able to talk to the head nurses." Exactly her words I'm quoting. . ."that you'd be able to talk with the Head Nurses."

My jaw dropped! "What?!" I mean, just the same way you see me talking, I interact with some [ ] nursing right down. I 
didn't see any problem. I didn't see any problem. .. that we talk, we interacted. I thought that was a pretty lame excuse, because right then they turned around and went to another unit and got a Caucasian nurse with no experience. . just the same kind of charge experience like me... no educational experience $\quad .$. and put her in the position. She stayed there a year and promptly left. Right then I started thinking, "why was that, because that was a pretty lame excuse!"

Then I said, “okay now, there's a position for nursing supervisor. . . 3 to 11 . I don't like the shift, but let me try. In that position you do alot of interacting with nurses, with different people. You get a chance to teach. So I applied for that one. I didn't hear anything, and then one day somebody told me, "Oh, that position is filled." They took somebody without any experience and put them in the nurses slot.

One day in the unit the Assistant Director of Nursing came to the floor and called me into the office. "Close the door," she said. "- , I. . .,"she happened to be Armenian or something like. She's from Europe. . . kind of a little bit dark, but can see the White, but dark... She called me into the office and said, "-__, I'm sorry you didn't get that position, but keep on applying for something. . something." I told her, "You know, I have applied for a few things, and the excuses that were given, I don't think they were justifiable. So, my philosophy is that I prepare myself in everyway 
that I can, and the right thing will come at the right time. So don't worry, because I'm not worried." And she said, "Oh. .., and she looked..."

So I never applied for anything again, there. It was like a week or so somebody called me to set up a headhunter. . they gave my name to a headhunter. This headhunter called me and told me about a job at Cedars as a clinical specialist. I went for that.

Then in my class at U. M., somebody else came and told me about a clin. spec. job at Mt. Sinai. I went to the interview at Cedars. Everything went okay. Then the lady from Sinai called me and said, "Why don't you reschedule?" .. because I had canceled. So I went, and that seemed like a most favorable. . thinking of ...

When I look at everything, I was going to be working with an African-American head nurse, so the two of us would be pairs collaborating. When I looked at the mix, I just thought it was a better place to be. I took that job and not the other one. Then the people at my hospital offered me a job as a head nurse, and that I could teach while I. . I said, "Thank you, but no thanks."

Over there at Sinai, you have a kind of covert racism also. As I said, the older I grow and the more experienced I am. . .you kind of become aware of these things happening. . . that you see African Americans in certain positions, and then you go no higher. You try to up a little higher, and the obstacles...there would be the lame 
excuses they give you why you can't do that. So the same thing happened. . . that's why I'm here.

You want to grow. Me. . I want to grow. You become stagnant in a position after a while. Now when they're talking about glass ceilings, I can relate to that. . . and see how you can be kept. . . You can progress so far in certain areas. If you want to do other things, you can get out of the hospital. . you can become an entropinary (?). . you can do other stuff. There's lots of stuff that we can do! But within certain areas you can see where there is a cap on what you can do.

Interviewer: Right. . . right. Now, tell me about some of the experiences you had at your other. . . when you got. . . as a clinical specialist.

Participant: Well, there it was. . I had free reign. I had a lot of autonomy there doing what I do best, and I think it's teaching. I love to teach. I did that. You're on committees, you're this... you're that ... do alot of things with nursing aides. . and all this kind of stuff. The problem there was. . . I worked with a head nurse. . . I thought I was on an 80 -bed unit with one nurse manager.

Then they split the floor and had two nurse managers. The floor was against split, so we had that. Then I had another floor in another unit. . . on a different floor. So I had two areas to cover. Then you tour the floors, and you're teaching nurses aides. My Director would call me sometime and ask me to go to another unit to 
give an in-service. . . it was fine, up to a point, but then again, you're talking to the same nurses year after year. . . telling them the same thing. . . trying to be innovative. As you know, it's the hardest thing to change an old nurse.

After a while, I got to participate in some research. Then after I got my AR\&P, I decided I would like to change that mode, and go more into the AR\&P mode. . that wasn't to be. I found out that my nurse manager is the kind of person who likes to lean on somebody. So actually, she would use you as a crutch. The minute I said something about leaving, "No, you ...no, you can't do it."

Then it goes up the chain to the powers of they who favor this person. This is a nurse who you look at and you say, "How can this person with this personality, and what they do, continue in that position?" Whereas, if it were you or I, you'd be out of there so fast.

Everything. . . like I would apply for something, would be a block. .. it would be like the door was just closed. . . and they would say, "You're wonderful!". . . but the door would just close.

Interviewer: Was this an African-American manager?

Participant: No!

Interviewer: Okay.

Participant: No, the African American one left. She left her position...

Interviewer: She left her position. . . 
Participant: $\quad \ldots$ because she didn't want to work with these other. . so she left.

\section{Interviewer: Okay. . .}

Participant: She's still there, but she works in a different capacity.

Interviewer: Alright. . . Let me ask you another question. Have you. . . your experiences of racism, or as an African-American nurse experiencing racism. . .has that affected your self-esteem?

Participant: No! I know who I am. I know where I'm coming from. I know where I want to go! So that hasn't bothered me, because at some point I didn't know what it was. In retrospect, you look back and you think, "Uh huh. .." Right? Some of the things are actually happening, because it's not in your background. You sit and you listen to other peoples' experiences, and then you put two and two together and say, "Uh huh!". . . I'm becoming more and more aware of it.

For instance, I'm now doing my Ph.D. Even in the schools, the universities, they have a quota that they will take in. Some of them are more overt at whatever they're doing. I heard stories, but never thought of it. I went to an interview at the University of Miami to get into their program, to get that. . . it was a scholarship that they had for minorities. The interview was a farce. It was a joke. . a big joke. That went on... and the excuse they gave me... 
I received one letter from them. It so grated on my nerves, I just threw it right in the garbage. I should have kept that letter! Right on the heels of that I got another letter in a different tone. I should have kept the first letter. Whoever generated that. . I mean, it was just terrible!

The second letter I got told me that they were sorry, but they have a certain number of students they can take because they have a limited number of faculty. With the doctors and all. . you have to have one to two or three, or stuff like that, which isunderstandable! . ..Wishing me luck and stuff like that.

But the other letter. . . the first letter I got was horrible. . . I can't even quote it to you, because I think I blocked it. I'm sorry I threw it away. I was told I should go and find out from them exactly why it is they. . .but I don't do that. I say that if something closes, that means to say to me maybe that's not the direction I should have gone... I should have gone this other way.

I'm at F.I.U. now. A couple people have told me, "When you go, don't let them try to put you in Adult Health or Community College." They're telling me from their experience. They have done Adult Health. They have done Community College. . . that's their specialty. When you get your diploma. . . it might be trivial, but. . . when you get your certificate, it says on it Community College or that. . . it kind of limits you. Whereas, if you do Curriculum and Instruction, it sort of covers a wide spread. 
So I knew already what I wanted to do. So I went in to the Advisor and asked for Curriculum and Instruction. He talks to me and says, "Now what would you like to do?" I said, "Curriculum and Instruction." And would you know, he's trying to tell me, "You sure you don't want to do Adult Health?. . or this. . maybe this one is not. . ."And I said, "No! This is what I want to do!" So after I insisted, he gets up and starts telling me, "Now, these are some of my students. . . they have gone on to things like this..." Why?

In talking about that, I'm in a class with all educators . . teachers in the high schools, from elementary right up to high school, colleges. Something we read about in our books on the history of education. . . a long time ago, when you had advisors, there were certain people who would tell you to go to vocational, and other people who needed to go on to college. You know what I'm saying. . . almost like, you're streaming the people. That still exists today!

Over the years I've heard a few Jamaicans complain that their kids come here, they graduated at home. . like my daughter graduated at 16 from high school at home, but I made her go one more year here at high school, but she already knew what she wanted to do. . . but there are kids there, and so many parents are too busy. They don't realize what is going on with the kids. They have counselors, and they're telling them, "I want to be a doctor." "Why do you want to do that? It's hard... you have to do this. 
Maybe if you do this it will be..." They just divert them! I said it in the classroom, and one of the young ladies, she teaches at a prominent high school here in Miami, she said, "Yes, it's still going on." She's an African American. She says that it's still going on.

So from back to nursing school, as such. . . I mean, from Miami-Dade to U.M. At Miami-Dade they're having a problem. At U.M. . . I didn't have time to even think, "What is the problem or what..." Now looking back in retrospect, I can see some things. That's how things were handled. You see other people just sailing through. . I didn't know a lot of things, I didn't know the system here. I was just working hard, busting myself to get through ... having four kids, having to work full-time, overtime, and to get through. Now I look back and I say, "My gosh. .." 


\section{Participant \#5}

Interviewer: What is it like to be an African-American nurse?

Participant: Being an African-American nurse is a challenging position to be in. It's one that, despite the educational achievements that you have, you're still trying to prove yourself in your daily profession. You think that you. . you feel that people are looking you, at your skin color first, before looking at your ability as a nurse ... as a professional nurse. . . that people are always stereotyping you.

I had an experience in 1993. This was in Georgia, where I was the first Black nurse at this place. It was a nurse-managed prenatal clinic, and I found that very hard to believe in a place like. . this place was 45 minutes outside of Atlanta. . . I found that my supervisor was threatened by me, because I found out that she only had an associate degree, and I had a master's degree. The way that I was introduced to other people was, "This is _-, and she has a master's degree," like Black nurses don't have master's degrees! But I thought this place was a really neat place to work. It was a really good experience. It was a nurse-managed prenatal clinic. If I had stayed at that place, I probably would have gone on and gotten my 
training as a nurse practitioner, because I got alot of hands on experience doing that there.

The nurses felt that. . . I'll never forget when it was time for the evaluation. My Supervisor wrote on my evaluation that I failed to ask for needed assistance, as if I didn't know what I was doing. . . like I had to have some help all the time. They found that I'm not a gossipy type of person. .. I don't get in cliques and everything. She wrote that I tend to isolate myself. . . just because I spent time in the room with my patients and did my documentation in the room, instead of going out to the nurses' station with the White nurses, gossiping and getting into family business and private lives. I didn't do that.

There were times that I would go to lunch with the secretaries, because all of the secretaries at this place were Black. I would go to lunch with them, and they didn't like the fact that I was going to lunch with them. As a matter of fact, one of the secretaries and I. . . we became really good friends, and to this day we still keep in touch. They didn't like that. . . that we were close with each other, and I didn't get close to them. I just felt that they were always nosy, and always trying to get into my private business... of what goes on with my life after work.

That experience. . . It was a good experience. It taught me how to relate to people when challenged with those situations, not to really let it get to me, and just brush it off as ignorance on their 
part. It just showed them that I can be a professional. I know what I'm doing, and I don't need their help. I've had people come up to me in positions, "How did you get this position?". . this is at my present place of employment. I said, "I applied like anyone else and went through the interview process." I've heard people say to me that they expected a White nurse to get this position. I go, "Well, they saw something in me for me to get this position."

I find that some doctors. . . Caucasian, White, whatever you want to call them. . . have problems when I come and tell them something. Even though I'm right, they'll argue against it. Next thing you know, they're writing orders out of my presence. They'll go ahead and write what I said. They'll go ahead and do what I said. But in my presence, they won't accept my suggestions and advice. I know what I'm doing.

I've had patients and family members come and question me. I find that is. . especially the Whites. .. One particular lady, this was the typical Jewish lady from New York. . . rich. Her kid was in the hospital because she had a transplant, and somewhere along the line she came down with T.B. This lady ... she would just try to drill me on everything. . . try to trick me. . saying, "whether this and that. . . the doctors told me this and that and everything. . .", and would try to pit me against the doctors. But I knew what was going on, and the doctors knew what was going on, too. She would always threaten to go up to the higher-ups... and "her husband was so powerful in 
New York." In the end. . . from just standing my ground and answering the questions with the information that I knew... in the end we became friends. Her daughter was there for about three or four months. She just couldn't accept it. When she found out that I had a master's degree, she started trying to. . . she just started saying positive things to me after that. We became friends, eventually, after that.

I've had nurses. . . when I first started in this particular position, it was a new position. In the beginning we were all fumbling around trying to figure out what to do and how to do things. Nurses would try to trick me. When I would try to tell them to do something, they'd resist it. I still just came around them and smiled, and eventually we all became friends. They're doing the things that need to be done now.

I haven't. . . so far in my nursing career, I've been blessed to get most of the positions that I really wanted. I haven't really ventured into management, or tried to move up in the position that $I . \ldots$ in a position other than what I've been hired into. At this point I have no interest in going into management.

The present position now. . . initially it was just me and my supervisor in the office, she's Caucasian. We didn't talk much. Now she hired her friend in this position. . . it's a grant position, and her friend is in the office now. I find now, it's funny. . I laugh at it now. They'll be just yapping away, talking away, and when I come in... 
total silence. So I just go on and do what I need to do. I find that I avoid the office now ... go in in the morning, do what I need to do, get out on the floors, stay out on the floors as long as possible, and then go back in the afternoon. . maybe an hour or two before it's time to go home.

They get in and they just. . . I find that they always want to know your personal business. I don't get into that with them. But they'll tell me their whole life story, and I just listen and nod. I don't get into that. It's funny. . . they plan stuff among just the two of them, and they ask. . . one asks the other, "Do you want to go get coffee?" "Do you want to go to lunch?" . . like I'm not even there. I just overlook it, and just go on with my buddies. They just. . maybe just. . . act like they're comfortable with each other, because they go way back years and years.

In the beginning of my nursing career $I$ attended a predominantly Black university, Howard University. I found that my professors were tough and challenging, but it was. . especially one professor, Colonel Palmer. It was not like she picked out one person, it was across the board. She was tough, challenging and intimidating to us. . . to all the students. That was her way of making us learn.

One professor in particular. . this professor was oriental. I just thought she was totally out of place there at that time. I thought she was just too petty and too picky. I learned to hate nursing more 
from her than to like what I was doing at the time, because of her teaching style. The instructors, they tried to make...

My experiences of my instructors were good experiences. They tried to make us feel at home. They treated us like family, like we were their little... One teacher, it was just so nice t hat she would always say, "My little darlings. . Y You little darlings." That really helped hearing it from one of the professors. I'll never forget her, Dr. Epps (?). She looked like the grandma, too.

The experience in school was really. . . a good school. We all hung together. We had one or two Whites in our class. . . one was a male and the other one was Chinese, but they just blended right in with us. We. . you know in all classes you have your little cliques, but it still was a good experience. When somebody found out some information about a test, it was. . " share with the whole class." It wasn't like one group kept something from the other group.

When we had clinicals, our clinical was done over at Howard University Hospital, a predominantly Black hospital. All the doctors and everything over there were African American. There might have been some doctors from India, or places like that. . . maybe one or two Whites, I don't remember any at the moment. Most of them were Black.

Alot of the nurses over there were Philipino nurses. As senior nurses, we worked in the hospital on the weekends or every other weekend, and we found that the Philipino nurses were dumping stuff 
on us. We took it as a learning experience, but looking back, they were dumping their work on us. They were sitting around talking in their language while we were running doing things. All they would do. . . we would write a note, and all they would do is co-sign the note. That was what my experience was.

After I graduated, the hospital tried this new program. They wanted to see if new grads could function in the ICU's and Emergency units. . . Emergency Care area. I was assigned to go to the Medical Intensive Care unit. But their reasoning was that they would start all of the nurses out in the Neurology Intensive Care unit, and after a couple of months you would go to your assigned unit.

Little did we know. . . we were all Black nurses, one man and one Chinese guy. . . we all, that unit was the unit that was hard to staff. They stuck the new grads on that unit. When it was time, we kept questioning them as to why we weren't moving on to our assigned units. They would always say, "Well, the unit is full." "They have all the F. P.'s." "When an opening becomes. . . when there is an opening, then you will go to that unit." This never happened. I got frustrated and ended up leaving that hospital after about nine months.

I went over to a Catholic hospital. . . but I found on this unit only Blacks and Philipinos worked on that unit. . mostly Philipinos... Interviewer: Was this a White hospital? 
Participant:

Interviewer:

Participant: ...a Black hospital.

this was a Black. . okay.

After I left that hospital, I went to a private hospital, which was the ... it was the Catholic hospital run by nuns and the fathers. In this hospital there were more White nurses than Blacks there. In that hospital. . . I experienced. . I feel that some of the White nurses were standoffish. They weren't helpful. They were really picky. . . they would look for things wrong with your work instead of helping you as a new employee there.

Some of the doctors there would try to be intimidating and demanding. One doctor, in particular, he just couldn't break me. I would just go at my own pace. But eventually he went to my head nurse, and she just told him that that's just how _- is. "She's not going to jump when you say jump." Here's the emergency. . I'm going to move, but I'm not going to run around there like a chicken with its head cut off. After that I didn't have any problems, because she told him that that's just how I am. "As long as she does the work and get the work done, leave her alone." Sometimes I would get defensive with him and deliberately do things slow and piss him off.

I found that in this unit the Whites hung with the Whites, the Philipinos hung with the Philipinos, and the Blacks hung with the Blacks. It could have been that we were just comfortable, and it was just something we didn't even look at. One of the nurses in the unit, 
me and her are still good friends ... we keep in touch. She has since moved on.

The hospital, the patient census. . . it was mixed. . . mixed, Black and White. That was a good learning experience there, too. Most of the doctors there, about 50:50 Black and White physicians there. Being in a place like D.C., it was a really good experience. Then coming down to Miami, where in the whole hospital you may see one or two Black doctors. Here it was just... Up there it was nothing to see the Black doctors, Black attendings, Chiefs of Services. Here at this hospital, here in Dade County, not one of the Chiefs of Services is Black or African American. I think something is wrong with that.

The C.E.O. of my present hospital is Black, but there is always negative stuff. . . people are always trying to get him, trying to bring him down, but he's been strong. . . he's been hanging in there. There's always something negative being said about him. They're always trying to find little things to bring him down.

Interviewer: Have any of your experiences of racism. . . have they affected your self esteem?

Participant: In the beginning it did. It made me feel. . . in the beginning when the nurses wouldn't help me. . you just struggled and did what ever, and then the next shift would come on. If something wasn't done, you'd feel so bad. You felt incompetent. I 
felt incompetent. . . like I wasn't catching on, or I didn't know what I was doing.

Now that I've grown alot. . . like the experience in Georgia, especially. I just took it as their ignorance of. . . just took it. . . here we're in this particular county, and they haven't accepted that we're here to stay. We're going to move up, and we're going to move them out. They just need to accept us.

I just moved on from there. I really could have stayed there and tried. I really could have stayed there, fought, tried to make her life miserable, and move her out of her position. . . if I was vindictive. I chose to come home. I was homesick, and other crazy things that were going on in my life. It just makes you grow. It just makes you stop to think that there are more important things in life to be worried about and concerned with, not how other people act in their ignorance. As long as they're not causing any physical harm, just overlook them and let it go. As long as I am able to still do my work and get paid, I'm alright.

Head nurses were Black, and older nurses. . . they weren't helpful. They were just negative people who, I felt, shouldn't have been. . needed to be retired. They were against young people. It was like you had to learn things on your own.

Interviewer: Was it because. . . you know, there's a saying in nursing that nurses eat their young, or do you think that they were 
threatened because here's a young Black nurse trying to make it. Do you think that it was reverse racism?

Participant: Yes. I think they felt threatened. Here's a young person coming in. They were working because they had to work, and...like in my case, I was working at that particular place because I liked what I was doing. It was a means to another end. With them, they were just burned out and couldn't function anywhere else. I knew I had a goal, that I was going to stay there a certain amount of time and then move on. I just felt that they were going to make it miserable, because I had heard of people quitting because of the way they treated them there. . their nurses. The pay was pitiful, so it was definitely because I liked what I was doing, and not the pay, that I stayed there. 


\section{Participant \#6}

Interviewer: What is it like to be an African-American nurse?

Participant: What is it like? Well. . . for me, it's been really interesting. I find, in the later years. . . the last five years, or probably since I've been in South Florida. . . it's been more of a struggle. I've always wanted to fit in, be a good nurse, take good care of the patients, and feel like I was a contributor to the unit I was on, whether it be administrative or clinical. I've always felt like my suggestions did not count.

I always did feel like I took better care of the patients than someone that was not Black. I always felt like I cared more. It seemed to me that my White colleagues mainly cared about the money. I love the money, believe me, I love money! I care about the money, but when I was at work I didn't necessarily think about the money so much. I thought about, "is this patient clean?" I've known that my other White colleagues or non-Black colleagues. . . they didn't seem to care. If the patient's face was clean, it was good enough for them. .. as long as they got their breaks, plenty of them. 
That's just what it's been like for me. Especially here in South Florida. South Florida is just a little different to me than any other place I've ever been, as far as the race thing.

Interviewer: Could you talk to me about some of your experiences that you have experienced, be it positive or negative, involving racism amongst your colleagues.

Participant: $\quad$ Yes. . . One episode I had, as a matter of fact, was not here in Florida. I was a brand new nurse. Me and my husband had just gotten married, and we moved to Reston, Virginia. I worked at the Reston Hospital Center. My supervisor, her name was Marie. . . I don't remember her last name. I worked night shift ... I was off every Monday and every Tuesday night. I remember working on the surgical unit, and I remember the brochure for A.C.L.S.

I was thinking, "Gee, I've always wanted to do that . . that's exciting." I'm a total type " $A$ " in personality, which in the E.R. is perfect for my personality. I said. . . I remember thinking out loud. . . she was looking at it, my other nurse colleague was looking at it, the other nurse that I was working with that night. . . we were looking at it, and I said, "Gee, I want to take that. I should probably take that." Then the nursing supervisor looks at me, "Oh _-_--, that's very hard. I don't think you'd ever be able to pass that." I looked at her. She told the other White nurse that I worked with, "Well, I think you could probably take it," but she told me I would never be able to pass 
it. Thank goodness I never listened to her, because the next year, not only did I go down to the E.R. to work, but I took it and I passed it. Every two years since then, I don't even have to study for A.C.L.S., because I know it so well. For some reason that incident really sticks out in my mind. Anything else?

Interviewer: Yes. I need you to just talk to me about your experiences. They don't have to be in any order.

Participant: Okay. When I worked at Cedar's Medical Center, the Head Nurse that's there right now, Deanna, she really. . . she almost makes it totally known that she does not like Black people. She's come out and made comments about Blacks, and says, "Well, she's Black, you know." I notice that when I was on the pool there. . . this was last year. . I was on the pool, and she would never let me work as charge nurse. In this incident, it was not only racism, but it was also a gender thing. She told me I couldn't work in triage. I remember when I first became an E. R. nurse. . . I was afraid to work triage, because I said, "Suppose I don't know. ..." I remember Joe Brubaker, who was my head nurse then. He said, "—_, you've got to learn it, and you will learn it." Remember Rachael Jackson?

\section{Interviewer: Uh huh...}

Participant: She's the one that got me to be a Triage nurse. I actually perfected it. I got it so well that I could just look at a patient before they even told me what was wrong. I could tell whether they should go to the back or stay in front. I mean, I've gotten very, very 
good! I've got a sixth sense for Triage. But Deanna. . . she would never let me work Triage. She would never put me in charge. I asked her why? "Well, I just don't think you're qualified." I mean, I have been an E.R. nurse for what. . eight years? I mean, seven or eight years? A.C.L.S. . . P.N.C.C. . . E.N.P.C. . l loads and loads of experience at Jackson's Emergency Room, and I can rotate through all of Jackson's E.R.'s with my eyes closed. . . North Shore . . you name it. . . Broward General, the Trauma Center. . . and this woman is telling me I can't work in this two-bit E.R., I can't do Triage at this two-bit E.R.

We all noticed. . . me, Rose, and some other Black nurses ... we noticed that she didn't ever let the Blacks be in charge. Susan, a White blonde, came in off the streets. She put her right in charge over me ... over her other Black staff members who had been there five or six years, who knew the place. She's still doing it. She's still doing it.

As a matter of fact, there's another nurse that's getting ready to sue the hospital now. She's from the Caribbean. She's a Black nurse. She's going to sue. She just put. . I think she just put in her E.E.L.C. complaint. She's got an E.E.L.C. lawyer, a civil rights attorney. She's filed her grievances. I mean, she was there yesterday, as a matter of fact, filing the grievances and complaints. I just keep hearing it, time after time. . . it's just. . . let me think of what else. 
I had another head nurse. Her name was Margaret Kolfer. She was from Georgia. This was when I worked in Virginia. She would not. . I had requested every Monday and Tuesday night off. I had agreed to work every weekend because that's the shift my husband was working. When it came time for me to switch, for me to get every other weekend, she told me I couldn't. . . it wasn't available.

Then I asked for day shift. . . it was not available. The next week she hired two White nurses to do the day shift. She still told me that days. .. well, about any days. . . weren't available. I had worked with another White nurse on the night shift who asked after I did. She put her right on the evening shift. I was still stuck on nights. I had to quit, and then be rehired. I claimed "racism" to the hospital administrator. So that I wouldn't take it any further, he hired me back on days. They knew. . . It was to bad that I was so young and so naive, and didn't have anybody for a mentor or for guidance, because I would have pursued it.

I've seen my other White colleagues get promoted to Assistant head nurse, head nurse. I have an associate degree in nursing. They've had associate degrees, and I know that their nursing skills and their judgments haven't been anywhere near where mine are. That's not just my opinion, that's just how it was! Of course they were moved up, on and beyond. 
Not only that, the hospital would give them time off to go to school during the day. "Well, she's working a modified schedule..." There's been times that I tried to work. . go to school and work and, "Well, we have to have you here this day." So I would have to quit the job in order to go to class.

Right now I'm not working. I don't plan on even going back, trying to go back into the work force full-time with anyone until I have my bachelor's degree. Because when I go back, it will be only management. It will not be hands-on patient care, it will be only management. If they don't hire me, they will have to tell me why. They're going to have to give me reasons why they hired someone else, because I'm going to ask. I'm not going to take anything sitting down. . . laying down any more, as long as I'm educated. I think that's just very, very important.

Back in 1984, I started nursing school at Robinson Technical Community College, in Lumberton, North Carolina. Lumberton is where the Lumbee Indians are from. There were thirty students. Four of us were Black. . Black Americans. About another eight were Native Americans. Everybody else was white, even in this predominantly Indian environment.

One of the instructor's names was Lois Kinloff . Miss Kinloff looked like one of those Army nurses. She wore those hard Army nurse shoes. . . heavy set. . . big-busomed lady . . . blonde, short hair ... loud, I mean her attitude was just how she looked. I felt like she 
was mean. I remember going home everyday to my mom and telling my mom a new story, and erying, "She doesn't like me, she hates me." My mother said, "____, you can take anything, you're strong. All you need is what's in Miss Lois Kinloff's head! Then you're getting out. It's not a life-long thing. You haven't got to live with her all your life."

Miss Kinloff would do the most ridiculous things. I remember going to clinical, and Miss Kinloff ... I remember, I had a patient, it was a Black woman. When I went into her room that morning, she had the covers over her head. I said, "Miss Smith, Miss Smith." She wouldn't answer me. "Miss Smith," thank God she moved. I said, "What's wrong? Why have you got the cover?" "I want. . I I want my head covered up. I'm not uncovering it!" I was suppose to bathe this lady, and believe me, with Miss Kinloff you'd better have had them bathed by a certain time or you were going to get a " $U$ " for that day and slapped across the face, or whatever. I went back out to Miss Kinloff. I said, "Miss Kinloff, this lady has her head covered up. She won't take it off. She didn't want to come out. I need to bathe her."

I had spoken to the lady for a while trying to get her to come from under the covers. Miss Kinloff got on the intercom and called all the students around. "Well, - has this problem. There's another thing I want to let you know about most Black people, ..." She announced this in front of the class, "... they sleep with the covers over their heads." I was nineteen years old at the time, so I 
didn't. . I I remember thinking, "I don't sleep with the covers over my head! My mom and dad don't. None of my. . . I have four sisters, and none of them do. My two brothers don't." That's a pretty large family. I spent the night with girlfriends, they spent the night, and none of them slept with the covers over their head. I should have asked her, "Where are you getting your information from?," but I didn't. It was just a very stereotypical comment.

Well, I wish I had kept this book. I lent this book, it's a clinical skills book we had, I lent this book to someone. I don't know who the author was. I never got the book back. In the book it said that if you get a patient from the E.R., and say, for instance, they were in a car accident, and they had alot of dried blood and dirt in their hair. . . they were Black. . . the way that you should clean their hair, or detangle the hair was pour rubbing alcohol in it. This book said that! I will never forget it, because I was going around the class and showing everybody!

Of course, the same instructor said, "Well, that's true." This was during class. Quickly, I stood up. This time I stood up and I said, "I want to let you all know, for those of you who are White and don't know anything about my hair, I tell you what, if you ever try to pour rubbing alcohol in my hair, you'd get your face slapped." They started laughing. I said, "You don't do that. Our hair is just like yours. You can wash it with water and soap. You could, perhaps, ask the family members if they have any hair grease to moisture it. 
That's it or, if you have baby oil, you may want to put a little oil in it if it seems dry. .. but that's it. You don't pour rubbing alcohol on our hair. Alcohol dries. We put oil on our hair to keep it from drying."

Then another incident happened. We were taking a. . doing a section on cultures, Miss Kinloff again. We're talking about different things. Each one of us had to do research on a different culture from our own. . . cultures and religions. I don't remember who I had, but I remember one girl got up and talked about the Black culture. Her schpeal was very good. Some of the things, of course, were kind of stereotypical in her talk, and we told her, "No, that's not true." She was very open to it.

At the end Miss Kinloff stood up again and says, "Well ...," and started dishing out all of this. . . some stuff which was very true that she was saying. She knew alot about Black people, obviously. But one thing she said was that Blacks like to have their furniture catercornered. As you see, I have two chairs over here catercornered! That's what she said! I did call her on that and said "Miss Kinloff, I know in my house, and I'm a Black person, my mother hasn't one thing catercornered in the house, because she doesn't like things to be catercornered. Sorry." The thing was that these people were believing it.

I noticed that when I had turned in a paper. I had missed a day from school and was sick. It was the only day that I had ever missed from school. The next day a paper was due. Before I went to class 
... I was late for class. . I I went upstairs to Miss Kinloff's office. She wasn't there. I knew I had to turn in this paper, because you just can't. . . if you wait until the end of the day, she'd think you were sitting in class writing the paper. So what I did, I took the paper and slid it under her door. I don't think anybody. . . there might have been another nurse. . . another nurse was with me, my friend Mary .. .she's Black, too,. . . I still talk to her this day. I shoved it under the door.

Later on that day, nobody said anything. The next day, she sent a message down telling me to come upstairs to her office during class. I went right up. I said, "What is it?" "And just what is the meaning of this!?" She had given me an ' $F$ ' on the paper. I said, "I don't know why you're giving me an 'F'?" "Because you just turned it in today!" I said, "Miss Kinloff, I didn't. I turned that paper in yesterday morning, Mary Eastman was with me. . she can tell you. I came up here and slid it under your door." "No you didn't! I just went to the bathroom. You just walked into my office. . . you snuck it in my office. . you snuck in here and put it on my desk!" Several of the White colleagues had been out, and I saw their papers laying there with " $A$ 's" on them. They had turned them in after I had turned mine in, but she just gave me an outright ' $F$ '. She refused to even give me a grade on it because she accused me of...

Nursing school was very. . . the first year of nursing school was very difficult. The second year, I had two Black instructors, 
which was like. . yes!!!! I mean, they were really good instructors. This lady was just...

Not only that, I stopped by..., this school is right on I-95, once you get into Lumberton, North Carolina. Last year I stopped at the school. Miss Kinloff was there. I hugged her and asked, "How are you Miss Kinloff ?" I asked her, "When is the class reunion coming up?", because I knew the class reunion would be coming up. Actually, it was supposed to be in 1996, it had been ten years. "Okay, well leave your name, address and everything, and I'll get to you." I left my name and address with the secretary. My mother called me the other day and said, "__, did you know your class had a reunion? April 26th of this year?" I said, "What? I left my name and address at the school."

I called the secretary. The secretary remembered me. . . she's a Black girl. She told me, "-__, I remember you. You're that girl that came in here and talked alot. You were just so happy. . . You live in Florida." I said, "Yes." She said, "I gave your name and number to Kinloff. I don't think Miss Kinloff even wanted you there. She invited who she wanted there." She then said, "Why don't you give me your name, address and number again, and any time I think the school is having anything, or if you have anybody else's name and number you want to give me, I'll keep yours and theirs here, and I'll inform you of whatever is going on here at the school. She isn't going to inform you." She didn't. She said, "I gave her your name. 
She asked me to put down your name and number. I know she had it. . I know she had it." She's still the same Miss Kinloff. She's still a racist. The Black students cry every day. . . every day. School was a nightmare!

Interviewer: Your experiences of racism as an African-American student and an African-American nurse, did that affect your selfesteem?

Participant: Oh yes! Of course! I was the first Black nurse that the Reston Hospital Center hired in their E.R. The hospital opened up in 1987. . . no, it opened up in November of 1986. I started working there in February of '87. I started in the E.R. in March of '88. I was the first Black nurse to work there. I remember in October .. . March. . . April. . . May. . . June. . . no, it was during the summer ... June? March, April May. . . May or June, I remember seeing a name on the schedule. We were all sitting around looking at the schedule. I was the only Black nurse. They would never let me take care of a cardiac arrest patient. "You don't have the experience, so get away." How else am I going to get the experience unless they give it to me.

Not only that, they were all very resentful that I got a six-week orientation to the E.R. I was also the lowest paid nurse in that E.R., even though I didn't have the least experience. There was another nurse who was younger than me, and she had less experience than I 
did, but she got paid higher than me. We kept up with each others salaries there.

Anyway, I remember a name came up on the schedule, 'Rachael Jackson.' The head nurse had already told. . . I didn't know. . . The head nurse had already told everybody that she came from D.C. General. Everybody knows that D.C. General is "the hood." If you come from D.C. General, it's like the war zone down there. There's alot of trauma, trauma, trauma. . . alot of gunshot wounds, alot of neglect. You just know that this person has had alot of experience.

This nurse's name was Rachael Jackson. Jackson, what do you think of when you hear Jackson? You think of Jesse Jackson, Michael Jackson, you think of somebody Black. They all turn to me and go, "_-, Rachael Jackson, you know her, right?" I mean, they just assumed, because I'm Black, that I know every other Black person in the world! That's how I met Rachael. Rachael came there, and I'11 never forget it. She even spoke up for me.

They had me orienting with a nurse that hated me, of course a White nurse as I was the only Black. The nurse absolutely hated me! I was supposed to be with her during orientation. She wouldn't let me near her. I had to literally go stand in a corner. . I had to be away from her. She would just snatch things out of my hand. I kept going to the Head Nurse, "Tell me what I can do to get this woman to orient me!" I begged them to put me with somebody else. It got so bad. . one night I finally stood up to this girl. She was older than I 
was. I was. . . 1988, what is that, eight or nine years ago . . so I was twenty-four. . . twenty-three, twenty-four. It got so bad. . . I remember, her name was Sharon. Sharon was such an evil witch. I'm sorry, but she was so awful. Everybody knew that she didn't like me. So whenever Sharon and I were around, everybody was quiet. They'd all flock to her and kind of leave me hanging, even though I didn't know how to do anything in the E.R.

I remember one night, Nancy worked in the E.R. Nancy and Sharon were good friends, but Nancy usually worked as a nursing supervisor. She just happened to be filling in in the E.R. that night. Sharon had talked trash to her. She was so nasty to a lab tech that was trying to draw blood on one of my patients, and she yelled at me. I told her, "Get over it, honey! You don't talk to me that way!" She started yelling at me, and I started yelling back at her. . . she was in charge.

Nancy, who usually works as a nursing supervisor. . . and I was really upset. . . she pulled me to the side and said, "Dawn, you and Sharon are about to fight each other literally." I said, "Yes, because I'm not backing down tonight, honey. I'm sick of her, and her treating me... ," "I know she's treated you bad in the past, - - everybody knows that. I'm afraid that you both are going to start fighting, and we're so busy tonight, we can't have that. I tell you what. Why don't you just go home... just clock out and go home. I'll cover your patients, and I'm going to call..." I said, "Look, I need 
to call the nursing supervisor if I'm going to do that. You feel like it's a volatile situation. I respect your judgment because you usually work as a supervisor." She said, "Yes, I think that you should just. . . let me get your purse for you."

She got my purse. I said, "let me call the supervisor." She said, "No, I'll take care of it with the supervisor. Dawn, you know me. I always work as a supervisor. They know my opinion counts. Don't worry, I'll talk to the supervisor, but I want you out of here! I'm telling you this on a supervisory level, because this is a volatile situation. You cannot go back in there with Sharon!" It was just that volatile. So I left.

I was twenty-four years old. This woman was forty. She was not the Supervisor that night. I've never, ever, ever left the job, never. This girl said she was going to, "...square it with the supervisor. . I'll tell Sharon that I was afraid you and her were getting ready to fight, and I would rather see you go because you're not as experienced as Sharon."

Well, I left. The next day I get a call from the head nurse. She calls me in and she suspends me for three days for abandoning my job. Nancy's story had completely changed. "I didn't tell her to leave. She cried and told me she wanted to leave!". . . I was suspended for three days! I'll never forget it! I felt so silly, because actually it was job abandonment, if you look at it. It really was, but I was just so stupid to listen to this girl. I was just so upset, and she 
was just so convincing. All I had to do was pick up the phone and call the Supervisor. .

Interviewer: $\quad$...Right, but she told you that she would take care of it. . .

Participant: . . .I shouldn't have listened to her. I didn't know! To this day, it just really eats at me. I remember, I worked with a doctor one night, and I worked with Lisa. Lisa and I were. . I'm 32 ... Lisa will be 32 in July. We were both. . I was 24 . We used to work night shift. I remember, we were working, and Lisa was talking about what she wanted to do with her life, and I was talking about what I wanted to do with my life.

She said she wanted to be. . I remember, at one time I wanted to be a lawyer. She said she wanted to be a doctor, or physicist, or something. He goes, "I can see you doing that..." His name was Allen. . . White, blonde doctor. He must have been all of 35. "I could see you doing that." We were all three standing there talking. I remember saying, "Yes, I wouldn't mind going to law school. That's always been a dream of mine since I was in high school. . .junior high." "I can't see you doing that. You're not smart enough for that, $-----! n$

To this other White girl, "Yes, go for your dreams, girl. Go for it!" And to me, "I don't think you're smart enough. I don't think you can do it. You're not mature enough, and you're not. .." If he said that to me now... he knew I would put up with it... young and 
naive. . " just a dumb, Black girl." That's what he's thinking. Now I would have chewed him up and spit him back out, and said, "Excuse me, I think that's inappropriate."... Now I'll just simply tell him.

Interviewer: So how. . . You started off saying that yes, it affected your self-esteem. How have you. ..

Participant: $\quad$...In the E.R., as a matter of fact. . . remember I was telling you about triage, how I learned to perfect triage? I'm a perfectionist when it comes to my nursing. When I put in an I.V., I don't care how busy we are, I've got to label that I.V., I've got to put that Betadine squirt on it. . most people don't use the little Betadine squirt! I've got to use my Betadine squirt with the bandaid over it, and it's got to be perfect!

For example, Yolie, she's a Philipino nurse at Cedar's. She loves to just put the needle in with the P.L.N. adaptor on it and some tape. . . they all love to do that! When I get to my patient, and their I.V.'s like that, to me... I think of that hand being blown up and filled with infection. "If you're not going to do it right, don't touch my patient!" I've gotten in trouble with colleagues for that type of attitude.

When I worked at Cedar's, they told me so often that I was a bad nurse. "Oh, she has no experience. She's not good." I remember going to. . . taking all these in-services, trying to become better. . . trying to increase my knowledge base, and not only that, I was in school at George Mason University. I had gotten an 'A' in the 
course. I was going to register for another one. My self-esteem was just so low, because I knew I would never be a good E.R. nurse. I remember I used to find ways to not go to work. And what's really interesting. . . See how I'm dressed now, I have a full face of makeup, my hair is fixed, earrings. You don't see me at work unless. . . Did you ever see me work night-shift at North Shore without makeup?

\section{Interviewer: "No."}

Participant: $\quad$ My hair might have been back in a ponytail, but I always wore my. . . if nothing else, lipstick. When I went to work at Reston, I would go with my hair. . . it was unbelievable how I looked. .. never wore make-up. . . sometimes I didn't brush my teeth. I didn't feel good about

myself. They always made me feel bad. They always made me feel bad for being Black.

I remember the radio was on. They would always play this radio in the back. I like all kinds of music,some Country \& Western songs I like. I like rap. I like all kinds of songs, it just depends on the song. There's not necessarily a particular artist. . .En Vogue I love. The radio used to be on. I remember one, several of them had done this. They would turn the station, and then you would hear a heavy Dion hit, "All The Way Lovin' In The House,". "Oh,_, you'd probably want to hear this!" Little comments like that. I'm like. . get 
over it. It was just so inappropriate.

“Oh --.--, you'd. . . --.--, --, would probably like this music."

If a Black patient. . . we didn't have alot of Black patients then. If a Black patient would come in, they'd make sure they'd give him to me. I didn't mind, because I'd make sure they'd get good care. I remember Sharon, she would touch their clothes like this. . . by the very tips... drop them on the floor and have the aide pick them up. If it were somebody White, they'd rub their back.

And I remember them, "Oh, _-, you're not a good nurse." They would always tell me that to my face, "She's not very experienced." They'd tell the patients, "She's not very experienced." Even the doctors would treat me that way. You've seen me nurse in the E.R.

I really had to. . . I remember praying and I said, "God, I promise You, when You move me to Florida, I'm going to be the best that I can be. I will never go to work without makeup..." I did one time, only because they called me and needed me right away. I said, "The only reason I'm going in without makeup is because it's night shift." Other than that. . Believe it or not, the makeup helps make me feel good about myself, because I feel like I look good. If I do my hair, I feel like I look. . .if I look good, then I feel good. It's just a state of mind for me. So I make sure that when I go to work that I look nice. My uniforms are kind of old and dingy, but they are always clean and pressed. I make sure I look nice. 
I say, "I will never let people talk to me and tell me how bad I am ever, never, ever." Because the first time that they do, that they try to be condescending to me, I will take them to the side and talk to them. When I worked Cedar's after I first moved here, I did, I took two nurse practitioners to the side and told them, "Don't talk to me that way again. I'm a person just like you. You might not think I'm all that great and wonderful, but I think I am." You know what, they never did ... they were very nice. These are White people. You never heard them talk to the White male nurses or the White nurses that way.

I worked at Jackson one time. I worked there the whole time I was pregnant with my daughter, Lisa. The nurse was White and everybody else was Cuban, and they would always speak Spanish to each other. There was one secretary who was Black, that I was real tight with. When I would go and whisper something in her ear, they would talk about me in Spanish. I knew they were talking about me to my face. They would just start talking Spanish whenever they didn't want me to hear.

The first time I went and whispered in the secretary's ear, we were laughing about something, she went and told the head nurse. "You're just being obtuse and obnoxious, the way you go and whisper with her..." I said, "So, all of you can speak Spanish, but it's not okay for me to speak English and speak low to my friend when I'm talking about something personal?" 
I remember, we used to run the Sickle Cell Clinic in Hemoc Pediatrics. God is good, and I'm so glad this happened on a day that I wasn't there. I used to always get so hurt. . . Tuesday was Sickle Cell day. The Sickle Cell lobby was packed. The girls that were there were talking about their boyfriends, who they slept with, how good somebody was in bed...it was just ridiculous, the conversation. They put me up front to do vital signs, even though I could stick a kid with an I.V. ... I was excellent. . . these kids with no veins. They didn't want me to stick the Spanish kids. They'd go, "I want her to stick me." It happened twice. They knew I could get their I.V., and it made them not look so good. They didn't want a Black woman doing better than them, so they put me up front doing vital signs only, for $\$ 28.00$ an hour, Monday through Friday. I got 40 hours a week, $\$ 28.00$ an hour, I was happy.

So what happened was that Dr. Charles Pegalow, he was a White guy. He loved the Sickle Cell patients, and the Sickle Cell patients always loved him. Of course, people withSickle Cell are predominantly Black. He came into the clinic. None of the rooms were filled up, all of the patients were out front, and the nurses were in the back talking. I happened to be out for a doctor's appointment that day. When I got back, I heard about it! They said he cursed all those nurses out. He used curse words. He said, "You all are racists! You're prejudiced against my sickle cell patients, and I'm not having it!" This is a White man talking to one White and four Spanish 
nurses. He said, "When your Spanish and White people get in here, you look and keep that cabinet locked. You give them all the big baby dolls and all the games. My patients. . . you give them a little, squiggly plastic toy! I come in here at $8: 30$, ready to start my day, and my patients aren't even in their rooms! Well I tell you what. From now on, I want all my Sickle Cell patients in their rooms, or I'm going to find a way to get rid of all of you! All of you are treating Black patients bad, and I'm not having it! If you don't Black. . . he was saying this in front of the patients. . . if you don't like these Black patients, then you need to go somewhere else and work where it's all Cuban or all White!"

I had been complaining about this the whole time. The secretary and I, we would talk on the phone. . " I can't stand the way they're treating patients. It's killing me." But I needed the money. I was so pregnant that I couldn't do anything stressful, like the E.R. I was very pregnant and I had been bleeding. So I knew.

I remember another girl and I were pregnant at the same time. I had been working there almost a year, but nurse had been there a little while, she was Cuban. I remember them talking about her shower, "-_-, it's $\$ 15.00$ a head for the shower." I paid my $\$ 15.00$. She and I, as a matter of fact, Lisa and her little boy are a week apart. That's how close we were when we were pregnant. 
I go to the shower. The shower was not for me. They never gave me a shower. These are my coworkers. They had a big shower for this girl at a Spanish restaurant. My friend, Pam, who lived on the other block, knew the Assistant head nurse, and another Assistant head nurse, who was Black, and who helped plan all this and hadn't given a second thought to me. "Pam, aren't they giving you a shower?" "No, they're giving another girl a shower." Pam got on the phone and called that girl. She said, "You know what? That's a shame. You and - are the only two Blacks there." Every time they would talk about Eleanor, I would go, "Look, I don't want any part of this." Eleanor was something to talk about! You wouldn't believe how. . .and this is a really interesting thing ...we say, 'Black against Black.' This girl would tell the most ridiculous stereotypes to these Cuban nurses.

I remember being eight months pregnant. I'm looking down at my legs and my toes, and I said, "I've got to get my husband to paint my toenails and shave my legs," I couldn't reach my legs in the shower. "I've got to make sure it's all shaved before I go into labor. I don't want to be up there with hairy legs!" Alot of this is a cultural thing. My girlfriend from Haiti. . . it's a good thing to have alot of hair on your legs and under your arms. That's fine for your culture. For me, I want to shave my legs and paint my toenails and shave under my arms. We're standing there talking, and they stop. I keep talking, "Excuse me." I said, "What's wrong guys?" “-_-, you're 
Black." I said, "Yes." "Black people don't like to shave their legs. What do you mean you're going to shave your legs?" I said, "What do you mean we don't like to shave our legs?" Well that's what Eleanor says. Eleanor says that Blacks don't shave under their arms or their legs. I said, "Eleanor! Well, maybe that's good for Eleanor, but I shave under my arms, and I shave my legs." I think it's a personal preference, whether you do or you don't. I mean, it's not bad, it's not good. Whether you do or you don't, it's just your preference.

They said that Blacks don't shave under their arms, and that Black women. . . this is from Eleanor, this is the other Black nurse I've been talking about. . . Eleanor had a child out of wedlock. . .I think it was someone else's husband. . that Black women just, basically, like to have babies out of wedlock. I don't know any Black ladies that like to do that. I know some of them that have. I can't say any of them just love it. This was another Black person busy tearing down. . I always felt like I had to prove myself on the job.

A nurse that we were talking about. . what had happened was that my husband worked for the C.I.A. at the time. My husband had graduated from college the year before. She seemed to be very impressed. "Your husband is a college graduate?" Because her husband wasn't, and she just couldn't believe that I was a Black person talking to her, and then my husband graduated from college ...I mean. . . the 1980's. 
This is up in D.C., the 'chocolate city,' where everybody ther. . if you're Black, you're educated up in D.C. In D.C. you've got some rich brothers and sisters. I remember driving on the Freeway. There was a brother driving a Rolls Royce. He was a gentleman about 48, 50. We were so proud! Half of the buildings in D. C. are owned by Blacks. . legitimately owned, not drug money! It is just so weird.

I have been in hospitals where. . I worked in North Carolina, which is my home town, right before we moved here. . when Duane was in the F.B.I. Academy. I remember pushing this cart around. One of my patients. . there was a cart, and I was going to return it. Everybody thought I worked in the kitchen. There's nothing wrong with working in the kitchen. I think it's fine because it's legal, legitimate work, and you work very hard. Believe me, I thank God for the people that work in the kitchen. Every day I'd go to work in the hospital, and they just assumed that I worked in the kitchen.

One time I had a lady at Reston E.R. who came in. She said, "I don't want any 'Nigger' taking care of me! I don't like it!"

Interviewer: So how is your self-esteem now?

Participant: My self-esteem, it took a lot of work. Even with my husband, he had to tell me, "Dawn, you're such a good nurse. I came in and was watching you at the door. You know exactly what you're doing." It's a lot better.

As a matter of fact, I've been branded as the 'nurse that knows it all.' 'Little Miss Know-It-All.' I don't care, though. Guess what, 
if I act like a know-it-all, when actually I'm not a know-it-all. . . nobody knows everything. I tell you what, when I get in that E.R. I feel like I'm home. I know what I'm doing in the E.R. Those patients have got to have somebody who knows what they're doing, at least part of the time. My patients. . . they're able to lay back on that stretcher and know that their nurse knows what she's doing, even when it gets busy. I even know how to. . . even though I can't give a patient alot of care, because they're on the back burner, because I have somebody else who is a C.H.F.(?) pulmonary edema, I'll stick my head in the room and say, "I've got a patient next door who isn't breathing, but I'm going to be with you. . . I'm not going to forget about you!" You know what? They don't lay on the call light. They don't go, "Oh nurse, I'm. . !" They're quiet, because I've spoken to them. I know how to handle it. They call me 'Miss Know-It-All," and I don't care!

It seems like I'm more intimidating, not to the Black nurses, but to the Philipino nurses. They back away real quick. I don't know why that is. I just found that they... What they try to do, now this is just my experience, what I found with the Philipino nurses is that usually they end up in charge. They usually hop in one E.R, in one or two E.R.'s. . . they try to take over. All of them work back and forth, three days in one E.R., three days in the other. . . full-time. . . both hospitals. 
What they try to do is give me most of the work. " $\mathrm{I}$ 'm going to give you this bay." What they do is that they clean out. . If it's another Philipino nurse, then we'll both work eight bays. I'm working four through eight. She's working one through three ... one, two three, four. . I'm working five through eight. What they'll do is try to clear out their Philipino's bays and give me all the critical patients.

Actually, it's fine with me. First of all, it keeps me from gossiping and talking with anybody. Next, it keeps me there taking care of my patients, and makes my time go past faster. I can do the work. I give quality care to the patient, because for me, that's really all that counts. Patients don't come to the hospital because they want to. . . because they think it's fun, they come there because they're sick! I think people are losing sight of that.

You know, the incidences I told you about in Virginia, I never even looked at them as racism. Now that I look back on them, it is racism. Being a Black nurse, it's part of the definition. . ."Racism." We have to deal with it day in and out, whether we want to or not. Somebody will make a comment.

Let me tell you about one more thing. This doctor, Karen Tette ... North Shore, and I think you were there, because I was so angry that night. You know where North Shore is located?

Interviewer: Uh huh. . . 
Participant: I don't have any idea about the neighborhoods around North Shore. I know there was a very rich, Jewish family that came in. The father was very sick, and she let the whole family back. I remember her signaling for all the brothers. . . all the brothers that were standing by their girlfriends. . .she was signaling them to get out of the E.R. I will never forget it. There were three Black men she made leave.

She was telling the White people where to get the best hotels. She said, "Keep your windows up and your doors locked. . .because this neighborhood around here is very dangerous. So you want to understand that it's just a bad, awful neighborhood!" She said it very loud! If you're going to say that say it, don't say it loud. Take somebody to the side and be tactful. She's supposed to be a doctor, a professional.

While she's saying this a tech. . . not a tech, an E.R. clerk from up front. . . was walking by. She lived right down the street. . she lived in that neighborhood. I remember the girl's eyes looking at the doctor and putting her head down. She slumped her shoulders and walked back to the front. You know me, I certainly called the doctor on it. I said, "Come here Karen. How dare you say that! Don't you know these people around here live in this neighborhood? I said that's your. .." "Well, it is a bad..." I said, "No. That's your opinion. You need to keep your opinion low or to yourself. Nobody wants to hear that, because you hurt other peoples' feelings, as they 
are predominantly Black people. I could take it as a racist comment." She rolled her eyes and walked away, but I bet she didn't talk about the neighborhood anymore.

That's the definition of being Black. You don't even realize you're dealing with racism everyday. It's funny, in retrospect. . . when I look back on all this. . . there are acts of racism almost every single day that I went to work! The comments. . . the sly remarks. . . the actions.

I wanted to tell you about this experience that I had at North Shore. I worked with you, _-_.-, at North Shore. I had eventually gotten to the weekend, night charge nurse. First of all, they weren't going to give me anymore money for that. I asked Diane Allemond. She wouldn't return my calls. It was her third to the last day there. What I did was make an appointment with Jim Ransen. I had already gotten all my certifications. I went to him and said, "Jim, I've worked very hard in this E.R. I've worked overtime. I've renewed my A.C.L.S., my B.L.S., I've gotten T.N.C.C., E.M.P.C. all in four months. . three months! I've gotten all that, and now you want me to do weekend charge nights. I don't have a problem with that, but I need more money!" He was looking at it, and actually he did. He gave me a five percent increase, which was fine with me.

They would never name me... Maxine would run the day shift, she made out the schedule. Rachael ran the day shift and some of the night shift, too. The three of us were basically running the E.R.! 
They would never name anybody as Assistant head nurse. We heard rumors that, "Yes. You all are candidates." We had nobody leading us. They didn't even hire another head nurse ... Diane Allemonde left.

Finally, basically, North Shore just waited for us weed ourselves out. I requested days, they wouldn't give it to me. They kept me on nights ... kept me on nights. I needed to go to school. So basically, as you know, Rachael Jackson had a drug problem, so she weeded herself out. Maxine was so tired. They just kept it up. We kept doing all the work. We were even doing evaluations for coworkers! Paywork did evaluations on Joan, or whoever was on night shift, and Maxine was doing evaluations and even giving out raises. Still she wasn't named Assistant Head Nurse!

Maxine found another job, still working for North Shore, but in a clinic. They waited. . I think they wanted to give her that. As soon as the three of us left, they promoted Ray. He's Cuban, I mean Puerto Rican, but a White Puerto Rican. . . he had White skin to me, and curly hair. They gave him the promotion to head nurse.

Interviewer: Did he last in the position?

Participant: I think he was there a year and a half. I think they demoted him. Now they have assistant nurses. Believe it or not, two of them are Black now. I truly believe that there was something to that at North Shore. I know that Diane Alle-... oh, . . . this gets even better! When I was interviewing at North Shore with 
Diane Allemonde, I know that she made a comment that she didn't want to hire any fat people, which is totally against the law! Remember Cindy Williams? She didn't want to hire. . . and Cindy Williams was a good nurse! Who cares what she looks like! If you saw my family. . . you know. You saw my picture. . . everybody on there is this big! I'm the smallest one in my family.

Diane Allemond. . . I went in for the interview with her. She offered me the job. She knew she had to. . no nurses in the E.R. with any experience. I was the meganurse, with all this experience. She hired me. She gave me this salary, and I remember my face fell. Now, whenever I go for an interview, I never accept the first salary given. . . never! I just don't! I made it a practice, because these people always give me the low end. She went up on the salary. . about another $\$ 0.52$ an hours, which was much better.

Later on I was speaking to Judy. . . remember Judy? I found out that Judy was offered. . . Then Diane Allemonde(?) wanted to give me only a $\$ 2,000.00$ bonus. The bonus was $\$ 5,000.00$. It was written in the newspaper. . . all over South Florida! I told Diane Allemonde, "I cannot start working for you until I have in writing that I'm going to get a $\$ 5,000.00$ bonus and this salary!" "Well, let me talk. . " She called me back, "I'll give you $\$ 3,000.00$." I said, "I'm sorry, it said." I remember, I stood my ground, and she finally gave in to the $\$ 5,000.00$ bonus ... finally! 
When I got to work, I found out that Judy had no E.R. experience. . . zero. I had been a nurse seven years, Judy had been a nurse two years. She had no E.R. experience, I had four years. . five years E.R. experience. I found out that Judy was offered the same salary that I was originally offered, and was offered the $\$ 5,000.00$ bonus the first time. Judy is a White nurse. Judy had no E.R. experience. Here I came with all this experience! I worked so hard to get this experience! 


\section{Participant \#7}

Interviewer: What is it like to be an African-American nurse?

Participant: Being an African-American nurse, to me, is very similar to being an African-American person in the United States. The issues that come up from just being African American extend into your nursing career as well. Issues of prejudice, sometimes not outwardly, but you. . . it's sensed or it's felt. . that people are not being fair, not just because of your type of work, but because of who you are. It hasn't been that much of an issue with me, but I've seen it. It has happened with me, it's not that I'm immuned to it.

It has happened with me, and I've seen it happen to others. Even recently I saw a group of nurses being interviewed for a position. As a matter of fact, I sat on the panel that did the interviews. This one particular girl that did very well, and was recommended further on to me. . with the hiring authority. . was not selected in the end. The reason that was given was that the people who made the final decision felt that she just wasn't the type or, I can't remember the exact word they used.

Looking at the girl's resume, the way she presented herself, the job she does now, and everything else, and the fact that the panel sent her on with one other person... the other person being not 
African American, and that second person dropped out! This girl was the only one left, and she was not given the job. It makes me think that it was related to her being an African American person. I can't see any other reasons why she was not selected for the job.

For myself, like I said, I've felt it alot from, even my job. I was on one. . . shortly before that I had come to the United States. L.P.N.'s, I understand, were allowed to be in charge on floors, before I got to that hospital. Just as I got there the rule was changed, and I think it was by joint commission or wherever it was changed at. . . an R.N. must be the charge person. Well, this particular L.P.N. had been in charge for a while on that area, and I can see her frustrations with that. She didn't mind when the other R.N.'s, who were White, were in charge. Whenever I was in charge, she had an issue with me, she had an issue with the assignment, just constantly she had problems. She didn't tell me to my face, but she told it to someone who told me, that she would never continue working there with a Black person in charge of her. She did quit. She quit the job.

I was at that hospital for two years. This happened about six months after I got there. She quit. I left after two years, and she came back! She had been checking with friends and what-not. She heard that I had left, and she came back. Coming back, she was still an L.P.N. She was still going to work under R.N.'s. As long as I wasn't there she was fine with that. To me, that stood out. That was one of the things I remember. 
Then, when I got to the hospital where I work now, say in the Intensive Care Unit, which seemed then, and rumor had it that that was an exclusive. . . not for African-American nurses. That was the undertone. I went in and I was the only one there. . the only African-American nurse $\ldots$ in that unit at the time.

There was a girl that was there before me, and she had lasted about a year, and then she left. She was an excellent nurse. After I was there, maybe a month or two, I heard that this person was coming back. Everybody was saying, "This nurse is coming back!" They were excited about her coming back. I didn't know that she was African American, or whatever. Then she came. We got to be friends, and she helped me. We worked together, and then she told me why she had left, that it was so hard for her because she was the only one there... the only African-American nurse.

She gave me this little story that I've always remembered. She was working with this other girl who was White, but they started together. They were the new ones there. When the other senior nurses gave her such a hard time. . . everything she did, they just felt it wasn't done right, wasn't done well enough. She had to constantly be on her toes ... just going and going. She confided in this other girl, because she felt that since they started together. . . even though the other girl was White and she was Black. . she felt that there was something in common, because they started together. She told her, "You know, I feel so badly about being here. Everybody is just being 
so hard on me." She said that the other girl said to her, "Well, why don't you go out and work on the floors. There are alot of your peers out there, and maybe you would be happy." She said that that was what made her stay for the year that she stayed. She said that she had to go out and get books. She had to do extra reading. She had to ask questions. She had to call some of the doctors aside to have them explain things to her. She said she felt like she was back in school. She made a concerted effort to survive, because she didn't want them to get the upper hand by her leaving.

She eventually left, after she had really made her name in that unit. That's why, when I heard of her coming back, I didn't hear anything negative. I remember the head nurse came to me and told me, "Oh this girl's coming. She used to be here. She's the best nurse we ever had, and we're so happy that she's coming back." Because of her, I think my experience was not as it could have been. I did feel some pressures coming from certain angles, but she had kind of already blazed the trail for me.

I have another side to being an African-American nurse that. . . I don't know if anybody else would feel that way. I feel that I get alot of pressures from African-American nurses, too.

Interviewer: Okay. You're talking about reverse racism?

Participant: Right!

Interviewer: Okay, okay. 
Participant: I feel that because I personally have done very well. . getting along with both sides. I get along well with the White nurses, Hispanic nurses, and the Black nurses.

I think it's mainly just my personality. There are African- American nurses who don't like that. They'll say. . . if you get a promotion or somebody likes you. . . it's because they think you carry news. I mean, I've never been accused of that. There's this undertone, "Well, why do they like you?" that I find even more painful, because it's coming from my own people.

I remember when I was in the Intensive Care Unit. I decided I was going to apply for the Associate head nurse position. . . it was on the night shift. I said to a friend of mine that I was going to apply for the position that was available. She said, "They're not going to give it to you." I said, "Why?" She said, "Because you're Black!" This was my Black friend. She said, "They're not going to give it to you because they don't want Black people in that unit anyway." This is the same unit I had been talking about, where that other girl had come back. She said, "There's hardly ever been any Black nurses in there. They don't treat them well, and the few that go in there end up leaving...," which she was right in a way. But I felt I could do it, and I was going to try.

So I applied for the job. I didn't listen to her, and I got the job. I thought that would show her at least, maybe, things were changing. It can be different if you face it and deal with it. What she 
said to me after I got the job. . . she said, "Oh, it's just because it's the night shift. They could keep you there in the dark and nobody will know that they have a Black associate in their unit." That made me feel less of a person. My abilities allowed me to get a position, and that was how my friend responded. It turned out that after about a year on the night shift, I became the day associate. Then she didn't say anything. I guess by then. . . that was one of the comments, "Well, I guess they like you." That was what she said.

Those are the main issues. I don't remember much about issues coming from doctors. To me, pretty much, they treat all nurses. . . kind of in general. They're not in our. . say, they don't evaluate you or decide which shift you work. They're kind of. . I don't remember getting any strong feelings or issues. It's usually from other nurses. I've also had some from patients. I have had, as you know. . . most of my nursing experience has been in Pediatrics. All of it, really. I've had parents say that they don't want a Black nurse taking care of their children.

I remember. . . the same place at the hospital. . . where the L.P.N.'s wanted to work with me. This was kind of rural Florida, it wasn't in Miami. I think there was much more prejudice in the people, because they weren't exposed to as many Black people in positions of authority. The few Black people that worked at that hospital. . .not a few, a lot. . . they mostly worked in housekeeping, or as nursing assistants. There were a few, maybe three Black L.P.N.'s. 
There was one other Black R.N., and she was from Barbados, and myself. . . from Jamaica. They weren't accustomed to that.

I remember a mother saying that she didn't want me to take care of the baby, because her child was not used to seeing Black people, and would be scared by me taking care of her. I just excused myself and got somebody else to do it. I went through that.

Again another patient, where the mother said. . . this was when I was the associate on the night shift. By then there were some other Black nurses in the unit. The mother had complained every time, and most of the Black nurses were on the night shift. The mother always had a complaint that the night shift wasn't doing right by her son. . . and the night shift was this. . . and the night shift was that. We couldn't figure out why. She said that everybody on days were fine. It was just the night shift.

The head nurse said she wanted me to meet with this mother, because she told her [the mother] that she was going to have the night associate sit with her. I had never met the woman, because the few nights she was there, I was off. So she didn't know I was Black.

When we had the meeting set up, she came into the office, and I gave her a seat. She didn't know what. . she couldn't say much. She just kept saying that her son was getting really agitated. Every time I would ask, "What specifically would make him agitated? What could we do? Is there something he likes. . . a toy, a game, music, or could she bring his favorite tape?" Whatever I said to her, because 
the little boy. . . he was an adolescent, as a matter of fact. . he was a quadriplegic. She said, "No, no, no, no, no." And finally she said, "You know what it is. My son has a very healthy prejudice. He is not accustomed to being around so many Black people. I think that's what's giving him a hard time on the night shift."

We couldn't help her very much with it. We couldn't ask the nurses to change their shift. Nor we couldn't lay them off or fire them, or put them on vacation, until her son was gone. I had to explain to her that the nurses that were here were qualified, welltrained, and were doing all they could to help her son.

Interviewer: How did the head nurse handle this situation?

Participant: I think she kind of avoided it. She never sat in the meeting when I met with the woman. I think that she just wanted to avoid the whole issue. She knew that that was the problem. After I told her. . . she even surmised that that was the problem before the woman actually said it. She never really dealt with it. She never said anything to the mother. She didn't make the nurses feel bad either. She just kind of avoided the whole thing.

I worked for a while as the Nurse Recruiter. I had a similar experience with the nurses that we recruited. There was a Personnel Specialist who was recruiting for a particular area of the hospital. She was not a nurse, but she was very well-learned in her ... she had her degree in human resources. She was a Personnel Specialist, and was the one who trained most of us when we got 
there, because she was there the longest. So she recruited for this particular area.

There were two head nurses, in particular. . . who were White . . . who just gave her a hard time. They just kept. . . they felt she never sent them the right candidates, she never screened the applicants well enough, she never. . . I mean, everything. This girl was knowledgeable...

\section{Interviewer: Was she Black?}

Participant: She was Black, but she wasn't a nurse. They kept this up. .. they kept it going for months. And then the supervisor... Our supervisor was White, and she knew that that was their issue. She felt that that was their issue. She would ask them, "What is it that this girl is not doing for you? What is it that you need in a recruiter, that she is not able to satisfy?" They said, "Well, she is not a nurse." They were smart enough to pick on the one thing that was true. . she's not a nurse. They felt that she didn't know nursing issues. . that she didn't know nursing concerns. So the Supervisor said, "Okay, I'm going to try to find you someone who is a nurse." Unfortunately, I was always the one that they would use in this kind of situation. She asked me to take over that area. The head nurses did not know that she was going to send another Black person. She was going to send them a nurse. That's what they wanted, and I'm a nurse. 
So she sent me. I got to the meeting. She went with me to introduce their new recruiter to them. Their faces dropped. They looked and asked, "Where do you work? Where did you work before?" They asked all sorts of questions. I was their recruiter. . they got a nurse. I started, but my supervisor didn't discuss this with me. She didn't say, "Well, I'm going to take you because they don't want a Black person, and you're Black." She never said anything like that. She just said, "Youknow, they're having a hard time with this other person, and I want you to try to handle it."

After I was there for a few months, the same issues started coming up again. Then my supervisor sat down and we talked about it. She said, "I really felt that this was the issue, but I wanted to see for myself. . . if it really was. That's why I asked you to do it, because you met what they were looking for. They asked for a nurse, and you're a nurse. However, I knew that you really didn't meet what they were looking for. I wanted them to play their own game out." That's how we dealt with it. I eventually left that area, so I don't know who they got as their recruiter afterwards.

Those are the kind of things that I've faced. I guess it wouldn't be fair to talk about all of these things, which sound kind of negative, without talking about things that I believe have been positive, and that I have experienced. I have had wonderful relationships with White people. . I I would say with Caucasians, primarily because they are in the majority, especially in nursing. 
As I've said before, I've been able to get along well with just about any race of people. However, I've had head nurses or directors who have looked out for me when they didn't have to. . to make sure that I had good experiences. They knew what my abilities were, and looked at this job I'm going to be doing soon. The Director of Nursing came to me and said, "We have this position becoming available, and I felt that you were the most qualified for this. I don't know if you are interested in it, but I would like for you to take a look at it for me." I think that that was very nice. There's seven or eight hundred R.N.'s or more at this hospital, and other people with experience and of her color. If that were the only issue, then I'm sure she could have found somebody else. However, she thought about me in terms of my abilities.

I had a number of experiences like that. I had a Director of Nursing who was just so wonderful. She always gave me credit for what I did, gave me praises, helped me when I had difficulties with... I remember one time I was acting as head nurse. There was a medical director who was very rude to me. I don't think it was related to my color. He just had a very bad attitude with everybody. This Director of Nursing stood up for me to him. That is something they don't do very often. I've felt that I haven't had that many bad experiences, in terms of the fact that I'm AfricanAmerican or Black. Except for those incidences that I related before, it has not really bothered me that much. 
Interviewer: You did your M.S.N. in the United States. Have you had an instances of racism as a nursing student?

Participant: One I can think of. It didn't start out. . . that I thought it was anything racist. What happened was that one of my professors, which is a Ph.D.-prepared person, gave us an assignment. We were working in a group. We had around three or four different components to make up our final grade. I remember that we had one midterm test, a final test, one paper, and then one group project. There were four things. I didn't get a very good grade on the midterm. I think I had a very low 'B.' My paper was good... I had an 'A.' The group project was lousy!

It wasn't necessarily me, but as a group you get the score that the group makes. Some of the people were not prepared. We couldn't get together to meet and discuss the stuff. When we got up there, it just bombed. . . it was like a 'C.' I'm like a 'B' now. . a a 'C,' a 'B,'an 'A', and it was a low 'B,' so I'm a 'B,' but a low 'B.' I went to the professor and said, "I'm very concerned." At that point, I think I was a straight ' $A$ ' student. . . I never had $a$ ' $B$ ' in any class before that.

I said to her, "Before we get to the finals, I want you to know that I'm very concerned about my grade. I don't think I'm doing as well as I could do. I had some personal things that happened during the time of the midterm and I didn't do well. Is there anything I can do to bring my grade up? Can you suggest anything?" She said to 
me, "Why are you so worried? You're doing fine! Your grade is alright." I said to her, "Are you sure, because we only have one other thing." It's not like you have ten different exams that you can use to bring up your average. I said, "We have one other thing, and I don't even feel very good about it." To be honest with you, I don't even think she gave clear instructions in her class.

It was a struggle, but I wasn't going to get into that with her. I said, "If you don't mind, I think we can get the group together again and redo our project, or whatever you think would be important. . . maybe if we could write another paper. . the four of us that were in that group. I'm willing to do whatever you say. I don't want to wait untilthe end to come to you, because I'm very concerned." She, again... At one point, it was at the end of class and some other students were waiting to talk with her. They could overhear the conversation. She said, "No, it's fine. You're doing fine. You're going to do well. You're not going to fail this class."

I said, "Alright." I guessed she knew something that I didn't know. It turned out that when I took the final, I didn't do well on it either. I ended up with her giving me a ' $C$.' You know that $a$ ' $C$ ' is not good enough in a masters program, so I was very, very upset. I went to her. . . I didn't go in anger or anything. . . and I said to her, "Can I talk with you?" And she went right away, "You have to make an appointment." 
I made the appointment, and I went. I was waiting. . . I walked up to her office door, and it was open. My appointment was around 4 p.m., I don't remember the exact time. I got there about 5 minutes before my appointment, and there was someone in the office with her. . . another student. The door was open. As I walked up to it, I saw the other student, and they were in a conversation. I stepped away from the door. When she looked up she saw me, the other person looked up and saw me. She kept on talking and talking with this person.

I waited and waited. . . then I went down to the office and asked the secretary, "Did you make the... did you tell her about the appointment?" I had to make it through her secretary. She said, "Yes, she has it in her book." I said, "Now it's ten minutes after, and I'm waiting." She asked, "Is there someone in there with her?" I said, "Yes." "Oh, she'll be out soon then." This time I had to walk past the door. So I had walked past the door two or three times. I stood up out there and waited and waited. Four-thirty ... this is now one-half hour after my appointment. She was still with this other person. She finally, around 4:35 p.m. or so, she let the other person go. By this time I'm getting a bit upset.

I went into her office. I said, "Good afternoon." I told her what my name was. She said, "Yes..." I said, "Were you aware that we had an appointment at 4:00?" She said, "Yes." I said, "Did you see that I was standing at the door." She said, "Yes." I said, "It's 
now 4:35." She goes, "Well, what do you need." I said, "Well, first of all I need to talk with you about my grade. I'm also concerned about how. . . what happened here right now." She said, "Well you know, I have a meeting with the dean at 5:00, so you had better talk quickly because I'm going to leave at 5:00. I said, "Excuse me? This is not good enough!"

She had not offered me a seat, and I asked her, "May I sit?" She said, "Yes." So I sat and she sat. I said, "This is not right! I have an appointment with you, which you said I should make, which took me almost two weeks to get to meet with you. This is how you're going to behave?" She said, "Well, what is it about your grade?"

So I started and told her, "Remember when I came to you during class, that I was very concerned? Remember how you assured me that there was nothing to be concerned about." She said to me, "Do you know what? I know you people are not concerned about your grades anyway." That was it! Right then. . I don't know what she meant by 'you people,' but I figured what she meant was Black people. That's what I thought she meant.

I allowed her to tell me what she meant. I said, "What do you mean by 'you people'? What group did you just put me in?" She wouldn't answer. I said, "I want you to tell me, because it's not a group of dumb people. I have a 4.0 grade point average. I've never failed a class. I've never gotten anything under an 'A.' 'You people' is obviously... if you had looked through my files... is not referring 
to a group of people that does not have any sense, or does not know how to do school work.

Secondly, I come to school because I want to come to school. My parents are both dead. If they were alive, they couldn't force me to come ... I'm grown. my husband doesn't even want me to come, because it takes me away from home. It takes me away from my children. . . they don't want me to be in school. So do you know the reason I come to school? Because I want to come to school! Do you think I would want to leave from work, then come here and spend three or four hours in the evenings because I wasn't concerned about my grade? You need to apologize! You need to find a way to get my grade changed, or I'm going to the Dean!"

She then told me that I needed to give her time, because she couldn't do for me what she couldn't do for others. There were other people in the class with 'C's. If she was going to change mine, she would have to change theirs. I said, "I don't care. I don't care about the others, because they're not the ones here talking to you." I told her that she was rude, and I waited. She said that she needed to take it up with the Dean. I said, "Well, I'll give you a week, and after that week I'm going to take it up with the Dean."

She called me at the end of the week and said, "Well, you can come in and take a test. If you do well with that, we will change your grade. . but not to an 'A'!" I said, "That's fine. I didn't expect an 'A.' So I went in, took the test, and got the 'B.' That was probably the 
one experience I had as a student that made me think it was all about my color and not about me.

Interviewer: Are there any other experiences you can think of? Is there anything you would like to elaborate on?

Participant: No. I think I've said all that was on my mind.

Interviewer: Instances of racism. . . have they affected your selfesteem?

Participant: No! Definitely not. Even the last incident I just mentioned, for some reason. . . I don't know whether it's because of my upbringing. . . because I wasn't raised with racism. It wasn't ingrained in me as an issue. I was born and raised in Jamaica. I came to the United States when I was 23 years old, so I was already grown. Even though there were types of prejudices in our country, it wasn't related to our color. It was more about people who were more educated, or people who were more wealthy. They had their classes. . . there were poor people and then there were people who weren't as educated, but nothing related to color. . . because there's alot of intermarriages.

In Jamaica, the motto for our country says, "Out of many, one people." There's hardly any pure race there because of that. Because of that, there wasn't so much. I think that that is what has helped me. When I came here, and was faced with the. . it was startling, but it didn't affect my self-esteem. My self-esteem was already developed outside of it. I stood up for myself. I wouldn't allow it. . I 
wasn't rude, but I never took it as if that's what I deserved, or that's my lot. It was not a normal thing to happen, and I would not just sit back and let it happen. It didn't bother my self-esteem at all! 


\section{Participant \#8}

Interviewer: What is it like to be an African-American nurse?

Participant: It's a big change. The experiences I have had ... I don't think I would advise anyone, or even influence my child to be a nurse. I was living in Chicago for twenty years. After graduating from [ ? ] College, I started at County Hospital. I had been working there for about eight years. The floor I worked on was a general med.-surg. floor. Another girl and I were the only Blacks. She was a Black American, and I was a foreigner. Most of the floors had Philipinos.

One thing I did not like was that the nurse who was suppose to be in charge. . we know that being a charge nurse, you can't pick up too much of a heavy load. . well that slipped by. Other Philipinos ... it just seemed like she made the assignments for her friends, they were her friends. The floor had alot of AIDS patients. I was seeing that most of the time I would be assigned these AIDS patients, especially the real bad ones. I was getting angry because every time these AIDS patients came in, I'd have to be assigned to them. They didn't say anything, and I continued working with it.

Another time, we had this patient come in. . she was a frequent visitor. I always noticed that I ended up with that patient. 
She was very obese. I think she had been in a car accident and both legs were amputated. They didn't want to do patient care on this woman at all. It was very gross. I think she had to have surgery, and they would never help me wash that woman. It was just like a punishment! I just couldn't take it. I don't remember exactly what happened, but I went to the head nurse and I spoke to her about it. Apparently she was Philipino, too. Nothing came out of it.

Another incident happened where I said, "I'm not going to do that patient!" I did say that! Apparently, they got offended, and wrote it up. They told me that $I$ had to meet in the Personnel Office. I did go, and I did prepare myself. . . from all that went on the floor .. from giving me the AIDS patients to not giving me any help. All of this was communicated to this higher person. I did get two days off. I thought I was being punished, but at least it wasn't anything severe! I didn't get fired. It didn't matter because I did overtime, so I didn't lose anything. Everything died down.

After all this, I applied for another position and began working with O.B. patients. That was much better. There were alot of Philipinos, too, but they were more understanding. We worked together more than on the other floor. After a while I left and came to Miami.

I came to work in Miami in 1992. I was assigned to work on 9 $A B$. Nine $A B$ was another nightmare! It was a geriatric floor, and I think I was the only Black nurse. The other nurses were 
Puerto Ricans. I had to go through orientation, of course. At this hospital, they had to go through the policies and procedures. You couldn't do anything, because you had to wait a month before you cleared. Then you had to pass medicine. That hospital reminded me of being in nursing school where the instructor had to be there. You couldn't do anything without the instructor.

I hung on, and saw that my month was up. . three months. . . four months. . . I'm still on the floor doing patient care. I was thinking, "What's going on? I mean, I came from Chicago, I'm passing medicine and hanging I.V.'s. . . doing codes and patient care work. I don't understand?" "Well. .."

The thing is, I would go to work everyday. What was in my favor was that I went to work everyday. I did what they told me to do. One day I said, "No, I was not going to take this any longer!" I was a qualified R.N. Those Puerto Ricans, they didn't have United States boards, and they were passing medicine. I know I was more qualified than them.

I went to the Nurse Manager and spoke to her. I said, "Look, I'm going to resign, because I'm on the floor doing patient care. When I was in Chicago we did team work, we did primary nursing care. We just divided the patients, and said, 'Well, you have six patients. You take care of the six patients. You give them the medications, p.m. care, and follow your doctor's orders.' Why can't 
it be like this on this floor? I feel like I'm being put down, and I'm going to leave!"

She took it into consideration. Things were moving slowly. First, they had me passing medication, which was fine. Afterwards I was advanced to doing I.V.'s. Eventually, things started working out. Then things started going down again. So I said, "No, I won't take this!" What I did was apply for another floor.

I got it because I think the thing they were looking at the most was my attendance. I think what really got me through was my attendance. . . coming to work everyday, in spite of all these downfalls, and my willingness to keep on going. I got the transfer and went to another floor. . . working with AIDS. It seems to be okay.

We had a Black head nurse. I was new to her. I was interviewed before, and everything. On my first day I was supposed to work with another nurse that was more familiar with the floor. Apparently, that nurse didn't come up so I went out and did my best! I did my very best, and she was pleased. From there on they watch you. . you take orders, you do what you're supposed to do, and everything that head nurse asked me to do, I did it!

Everything was in the swing. Then that head nurse went away and we had this White lady come in. We had alot of White nurses on the morning shift. At that time, I applied to be on the evening shift, and I did get the okay to be on the evening shift. I noticed that most 
of the time the White girls came in and didn't do anything. Most of them still had the doctor's orders there from 8 o'clock. When I came in I had to take it off. I'd call her attention to it, but nothing was done. She just went on like she didn't hear.

So, one day we said to her that. . I don't know exactly what happened, but it seemed like she was picking on the evening shift. We said to her, "You know, you're always picking on the evening shift. In the mornings the doctors write the orders. What happens to these nurses in the morning?" She said, "They are busy." We said, "Busy? But doctors' orders are important! This is part of the nursing. . . pick up doctors' orders!" She actually didn't say anything.

The morning people had been getting away with alot of things. There was a time when one of the patients, a man, was supposed to get a blood transfusion. At 8 a.m. the doctor wrote the order. When I

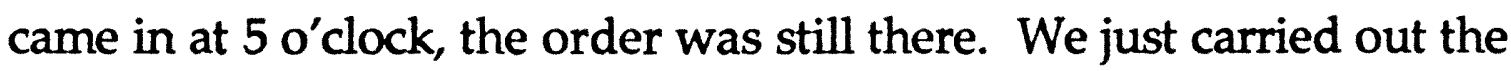
orders, because we saw that nothing was going to be done.

I think these instances stand out so much because of our color. They see that we are Black nurses, like we're supposed to get the pressure from the floor. The White nurses, they were just getting all the glory for the day, walking up and down, nothing done, nothing said. Every time there was something wrong, they would always blame us. Even the night shift.

Let me tell you something about the night shift. The night shift ... they are geared, because in the evenings there are mostly Blacks. 
The night shifts are mostly geared to write up the evening shifts. It seems that the bulk of the work is mainly on the evening shift, where all the Blacks are. In the mornings, patients are to go for their x-rays and whatever tests. . nothing done! In the evening we don't have nurses' aides and such. We have to bust our tails going for stretchers, getting patients down for surgery. All the activities went into writing doctors' orders. It seemed like in the morning there was a pause. There were no doctors' orders written at all in the morning.

In the evening. . . and the doctors, now, they are something else! They've been dogging us. I mean, they've been really making things rough for us, because it just seems like since we're Black, we're to be treated like that. They come and order us in a way that is just not right! This hand maid business is over with!

The other hospital that I worked in before. . take for instance, when I was in Chicago, Cook County. When the doctors came in they were oriented to the floor. They knew where each piece of equipment was. I've noticed that the doctors here, I mean, they never orient them to the floor. They come in, the nurse is doing her work, and they have to call you to come and do this or do that. Sometimes we get really distracted. We get distracted to a point that we're taken off on order. Then the doctor calls us, we forget everything, and then we get written up! 
Interviewer: Do you think that, could you think of any specific instances where you have experienced racism among your peers. . . your coworkers?

Participant: Yes. We had a Black patient. There was a White nurse. . . we had a Black patient, and he was a total care. $\mathrm{He}$ couldn't help himself, and I think the man laid in bed. . . when we came on in the evening to make rounds, the man was in the filth from morning. You could tell because that mess was hard on him. . real, real hard. I've seen it. I've seen these Puerto Ricans... I've seen it.

There was a man, a Black man, I mean, I felt sorry for that man. The man was supposed to be turned every two hours. When they did turn the man, they just pushed him over. The man was so ill treated. . . I mean, real bad! They didn't turn the man. The sore. . I mean, you could see his bone. The skin was so broken down that the bone stuck out. Some of these Black patients who were to be fed breakfast in the morning, most of them were diabetic. They got their insulin shot, but nobody was there to feed them.

Interviewer: Yes. I think we see alot of that happening, but do you think that reflects on working together as nurses? Do you think there's a difference between the White nurse and the Black nurse working together?

Participant: Yes. There is a big difference! The White nurses, the ones I've seen so far, they work together. They communicate together, and they will work together. The Blacks, I don't know 
what's wrong with these Black nurses. We are together and it's just like... for instance, our head nurse now. This nurse always does alot of transcribing with our orders. She writes her name on the order but never transcribes it to the M.A.R. We are friends. She went on another shift, but we are still friends. I said one day, "I wonder what Debbie's doing?" My other colleague said, "Debbie's signing her name and they're taking off these orders!" When we went up to the M.A. R., there was nothing there. . . there was just a blank. "Why don't you just leave it alone."

So she's been doing this a couple of times, and we haven't said anything to her. It happened that one day the doctor wrote an order. I saw the order. I did not transcribe it wrong. I had something else on my mind, so I put it down, but I crossed it off. However, I don't remember what I did with the sheet. . . the paper was tossed, and I probably must have thrown the wrong sheets in. She showed it to the head nurse. Well, of course, I was written up for that.

We were always covering for Debbie. We tried to cover for the Blacks, but some of them don't care how you try to work with them. They always turn against. We try working as a team, and then one will branch off, "I'm not working with her. She'll think I'm here to do her work!" I just have a feeling, especially when I'm in charge, that it feels like I'm the one they're working with.

You know what you're there for. You know you're there to take care of the patients and make sure everything goes right. But it 
seems like every time $I^{\prime} m$ in charge, and I give them their instructions. . . they rebel! They don't want to do it. . . they leave early. When a White nurse sets their duties for the day, they shut up! They go outside and quarrel, but they still do the work. When a Black does it, "I ain't doin' nothin'!" And then they leave early. Apparently, to get the work done, you need to pitch in and do the work, too!

Interviewer: That's called reverse racism. You find that alot?

Participant: You do find that alot, especially where I'm working ... there's alot, especially with Black Americans. You know me. . I love myself and I love people. I think we're there in the hospital. . . our main interest is to get this patient well, teaching, and to get us up and to be better. But it just doesn't seem that way at all.

Interviewer: The instances of racism that you have experienced, or have seen others experience, do you think that they have affected your self-esteem?

Participant: No, it hasn't. I know better. It hasn't really affected me as such. They have done alot of things to me while working on the floor, and I prayed. What really had me going was praying. As I said, while I was working out there on the floor and they only wanted me to do patient care, I could have rebelled and said, "Hell with this! I'm getting out of here and won't be coming back!" But I didn't! 
I went along with the program. I prayed and I got stronger. I was there, but when they had their little gatherings and stuff like that. . I remember, I wasn't there! When it came to doing the patients or telling them about the patients, that's fine! I'll do that. However, when it came to their little gatherings, I wasn't in it, because I know that they were just hypocrites!

Interviewer: Was there socialization, for instance, would the Black nurses socialize together and the White nurses ... have you seen that?

Participant: Yes, they talk with each other, and when it came down to patient care, a White nurse would say, "I'm not doing it, I'm White! I'm not doing that! She can do that. She can clean up his mess!"

Interviewer: Do you have any other instances you would like to talk about?

Participant: Concerning promotions... Where I work, it seems like, well, they have their requirements. If you have your B.S.N., you're okay. But say, for example, you have a White nurse and a Black nurse, and the position is there. They prefer to give the White nurse the position. . .although she doesn't have a B.S.N. . . over the Black. You have to be more than qualified. Sometimes even with your qualifications you're just not going to get it. . . because you're Black! 


\section{Participant \#9}

Interviewer: What is it like to be an African-American nurse?

Participant: Working as an African-American nurse, or working. .. or living in the United States as an African-American nurse? What do you mean by that question?

Interviewer: I just want you to talk to me about what it is like working as an African-American nurse.

Participant: Within the American society?

Interviewer: Yes.

Participant: It's very much like living as an African-American. Period. It is very difficult. It is very trying. It is very biased. It is a very hostile environment most of the times. It is a very demanding type of role that you have to play. . . sometimes submissive, sometimes passive, when you really don't want to be. It is kind of difficult, but such is life in America. . . also, as an African-American person.

Interviewer: Could you tell me of some experiences that you have had. . . any experiences of racism. . . as an African-American nurse?

Participant: Oh, without a doubt! From doctors. . . when it comes to pay scales, when it comes to contract negotiations, when it 
comes to positions, when it comes... really when it comes to just the type of person...

I'll even go back to the basic nursing, when it comes with the type of patients that you're assigned, as opposed to your counterpart of an Anglo heritage, or even of a Jewish heritage, or an Hispanic heritage. As long as the skin is light and the hair is straight, there is going to be a difference there. Depending on who is in charge of. . in a position of authority, in such a position that it may involve you as being the subservient one to that person.

Interviewer: Could you tell you tell me of specific instances of racism that you have experienced as an African-American nurse?

Participant: Yes. You get the indigent type of patients, mostly those who cannot pay. . . those who may be homeless. Not to say that the others don't, but you just seem to get them more often, because people have a tendency to assume, if they're Black or what have you. . . not to say that all the indigents are Black. . . but if the indigent happens to be a Black person who may be homeless, who may have a hostile attitude, they will not deal with it and assume that it is your responsibility. . . because the person looks like you, therefore, you should deal with that. That has happened to me on several occasions.

Even at some of the meetings that I go to on this level as a Practitioner. I go to a lot of seminars we have. More than a few times I've found myself as the only person of color sitting in these 
meetings, and it makes for a very difficult time. Sometimes you just want to be identified with your own culture, but because you don't have representation other than yourself there, who do you identify with, other than yourself? You can't have a conversation with yourself, not without people looking at you like you're crazy.

Interviewer: Did you work in the hospital?

Participant: Yes.

Interviewer: Did you experience any instances of racism in the hospital?

Participant: $\quad$ Oh yes... yes...

Interviewer: Could you tell me of any specific instances?

Participant: $\quad$ Back when I did I.C.U., patients that were maybe a step from coding. . . you walk in there and may have at least three of those patients. . which is really considered high-risk patients. You should not have those type patients, but to make your counterpart's or your coworker's day a little bit easier, she may have someone who is able. They may be in the I.C.U., but they're able to sit up in bed and care for themselves and have family members around.

I've been in situations where my coworkers have had maybe two of those. . three of those types of patients. To justify this, "Well, she has three, so therefore we'll only give you two." My two were totally comatose, maybe incubated. . obviously on a monitor, can't do anything for themselves, just all around high risk, and resusitate ... not even, 'do not resusitate.' 
It makes your eight-hour block of that day a very, very trying day for you. I found that to be a problem, though I did like working in the unit, but you always get the worst patients. No matter how you. . . they thought you performed well, "Oh, you work better with these people. ..," "Oh, you're such a good nurse..." That's a bunch of crap! I knew that. But that's to patronize you so you would go ahead and say, "Oh, okay, I work well with these patients; therefore, you just give me the harder ones. I appreciate a day's work. . .a hard earned. . . to earn my hard earned money, just by putting my back into the work."

You look around and your coworker, who happens to look different from you. . . she's able to complete her notes and have thirty minutes before the day ends. You're still not able to get done the first note! Yes. . . yes, I've had alot of those. . . alot of those!

Interviewer: You've had instances of racism. . . promotion-wise? Participant: Strictly in nursing, you say?

Interviewer: ...In nursing. . . as a nurse, as an African-American nurse. It doesn't have to be in nursing.

Participant: But you see, I worked outside of nursing, also.

Interviewer: That's right. . . well, as a Practitioner...

Participant: Yes. . you don't seem to get. . I did home health nursing. Certain nurses were able to choose. . I mean, this was before the assignments made it to the general area. They were able to choose what area or what type of patient or what type of care 
they wanted to be involved in. It may be like, just strictly I.V. med, which were paid more money. The hep locks would have you with the flushing, or whatever. . something that was, obviously, not much of a task, but paid more money. Before it ever made it to the assignment board, that job was taken up. You would find out around two months later through a slip of the tongue, or whatever...

When my assignment came about, I gave them a geographical area as to where I would work. Well, of course, I couldn't get any work in that area because, supposedly, I was told there was no work in that area. All my counterparts were getting new cases, that I knew didn't exist in that area prior to me coming there. I had to go all the way down south. I had to go between the north, out far west, Miami Beach. . . everything but the central location I wanted to work in. I just got fed up with it. . putting wear and tear on my car, and then going down to the boonies because no one else wanted to go down there...

Interviewer: You felt that you were being sent into those neighborhoods because of the color of your skin?

Participant: Oh, without a doubt!

Interviewer: As an African-American nurse, do you think that instances of racism. . . do you think that they have affected your selfesteem?

Participant: Without a doubt. I look at life, the situations. . they either make you or they break you. I'm not saying that with 
every incident of racism, because some people are just conditioned to be so, and are totally unaware of their actions. That's not an excuse for their actions, but others really have a purpose behind their action.

I can remember an incident in nursing school. I was a semester from graduating and, for whatever reason, this lady, my instructor, did not like anything about me. . . my looks, my eyes, the color of my hair. . there was nothing, nothing that I could do to satisfy her. She said to me, privately of course because this was for my ears only, "Well, why don't you just go ahead and be an L.P.N. If you can't take the L.P.N. boards in time, then just go ahead and take your Nurse's Aide certificate." I was a semester from graduating with my R.N. certificate, and this is what she says to me!

Now, as a weak individual, I could have said, "Yes, you're right. Wow, I'm so lucky to have you in my life! . . . to see my shortcomings. . . to see my weaknesses, and to have someone guide me in the right direction." To see what she. .. what I didn't give up, and see what I have today, on the Masters level. . . if I had been of a weaker character.

I remember, at the same time that happened. . . I think it was the only thing that really saved me in school. I obviously said something that was not proper as a student, because it was from her mouth to my ears, and therefore made it back from my mouth to her ears, saying, "Well, when you sit for your L.P.N. boards, I'll sit for mine!" 
We had a group of Anglo students that we had to do this thing called data base. I don't know if you remember data bases back in your undergraduate days. A data base consisted of around a 25-page report over some type of patient you had. . . everything, from beginning to end. This was due every four weeks or so. . one a month. We students were involved in this. It was found out that some had plagiarized about 20 data bases, between 5 of them. This should have been an automatic dismissal from school.

Well, the school I was in at that time all at once began to receive these donations. The donations happened to come from the parents of these students. Everyone in the school was waiting to hear the announcement that these students were terminated, because everyone knew that they had done it. Everyone, I mean from the sophomores, whoever, knew that this had happened. Needless to say, nothing ever happened. They graduated and they're working as a nurse just like me!

Now, ---.--, you can say what you want to, but I don't care how much money my family would have given, I wouldn't have lasted at that school. As a matter of fact, I don't think my family would have even been able to have offered the money, because they wouldn't have given me that chance. They would not have given me that chance. There is a difference. It is hard for someone who has never had the experience. It's like a surfer, who tells me, "Oh you 
just have to. . oh, the rush! Can't you just see the rush of the waves and get the feeling?"

No, I can't, because that's not my world. . . surfing, skiing, or whatever. I identify racism to whatever gives you your thrill. I'm not saying that racism gives me my thrill, but until you have been victimized by it, you cannot understand. You can sympathize with it, but you can't empathize with me.

You don't know how it is to walk into the store, or to walk into the nursing meeting and feel the tension. When they tell you, "Oh, that's really all in your head. Everyone loves you here!" No, everyone does not love me here, because everyone among my own doesn't love me, so why should I think that everyone who's not among my own loves me! When I can feel tension in the room, and the only reason that there's tension in the room is because I'm a person of color, I know that! I felt it enough to know when it was my color that was bothering someone. I know that.

As a matter of fact, I know that when my gas light comes on in my car, I need to get gas. I know that when a car hesitates a little bit, I need to take it to a mechanic. Well, I know the feeling of when I'm not totally welcomed. I know the feeling.

I primarily feel that that is the reason for, when I'm feeling this zone of being uncomfortable for no reason. . . I know I don't have any B.O. or anything like that. When the backs are turned or when the only chair, if you happen to arrive late, is sitting in the corner, 
and they know you're showing up, or what have you. . you can sense and feel when you're not welcomed. If you can sense it among your own, God knows, I can sense it around others as well.

Elaborating on 'your own,' also, there is such a thing as reverse racism. There are nurses of color that are. . . I tell you, I don't. . . I kind of accept non-Black nurses, as you said. . you're either conditioned that way or you have a goal in mind. Your goal is for you to destroy or your conditioning says that you just don't know any better, because through generation to generation you were told not to like Black people, period. But when it comes to your own demonstrating those type of behaviors towards you, all I can. . . I really don't even try to work with them. I do not try to accommodate them. The reason is that you're so far ahead of the game of racism, as it applies to Whites, that you shouldn't even be an active participant like that. In other words, if some of the same examples I have given you, if they had come from people of color, I don't try to figure out why, or to accommodate, or to even let them know that it bothers me.

I guess you say, "Well, you do the same things with Whites." I expect that of Whites. Then you work around that, and you kind of say, "Well, if she only knew me she wouldn't do this to me, or, if he only knew me, he wouldn't treat me this way." What usually happens, if I'm in a long-term employment there, Whites who begin to know me, they may not like me, but they gain respect for me. 
Whereas, if the same treatment is being rendered from a Black nurse, male or female. . . usually females, though I've had one or two encounters from a male. . I don't ever get that level of respect from them. It's almost as if they feel they are in competition with me to gain respect of the White counterpart. I know you can understand.

It's almost like they feel. . . the Black nurse, "If I show my White coworker that I am not pleased with her either, meaning myself as another nurse of color. . . then they'll have respect for me, and like me, too." I look upon it as really so sad that they allow themselves to play into this game of racism. It's like the saying, "United we stand, divided we fall." All the White nurse has to do is. . . she can take more of a passive, submissive role. If she sees that you, as another nurse of color, has allowed whatever of this feeling to transform herself and to give reverse racism, or direct racism or biased behavior, onto another nurse of color, then that achieves her goal.

In my case, some are just goal focused. The end result is all that matters. The end result means having you to perform the act for her. It keeps her hands clean, but plays you, as the one that's projecting the behavior, as a puppet, primarily. She gives you praises and tells you how wonderful of a nurse you are, and that you're not like the others, or you're different, or you're this. When in reality, if you take those words and go, "wow, it's unbelievable, I'm not like her! That's why I can treat this Black nurse, who looks like me, or this Black nurse who speaks like me, or this Black nurse who 
lives in my neighborhood this way, because it makes me more acceptable to my White counterpart."

But what she doesn't know, I feel, is that when she goes home . . . when everyone goes home at the end of the day, she's placed in the same bucket, or the same piece of conversation by her White counterpart, as the 'other nurse.' It's so sad. When I do see that. . . and trust me on this one, I've seen it!

Interviewer: Tell me of specific instances. Can you tell me of any experiences...

Participant: Without calling names?

Interviewer: Without calling names. . yes. . tell me about ...

Participant: About two years ago, a nurse had bad-mouthed and belittled me on the job because I had been the weekend supervisor. The sad part about it, --..-., was that she only did it for non-professional reasons. It wasn't because I had poor nursing skills. It wasn't because I had lack of knowledge, or just poor professionalism. She did it for personal reasons.

There was a driven jealousy within her. Rather than her dealing with that, what happened was that when the weekend. . . when Monday rolled around, she would give a bad report to the week staff while the doctors were there. She would report how awful the weekend went, how this patient wasn't cared for properly, and how this happened. What she didn't know was that I was getting it all back. What she also didn't know was, that they knew 
that alot of the incidences that were happening were happening during the week. I was basically coming in, not as a savior, but coming in to clean up a mess that I met, for the week. If certain things could not get done, it was because I was rolled back into trying to fix what had already happened.

What had happened. . . she was the supervisor. When that game did not, I call it a game, go the way she wanted, as far as the end result that I've spoken about. . . because everyone does things for a reason or a purpose. . so when her purpose didn't carry itself out, she decided... I mean, I'm talking bad-mouthed me every incident she had, every chance she would get. They let me go, and I was in the middle of buying a home when that happened.

Another thing to add to her monument of things to have against me here. She asked, "You're buying a house? You're only here on the weekends?" But I worked during the week, also, but just at another job. Then she said, "Everything I've said before is just not happening...nothing has happened." All of these negative things, the thing that really blew it, I never knew to this day. . I I never knew what it was that she told the Director, that made them decide not to bring me back. I was there for five years, so I had a very good reputation. All I knew was that I was told not to come back.

But like I said. . . let's back up to what I said to you about a minute ago... When I see reverse racism from my own, I don't even begin to see it. I feel they're so far lost, so far beyond help, that it's 
not even worth saving that. You see, White people, or people who are not of my complexion, I figure, "Well, it's your loss. If you really got to know me, you'd really see that I'm someone worthy of you knowing." So, if they decide to make a conscious change, I will give them a chance. But, on the other half of people's color, if you decide to make a change, I'm more hesitant at giving you a chance to come back clean again. I feel. . I f feel you should have never gone outside to begin with. You understand?

I feel your experiences in life. . . as a person of color, but you can't tell me, “Oh, I've never had that problem. I've never had racism directed toward me." Don't tell me that! It may not have been as blatant or as obvious. . . and I can say that. I've gotten wiser and more experienced with it, that I'm able to say, "Ah, this is blatant racism!" But it may have been the same incident that happened six or seven years ago, that I think was in a more subtle way, and I said, "Oh, they're just like that." But no, I know now that they're just like that with a purpose in mind. That may be something that I call blatant, where somebody. . .

I have a girlfriend who lives in. . I'm sorry, her husband was in med school. They would just go ahead and give you corpses to work with, and tell you to bring life back into it. You understand what I'm saying. . . obvious situations like that. What one's definition of one word is may be totally opposite for another. So that's what I'm saying, that the people of color who treat me that 
way. . I don't even try to make it better, or to make amends with them, because I feel they never...

Interviewer: Can you think of any other instances of racism that you have experienced in your present position or past position?

Participant: Within working or from clients?

Interviewer: I want it among your peers.

Participant: $\quad$ Yes, they're a little bit standoffish. You know what I think, ------, I don't know what the stats are for nurses of color, on the graduate and doctorate level are, but I'm assuming that we are really less in numbers. I find that the higher you go, you think that people are more intelligent, who are more educated are more intelligent in their choices of the things that they do, but they're just as bad as people who are not educated. They really are. They're just more subtle in the way that they show it. You just have to play the game, also, and just become more subtle in a way that you pretend not to see it. That's basically what happens. Though I had made some friends at this level, really good friends of different nationalities, of different cultures, but. . I still see it at this level.

Interviewer: Do you have any specific things. . .?

Participant: In nursing school? Please...

Interviewer: In nursing school? Tell me about it!

Participant: I was in a different career, with nursing as my secondary career at one given time. . for a fairly decent amount of time. A professor, a Caucasian professor, said to me, when she 
found out about that other career, that, "We need good. . . whatever I was at that time. We need..." I'll use the example of teachers or mechanics. "We need good mechanics. Why don't you just stay as a good mechanic, and leave graduate school alone." The same thing they said when I was an undergraduate. "Because, I think you'll be of greater service as a mechanic to society, than as a graduate nurse on the AR\&P level, on the master's level." I remember saying to myself, "I don't believe this. Keep that resident ----!!" It's all over. It's just basically all over.

So, ----, what really happened. . . I had to almost. . . you know how, when a puppy knows it has wet the floor, when it's being potty trained and it gets a spanking? Before you see the urine or the mess it made, you see the puppy with it's tail bent between it's legs. When I found myself, having to. . . when I was in her class for that entire semester. . . I had to be the puppy. . . hold my head down and bend my tail under my leg. She asked me to show her how humble I could be, just to show her, "Gosh, Miss White Lady, I am so grateful you are here in my life. I is just a po' ole' Black girl who don't know nuttin', and here I have you to be my Savior. But in the meantime while I have you, can you just help me pass this class?" I'm serious! I am so serious.

Afterwards, you just kind of shake this shame off you, you curse under your breath, you walk out of there saying, "I hate her, I really hate her." Honestly, as an individual, she's a very nice person. . . as 
a wife, as a mother, and as a friend. . . but she never allowed herself to be that with me. You understand what I'm saying? Only because of my color. I know, as an individual, as a mother, as a wife, and as a friend, I am a nice person. So here we are. . two very nice people, who can never share nice experiences, because she has this conditioning, I call it, versus her having this goal.

I sit back and wonder, "Why are they like this?" I think 'they', as in White people. I think that they're like this because, at least on this level. . . you know when you get the letters behind your name, meaning the graduates and the doctorates, and certain types of positions. . . even though there is a discrepancy in pay. . . different levels of pay scales. . y you will still make for a very nice lifestyle. Through the process of elimination, if they can do this at an early stage to discourage you, what better way to do it then, at the start of it, than to have you go through it...

You're at the end of your thesis now. Now is not the time to bring discouragement upon you. It would have been from day one... "Well, this program is not for everyone. You ought to understand this." If you walk in on day one, first of all, you're overwhelmed, "Oh my God, Graduate School. . . what is this all about?" They come out and say, "This is not for everyone." Really, we need people at the base level where you are right now. Just stay there Black woman, we need you down there. . . while she's up there making $\$ 75,000$ a year, close to $\$ 100,000$ a year, maybe working 24 hours a 
week! And you're doing 24 hours a week on a second job, just to make ends meet. You understand what I'm saying?

It's the purpose in mind. I'm sure they want all of their people there. Not having to deal with you. . . they keep you in the subservient role. .. it's a control thing. I remember that quite vividly. You know what makes it so bad? Whenever she saw my writings, I swear to you, it almost appears before she read it. . she'd mark it up. So I said, "Forget this," but I didn't say it as nicely as that.

I went to a scholar, who happened to be an attorney who is the most eloquent speaker and writer you'd ever want to meet. I said to him. . I took a sample of a White student's page but the White didn't know that that was what I was using her paper for, and an article that the White student had. I took a copy of my paper and a copy of the article, and I said to him, "Without you knowing it. . . I taped up our names. . . whose paper is whose paper, you tell me what's what." He read both of them over and said, "Well, one is outright plagiarism. I can't judge that one because all this says is, "...nurses in our society are better off today than they were yesterday." The student wrote, "...it appears that nurses in the society seem to be better off today than they were yesterday."

He said that other than the fact that there were a few changes in the words, he couldn't evaluate it. He said, “This article has some substance to it, because it seems to be the opinion of the reader. Is that what I'm supposed to get?" I said, "Basically, yes. But that 
article, I was told, wasn't professional enough." He goes, "If it's asking for the opinion of the reader, what are you judging? The reader has an opinion, or is the reader a writer?" I rest my case.

From there on out, I explained to him that that was my article. From there on out, only for that one class. . . Let me tell you, that's how you know when it's not you. . . only for that one class. I went to my school, my Graduate School for what ... two years? Only for that one class did I ever get him in to help me write papers. . . or to proofread my papers, should I say. . . because, I'm telling you, before she saw it, the red mark would come in. Then I would sit back.

It got to the point that she was getting better. . . never good. . . getting better. I said to myself, "How dare you!" She couldn't begin to match the intellect of this individual. I'm telling you, she couldn't begin to match the intellect. He happened to be Jewish. . . I don't know if she was Jewish, no she was Anglo, White-Anglo. Here she was trying to. .. she knew she couldn't find mistakes in the paper, but it was me.

Then it got to the part. . grammar! She would go, "Well, you really should have had a semicolon here versus the comma here." That was in the beginning. If that wasn't a moment of discouragement! Then what happened, I had to end up taking an incomplete in that class, because she held my papers out, saying that ... because I tried to do makeup articles... she didn't have time to 
grade all my makeup things that she would write up or what have you. No one else in the class had that problem.

No other professor either. They may have said, here and there, what have you, stuff that they would have done for other students, but this one, I knew it was personal. I wasn't the only one. I was not the only one, but I'm relating my story. You have to realize, she told me initially, "Stay a mechanic. We need good mechanics. Don't try to improve your lifestyle. Why would you want to come on this level. Why would you want to be a greater professional than the mediocre professional that you are?" This is basically what she was saying to me. It's quite obvious.

Interviewer: Can you think of anything else?

Participant: $\quad$ No. I just think that basically we, as a people, have to start building character early in the generation that's upcoming. We cannot soften our households to make everything pleasant and wonderful, and say, "Little Jimmy, if you don't want to do the dishes tonight...," “...It's okay mommy, we'll do it." Because when little Jimmy becomes a man out in society, and he doesn't want to work a full day, it won't be okay! Only because of little Jimmy's color. Now, little Bobby could probably go home early, but little Jimmy won't be able to, because little Bobby would be an exception to it. . .it's the reasoning. So, we do know that it does exist. 


\section{Participant \#10}

Interviewer: What is it like to be an African-American nurse?

Participant: To be honest, there are some positive and some negative, or advantages and disadvantages, whichever way you want to call them. But my own personal experiences, I don't feel that I've had a lot of negative encounters, but I've had some. I feel like I've really had more positive encounters. It could be the areas that I've worked in, because when I first finished... I finished at Florida A\&M University in Tallahassee. I decided to stay there until I took my boards, and then I would spread my wings a little bit. So, I did just that.

We were an all-Black facility, and we took care of all-Black clients. There was no problem. But, after I took the Board and I passed it, I decided to go into the V.A., primarily because looking at all the job opportunities, by looking into the journals of nursing and other advertisements, it seemed to me that the Veterans' Administration was paying the most money. That was what I was sort of interested in at the time. Plus, I had had a former Head Nurse who had been a V.A. nurse. She felt that the opportunities were great. . you had a wide variety of experiences, in that you could be very mobile. If you were a good nurse, you could go to one V.A. 
hospital and ask for a transfer to another one. I thought that was interesting and sounded real nice. So I paired up with two of my classmates, and we decided to try the V.A. When I went into the V.A., I went way up, I was working in Tallahassee.

I left there, and then I went to Chicago, at the suburban area. The area was called Heinz. The hospital was called Heinz, and it was a V.A. hospital. . . very huge. They had all kinds of speciality areas. I was assigned to a neurological unit. It was very interesting. There was a mix of staff because, at that time, even though there was alot of deep-seated segregation in the South. In the North they had more integration of staff and patients. Even though there were still some discriminatory things that were going on, they weren't as blatant, it was more hidden than blatant. In the South, it was really blatant. The people were open, and they let you know just where you stood. They let you know that there was a place for Whites, they felt, and a place for Blacks. In the Northern area it wasn't that blatant, but there were some undercover-type, discriminatory things going on like there are today. It's become a little bit more blatant today, too, like it was years ago. It was very successful there. The times were nice and the staff was nice. I had a wide variety of experiences, and I really enjoyed that. I didn't really encounter any discriminatory practices, as far as employment. 
When I got married and I left there, and came back down South to work, I ended up at the V.A. in Lake City, Florida. That's where I encountered some discriminatory practices. I will tell you about two specific instances that occurred.

When I arrived I had asked for, particularly, a medical ward. I like medical much better than I do surgery--they put me on surgery. They assigned me to a surgical unit because one of the nurses there, who happened to be a little older, had fractured an ankle and had to be out for at least two or three months. . . for rehab, etc., until she assumed her duties fully.

They assigned me temporarily to this unit until she returned. I had a male head nurse, which I had never worked with before. I had worked with male nurses, but not as my immediate supervisor. The first day that I was there, he called me in and had a talk with me. He let me know that he was the Head Nurse, and what he expected out of his nurses. . . which was fine!

Then, after I had worked there for about a month, he called me in again to talk with me. He said that the one thing he wanted me to know was that he was not going to have me giving orders to his White Nursing Assistants. I politely said to him that if they were on my team, and I gave them an assignment, that I was going to have to give them orders, because he had made me responsible for the whole team of patients. I was going to have to have some authority over them to see that they did the things that they were supposed to do. I 
couldn't work there if I couldn't tell them what they were supposed to do.

I was a little more feisty when I was younger than I am today. I thought of my license, and what would happen if they did something, and he held me responsible for it, and I couldn't do it. I didn't like that! I thought that was very discriminatory and blatant racism on his part.

I didn't tell him that, but I did tell him what I previously said. Things went on and I was there for another three weeks. Then he came after me again about something one of the White nursing assistants had said, as if I had spoken to them very harshly. Now, I might have been feisty, but in that respect I am just like I am today. I treat everybody just like the way I like to be treated. I never spoke to them openly. If I had something to speak to them about, I called them aside and we did just fine. . . it was just like I would want someone to do to me!

I felt like. . I told him that this was not true. Then he asked me, "Who am I to believe?" I said, "Well, the choice is yours. I am telling the truth. Now you have to decide whether the other person is telling the truth or not!" Then I just began to feel like he was after me, even though he knew I was just there temporarily.

The more that I thought about it, the more I had hindsight. Afterwards, after I got home, and I though more about it, I thought, "Now, there's got to be somebody else that I can go to!" So then I 
just decided to go to the Supervisor and tell her what had happened. I told her what had happened, and she told me that she was sorry that it happened, but I didn't have to worry about it any longer. She was going to move me. Now, that wasn't solving the problem, but the nurse was ready to come back, so I could leave the ward.

I left the ward and went to another ward where everything was just great! The Head Nurse was wonderful! It was a mixed staff. . . mostly all of the nurses, well in fact, all the nurses were White. In fact, in this hospital, there were only two Black nurses, me and another woman.

After I was there for about six months, the lady left, and I was the only Black nurse in the whole facility. This lady was very nice to me. She recognized all my strengths, and she really pushed me right along. During the time I spent with her, she went to the Supervisor and told her that I had such good leadership abilities that she thought that they should consider me for assistant head nurse.

You had to be an assistant head nurse then before you could move up to a head hurse. All wards did not have an assistant head nurse, but some of the really large wards. . . they had assistant head nurses. Her ward was a smaller ward, because it was just a 40 -bed ward. But some wards were 60 -beds or higher. Those people had assistant head nurses. Then my Supervisor decided to send me to another ward, because they had such strong feelings toward this Nurse Manager. 
She was really an excellent evaluator of people. She was very strong and she was very straight. They wanted to get more than one Nurse Manager's opinion about my abilities. So they moved me from this really nice [ ? ] . . it broke my heart to leave my ward, but then I knew why we were doing it.

So then I answered to this other lady, who was German. . but a very nice lady. I was assigned to her ward. She gave a very thorough evaluation of me. So then they made. . her assistant head nurse left, and then they made me assistant head nurse. Then she, unfortunately, found out that she had breast cancer. So they moved her from that ward to a smaller ward, and guess who became my head nurse. . again!! The guy who had been my head nurse before. They sent him over there, and I was his assistant head nurse!

Now, it seems to me that he had changed somewhat. He wasn't after me, because by that time, maybe three years had passed. He wasn't necessarily after me. I was his assistant head nurse, plus, they made me the education person for the unit. I had to plan all the staff educational classes. New equipment that came, I had to learn about it and show the staff . . . have an in-service to show the staff how to work it. I had all the in-services for the staff education, plus the role of assistant head nurse.

This other lady had given me such a fine evaluation. I worked with him like that for six months. . . we were fine, and we didn't have any altercations. At the end of 6 months, I was given the ward above 
his, which was another 60-bed ward. It became vacant of a head nurse, and they promoted me to head nurse, and I had been an assistant head nurse. So I became head nurse up there.

So things were going along nicely, but I missed a step prior to that. Prior to me becoming assistant head nurse, I left out a step. When I became pregnant I asked to go, until the end of my term, on the evening shift because there was less activity on that big ward. So they postponed my assistant head nurse role. . . that's what they did ... until after I had my baby.

In the meantime, when I had the baby, I wanted to come back ... in the beginning. . . on the evening shift. So, they made me assistant supervisor of the evening shift for six months, until I came back to the day shift. That's when I got my head nurse job. I left out that step.

What happened when I was on the evening shift. . . here's what happened. . I had a nursing assistant. They had a room where you put the patients who required the most intensive care, which had six beds in it right next to the nurses station. That's where your sickest patients went. I had a nursing assistant who wore a leg brace. He was good with those type of patients, along with the nurse. I put him in that room and let the other nursing assistant work the outside area, with the assistance of the nurse and my self. . . and nobody ever complained. 
We had a patient who died, so we had the morgue. . . it was where you have the pull out trays. This guy with the leg. . now I didn't put him in there because of the leg brace, I really put him in that room because he was such a good worker in there. He took such good care of critically-ill patients, along with the nurse. When he went down to the morgue. . . to put the body in the morgue. . . somehow or another, even though he had help, he hurt his back. I made out the accident report and sent him down to the emergency room to see the doctor, like he was supposed to.

The very next day, they called me up to the Chief Nurse's office to say that I was to come in early. . . like $2: 30$. . before my shift started, for a meeting! I wanted to know what kind of meeting it was, but the secretary didn't know. She was just told to call and tell me to do that. When I got there to this meeting, there were all these administrative people, including the Personnel Manager, sitting up in the Chief Nurse's conference room. They had the Assistant Chief Nurse in there, the Evening Supervisor in there, who was my immediate supervisor, because I was the Charge Nurse of the evening shift.

Then they had some other people. . . I don't remember who they were. . . in there also. I know, particularly, there was the Assistant. . . oh no, there was just the Assistant Chief Nurse, the Evening Supervisor, the Personnel Officer, and myself. So, when I got there, there were those people there and I wanted to know what 
was going on. The Assistant Chief Nurse told me that they were investigating this incident that had taken place with an employee. I wanted to know why, because I had filled out all the forms. I had informed the Supervisor. I had done exactly what I was supposed to do.

The employee wrote down his own statement. . I wasn't down there with him, I don't know what happened. I wrote down what he said happened. I said that another employee had been sent with him to put in. . . but the way they were lifting the patient in there. . somehow or another, he hurt his back. Now, I could only go by what he said!

They took x-rays, and he did have a sprain or something in his back. They were asking me all these questions. I said that I really couldn't understand, because other people had hurt themselves. . . what it was all about. They were acting like I was infracting the policy by showing favoritism toward him by putting him in there. I said, "Even if I was doing that, what does it have to do with his accident?"

I felt like. . . everybody else in there was White but me, and I felt like I was on the carpet. I spoke right up for myself, because I know I had to be my own self-defense. After I had gotten through explaining what had happened, and saying that I didn't understand all this that was going on about it because of that. . it was just an accident! I couldn't understand how all this other stuff played in. 
So the Personnel Officer said that they had to really look closely into it to see if it had a factor, in relation to his accident. So I said, "Well, what kind of factor could that be? If he was out on the ward and took the body down, he could have injured his back?" I told them that I felt like, if I was the Charge Nurse, and I made out the assignment, that I was to look at the staff member's qualifications, their. . . we call them grade levels.

He was a GS-5, which means that the Nursing Assistant could do advanced procedures, like catheterizations and things of that nature. They were supposed to be able to make better decisions in caring for patients, and be able to give better care to patients. He was the only GS-5. I used that, plus I know that he gave good care to patients.

I thought that if I was responsible for the patient, then it was my responsibility to assign these people to the areas that I knew they could do the best for the patient, or give the best care to the patient. I felt like that was my right, as the Charge Nurse, when I was responsible for the whole unit.

I spoke up so well for myself, and they said I had answered everything satisfactorily. My Supervisor spoke against me, instead of supporting what I said. When I had. . . I said that I informed my Supervisor that night, and she didn't say anything. She was the one, I had found out, that had wanted this meeting. I think it was the means to an end... that she was trying to get back after me, about 
something I wasn't even aware of, except that I knew I was a good nurse.

I knew that the thing that I did was right. I got all kinds of good compliments. . . right down to the Administrator's office. . . about how I was caring, how empathetic I was to the patient. . . how I gave them good care. They sent letters to the Administrator. One guy that I had, being on that evening shift, taken care of his father, who had cancer. . . kept him free of pain and everything. . . he not only wrote the hospital Administrator, he thought my family should know about it. I was from Sarasota, and he was some kind of person who had a district. . . I don't remember if he was a salesman, he might have been a salesman, I don't remember now. He made a point of going to Sarasota, going to my parent's home, and telling them what a fine nurse I was. Yes he did!

I don't know if all that had something to do with the denial, but I felt that it was discriminatory. What the Supervisor did. . . for the next six weeks, she never came to my floor. She'd come to the floor below mine, and she'd send a nursing assistant up to pick up my reports. She never got any verbal report from me at all, she just got my written reports. . . at that time we had to do written reports. They'd come up, see certain patients, and ask you certain things about what was going on on your unit. But whenever I had a problem, I still kept her informed. I'd call her up on the telephone and tell her. 
After six months I finally figured out, "Now what's going on here? Why is this woman shunning me?" Then I called up and asked to make an appointment to see the Chief Nurse. I went down and explained to her that I felt like it was discriminatory, by way of race or whatever. . . I thought it was race. I couldn't think of any other reason, because the nurse downstairs in charge was White, and she always went there. Or, it could have had something to do with that incident in the office that day, when I spoke up so much for myself. . . I really didn't know what it was.

I went to the Chief Nurse about it. I felt that it was wrong. I really felt that she was discriminating on the basis of race. . I can't prove it, but that was my thought about it. I came in early, I spoke to the Chief Nurse, and she was up there that afternoon. She was just really overly friendly. . .as far as her personality would allow, because she was somewhat of a reserve person. There she was, and she just couldn't stay long enough on my unit.

Because I spoke up for myself, I did all those things, and plus, they got all those wonderful letters about me being such a good nurse, and my head nurse praised me so highly, that was when. . . that's when they made me the assistant supervisor. In other word, I worked my ward on the days that the Supervisor was off, then I worked as supervisor. That's when they asked me to come off of days, then come to head nurse, and then move me up to head nurse, because of the different qualities. 
But those were the two main incidents that I had. . that I felt was discriminatory. Now the next incident I had happened when I moved from Lake City to Miami. Now, I had been given a head nurse. . . I had been promised. I was a head nurse there, and they were getting ready to open up this new V.A. on 16th Street and 20th Avenue, because they were still in Coral Gables. They were recruiting people for the new hospital. What I did was, my husband got this job in Miami, so I applied for a transfer. From all the good references they gave me, they offered me a Head Nurse position in Miami in the new hospital.

When I got there, I had my letter that came from the Personnel station. So when I got there. . the second day that I was there, the Supervisor. . . who was White. . . called me into her office. I don't think they knew I was Black until I got there. When I got there she called me into her office the second day, and it was like she couldn't even face me by herself. I was on a medical unit, and she was Supervisor for med.-surg. Well, she brought the Supervisor in, who was over some of the other areas with her, to talk to me. It was like two on one. She talked to me and said that they were planning a new type of care delivery of nursing care to patients.

They had decided they weren't going to have head nurses. They were going to have. . I don't remember whether it was Team Leaders. . I've sort of forgotten what type method of care delivery they were going to use. What they were going to do was have one 
nurse. . because the way their wards were, they were adjoining-one wing on this side and one wing on the other side. If you have been to this V.A., you'd know how it is. Okay, so they were going to make one nurse like a coordinator between the two, and then have nursing assistants and L.P.N.'s on each of those wings. She was going to coordinate both of those wings. However, she wasn't going to be called head nurse, she would be called something like coordinator.

So, therefore, since they weren't going to use "Head Nurse," it was going to alter what had been originally promised to me. I said, "Well, I feel like there's something wrong. Because I was promised, and I came here and expected to come here under the impression that I was going to be a head nurse, the same as I was where I was coming from. .. then it doesn't seem right to me. Then she spoke and said, "Well, as I said, we're changing our care delivery services. We're not going to need as many head nurses. . . they were called then. . . as they thought they were going to need. That sounded a little reasonable, but I still didn't like it.

So, what could I do? I had already transferred. We had already changed our place of residence. My husband had already gone to work. In fact, he came in the summer and I didn't come until the fall. There was nothing I could really do, so I just said, "Okay," and went back to my unit where I was. 
It just seems like to me, the head nurse on the unit was really sort of a weak person. They were pushing her to be really strict on me, like to see what kind of qualities I really had from all those glowing evaluations I got. Then I felt like, "Here I am. . . stuck!" I had to. .. and other people came in from other places, to whom they had promised head nurse positions. When we moved to the new hospital, they didn't even use that type of delivery care the Chief said they were going to use! They had head nurses on each floor, and they didn't make me head nurse.

I don't know if, at the V.A., you knew somebody named Ingram? She was a head nurse. She was a Black nurse who was already there, and they made her a head nurse. I guess, to me, they made it look like maybe it wasn't discriminatory, because at the time, they didn't have any Black head nurses. Then they made her a head nurse, but not me. I mean, they could have afforded to use both of us. Some other new people came in that they knew. . . White nurses. . . and were made head nurses, and that's what made me think that it was discriminatory. They knew my record, because they had gotten all my. . . and not only that, even the Assistant Chief Nurse and the Chief Nurse wrote such glowing evaluations about me. So, anyway, I then had to work my way all the way back up the ladder. Again, I worked so hard. I went through the assistant head nurse role again, through a head nurse role again, up until Supervisor of the Nursing Home Care Unit. 
This position was a centralized position. . . it couldn't be appointed locally. What happened was that when the lady came down from the central office. . by that time I was the Head Nurse on a unit... I asked to leave to leave the acute care area when they were opening up the nursing home care unit, to go to a less acute care area. I was getting tired of the way they were treating me in that area, so I asked to go to the new area.

I went, when they opened it up, and I liked it because I got more satisfaction out of my work. I didn't wake up in the middle of the night, "Oh my God! Did I do such and such a thing for the acute care patient?" Or, I didn't do this, and I called up, because I had so much to do as one nurse with two or three nursing assistants and an L.P.N. . . a and all the I.D.'s, and all the cardiac arrests. I just decided that I needed a change from that.

I felt very good! It was the first time that I really had time to talk with my patients, find out about them, and do things other than nursing care to help solve some of their other problems. Sometimes they just needed for me to spend five minutes to talk with them, to relieve their apprehensions. I got alot of satisfaction out of that type. . the long-term care, I call it. It was worth it! All the patients were there for rehab. . . we had a rehab nursing home, so they got alot. If they needed long-termed rehab, we got them also with some young people, too. 
So this lady came down from central office, and I made rounds with her on all the units. I think that she was impressed by me and my level of knowledge. . I knew about all the patients. The doctors really liked me because I knew about every patient on my unit. . . everything about them. When I made rounds, I knew all about their medicines. . . everything! I would make suggestions to them about what they needed.

So, when the Nursing Home Care Unit Supervisor developed glaucoma, she had to take a medical retirement. . so before that, because I had met this lady in Louisville, Kentucky... They needed a Nursing Home Care Unit Supervisor. Since this position was appointed through Washington, D.C., and not locally. . they could recommend you locally, but the central office did the actual choosing and deciding. So these were what we called 'centralized positions.' If you took these type of positions, then you were open to be transferred to some other area.

She called me up, long-distance, to the Chief Nurse's office. Then the Chief Nurse had the secretary call my unit, and asked me to come over to her office, so they could put the phone call through and I could talk to this lady from central office. She offered me the position as Nursing Home Care Unit at the V.A. nursing home in Louisville, Kentucky. I was just flabbergasted! She said, "If you're good enough for Miami, then you're certainly good enough for Louisville!" She told me about how she was impressed with me 
when she was there, and how I took her around, and all the good confidence that the Chief Nurse had given me.

I told her that I had to go home and discuss this with my husband. You should have heard my husband when I discussed this with him! He always said that he was the breadwinner, and I never had to work, so he wasn't following me! It had to be the other way around. I was just flabbergasted to have been offered that. So I didn't accept it, but when the position became vacant in Miami, this lady called me up again, and asked me if I would take it. So that's how I got to be a Supervisor.

I really have to say from that point on, I don't remember any really outstanding things which I felt were discriminatory because of my race. I really felt like I moved up very nicely in the V.A. If I had been mobile, the title was changed to assistant chief nurse of that area. If I had been mobile, I could have probably become a chief nurse. But see, being married, I couldn't be mobile. If I had been like some women, with their husbands following them around. . . so I couldn't, so I had to sort of stick to home.

More than likely, when people got in those positions, they stayed alot longer, so you didn't have to worry so much about them asking. What it was. . if they asked you... They would ask you two times. If you didn't go, then they would take you out of their centralized position, with that particular one. It made it a little more safer. But I never got asked to ... 
Interviewer: What about as a student.Have you experienced any instances of racism?

Participant: $\quad$ Okay, as a student nurse. . that was it, I was so fortunate because I was at Florida $\mathrm{A} \& \mathrm{M}$, and we were a Black school. The only time I had encountered, and we had all-Black people there, but the only time I really had any encounter as a student. . . discriminatory. . . is that we had our pediatric training at the. . . at Duvall Medical Center in Jackson. We had our own student nurse housing there, by $A$ \& $M$, and we stayed there. In fact, we were away from our campus our whole Junior year.

We spent nine months at the Duvall Medical Center doing pediatric and emergency room nursing. Then, the other three months we spent at Tuskegee, Alabama, at the V.A. hospital, doing psychiatry. They had nursing quarters there because Black student nurses came from all over the country. . . from three-year schools of nursing to collegiate schools of nursing, and they had a big dormitory. We all lived in the dormitory together. They took the students at a certain time each year. . . they took some for three months and then another group of students came for three months.

We got all our psychiatric experience here, because this was the Black V.A. hospital for Black veterans who had mental problems. If they had medical problems, they could take care of them when it was investigated that they had a medical problem, or if they had to have surgery. They had that there for them, too. Because the other V. A. 
hospitals, at that time, didn't have Black patients. If they had Black patients, they had a ward or two designated for Black patients. This was a whole hospital, primarily psych., for all the Black veterans who had to go there if they had a psych. problem. For the med-surg problem, they had a couple of units in the hospital.

The only encounter I had, and I didn't have it alone as a student nurse, is when we were working in the emergency room. The doctor sort of. . . the doctor and the nurse who was over the emergency room used to. .. and they had White students there, too, at the same time while we were there, from schools in Jacksonville. . . and they would give us, now this is the way we saw it, we thought that they sort of looked at us because we were the only collegiate students they had there. The other ones were three-year nursing students.

It was like they gave us alot more to do, and they said it was because we were collegiate students, versus the other. But, the way we saw it is that they gave us all-Black patients, and wouldn't assign the White students to Black patients but to all the White students. We felt like we needed to get some experience with the White patients that they had in the hospital. Unfortunately, all the Black patients seemed to have the worst problems. We saw it is like, that gave us... I mean, they were not so much interested in our learning experiences, just working us.

I don't say it was blatant, because nobody came out and called us a 'nigger', or anything like that. I really had more of that from (?), 
you understand. In a way, I feel like I was fortunate, because always, even as a student, we were thrown into an integrated situation, because we were. . even when I... I went to Pensacola, Florida, to do my [ ? ], because the students at F.A.U., for a state university, F.S.U., had first priority to the facilities that were in Tallahassee.

Our students. . . they could only take maybe a couple of our students. All of us had to go all over the state of Florida to get our public health experience. We would live with some nice Black person who would allow students to live there. We lived with a retiree. My roommate and I went to Pensacola for our public health experience ... to Pensacola, Florida, where there was a Public Health Nurses Association. We lived with a Black nurse who was retired from Tuskegee Hospital. . . the veterans' hospital. She took in students, you know, to also sort of help her. . .we had to pay, of course. She was very nice. She had one room and two twin beds, and we shared one big room, and we could have the run of the house to cook, and stuff like that, because we had to cook since we didn't have alot of money.

Not only that, we had to pay for our room and board on campus to keep our room, as well as, pay to go there and pay her, and have money to eat. We had to walk eighteen blocks to where we reported in the morning. . . to the Public Health Department. We had to go five days a week for one month. We would go there... unless 
one of those public health nurses would be coming our way, that we'd get a ride, otherwise we had to walk because we didn't have money to ride.

Now, the only discriminatory thing that we came across. .. and nobody ever called us a 'nigger' or anything like that. . . but when you live under segregation, you can see the things that were discriminatory. There was not one nurse in the health department, a visiting nurse, that had a B.S. degree. Here we were, B.S.N. students. They were envious, because they kept saying things like, "Well since you're going to have a B.S.N., you ought to be able to do this, and you ought to be able to do that. . you should be able to make this decision, and make that decision..."

They had us making speeches at all-White civic organizations. We had to tell them about the signs of cancer. . . we weren't into selfbreast exams then. . . but the signs of cancer so that they'd be able to recognize it. They had us going to Catholic schools and speaking to students about what the nursing profession, or nursing, was all about, and why we went into the profession, in order to encourage other students. They had us going to public schools doing the same thing.

When we would go to the Black. . . we went to, with them. . we didn't get to go to one White person's home. They took us to all Blacks. We felt like we should, since they were White nurses, why couldn't we go to some of the White homes. But they didn't. . they 
said they were for [ ? ], that we needed to learn to take care of the people that we were really going to really be dealing with.

At that time the hospitals were segregated, and you didn't take care of White patients. You took care of Black patients, and mostly, you got to work in a Black hospital. . except for the V.A. In the South, the Black patients were segregated, but in the North, they were not. In the V. A. they were all over the same unit, but down South.

When I went to Lake Saviorworth, I got in on the desegregation of that hospital. They were just integrating that hospital. But their trust. . that was something to go through. With patients. . . not wanting to be in the same room with people of different races. The lady told us, "Well, these are the type of patients you wanted to be taking care of, so you might as well learn how to take care of them well!" I felt like that was discriminatory, but you know, the impact probably wasn't as great on us during that time, because there was...

Interviewer: That's what it was. . .

Participant: $\quad$... That's what it was versus, say, when you came along. The way I feel about it today versus. . . I didn't like it, but I know for survival, I had to accept it. I didn't accept it, I had to put up with it!

Interviewer: Right. What about when you went to graduate school. Did you experience any racism as a student? 
Participant: No, I really don't think so. I attended Barry University, and the person who was over my department was a very fair-minded person. If there was anything with a fellow student, I took care of it myself. I felt like, if anything that I felt was discriminatory to me as a student. . . now, I don't know how I would have handled it if it had been with a faculty member, because I know I had to get through that program. . . but if it was with another student, then I would just tell them how I felt. . .

\section{Interviewer: $\quad \ldots$ I see, okay. . .}

Participant: $\quad \ldots$ but I don't remember any particular incident that I had with a student. Even when I did my practicum, all the people that I did it with. . I did part of it with the Vice President of Patient Care Services at Cedar's of Lebanon Hospital, and the other half I did at the Jewish Home for the Aged. The Director of Nurses Services was a very wonderful person. I got to go to everything, even to some of the board meetings. I don't feel like there was any discrimination.

In many ways I feel like I was spared, primarily because I worked in the federal agency, which had a different tone than the private agency. I think that's why I had less true. . . what I felt was true. . . discriminatory experiences. And I really had more racist things happen between me and clients than between me and employees. 
Interviewer: What about your present position. . . any experiences?

Participant: With my present position? No, I don't really think there's been any discriminatory. . . I think some things. . . basically, I think I've had it really pretty good. I don't think anything that I've encountered has been discriminatory. I just feel like some favoritism has been shown toward some people, but it wasn't by way of race.

Interviewer: Do you think that an African-American nurse has to work much harder to prove herself? Do you think that her abilities are questioned?

Participant: $\quad$ Yes, yes I do. I feel from experiences that I have seen, that other people have experienced, and I've feel that I've experienced myself. . . like the incident I told you about at the V.A. It was like I had to prove myself all over again, irregardless of the evaluations that came with me.

I feel that, too, for some reason, people, in general, of the opposite race, to me, seem to feel that we don't have. . that we're not as smart, or have the trained capabilities that other people have. Not primarily because. . . they feel it, too. It's sort of like an old cliche that's carried over. . . if you're Black, there's something less about you than there is about other people.

I just feel like the present situation here has been another fortunate situation with me. That's not true about my other colleagues within the same institution. .. that work in a different 
area than I work in. They really had it very bad! And there were alot of discriminatory things, from what they have revealed to me, that happened with them that hasn't happened in my own work setting.

Interviewer: Do you think that the instances of racism you have experienced. . . have they affected your self-esteem?

Participant: Not really, because I feel that all the things that happened to me. . . when there was deep-seated racism and segregation in this country. . I felt that if I could survive then, that I could survive anything, and that even though I didn't like it, and I'll never, never, as long as I live, forget it. . . but I felt that I wasn't going to let it keep me down. . that I was going to rise above that. Because I felt that within myself, that I wasn't what they thought I was, and that I had to show them this. . . that I was just as smart, that I was just as capable, that I'm just as intelligent as the next person. I felt like if I had let that lower my self-esteem, then I wouldn't have been able to rise above that, and let people really see what I really am as an African-American nurse.

I forgot this particular incident. When I left Chicago, I transferred to the V.A. hospital in Georgia, because my husband became (?) over the school nearby in Macon, Georgia. So, after I had my orientation, it was my turn to rotate to the evening shift. The doctor who was over the unit came to make rounds that afternoon. In fact, he wasn't just the doctor for the ward, he was over several wards. He came to that particular ward to make rounds that 
evening. He saw me there. I made rounds with him, and I didn't know that he was so concerned about me being there until I received a call from my nurse manager.

She told me that he had called her, and he was very concerned about me, as a Black nurse. [ ? ] the only one it could be, because here I was, in another situation where I was the only Black nurse. There were only two Black nurses at this V.A. hospital, and I happened to be one of them. She told me that she assured him of my capabilities, and that just because I was Black didn't mean that I couldn't have experience.

When the Nurse Manager came in the next day, she found out, when she made rounds, that the doctor had questioned a White patient. . . he'd gotten there before her and had questioned a White patient about how things went the evening before. . .if I had given them all their medicines, treatments, and whatever. . . that they were supposed to have. If she hadn't assured him then I wouldn't have been able to stay there. But that was another true thing of discrimination, by way of race. By the time I left there, though, he had a different opinion of me. 